\title{
The Potential of Utilising Residential Demand Response to Balance the Fluctuation of Wind Power in New Zealand
}

\author{
By
}

Hatem I. Alzaanin

A thesis submitted in fulfilment

of the requirements for the degree of

Master of Engineering

in

Electrical Engineering

at

Victoria University of Wellington

November 2014 





\section{ABSTRACT}

The substantial penetration of wind power introduces increased flexibility requirements on the power system and puts increased pressure on the instantaneous reserve levels required. Instantaneous reserves are a security product that ensures that electricity demand can continue to be met in the event of unplanned generation or transmission interruptions. This reserve must be available to respond very quickly to generation-demand variability. While this is an integral component of the power system, providing instantaneous reserve increases the production cost of power. More calls from energy researchers and stakeholders ask for loads to play an increasingly important role in balancing the short timescale fluctuations in generated wind power. The purpose of this study is to assess the current level of demand responsiveness among domestic refrigerators, freezers, and water heaters and their potential to contribute towards instantaneous reserve and balance the fluctuation of wind. Refrigerators, freezers, and water heaters can generally store energy due to their thermal mass. Interrupting these domestic loads for short time by employing direct load control strategies makes it possible to control these appliances by turning them on or off before their reach their maximum or minimum temperatures or by slightly modifying their temperature set point. Using this strategy helps to ensure that the overall satisfaction of consumers should not be affected. This study first modelled the load profiles of the participated residential appliances and statistically assessed the potential of controlling these residential loads using direct load control strategies to contribute towards instantaneous reserves to mitigate and balance the fluctuation of wind power in the years: 2014, 2020 and 2030. In the second section, it demonstrated the capabilities of the assessed residential responsive loads within Wellington Region network to compensate for and balance the fluctuation of wind power generated from the West Wind Farm in seven selected days in 2013-2014 as a showcase. Such technology can enable a power system operator to remove the burden of both providing instantaneous reserve from conventional sources, and instead maintain such capacity from available residential demand response. The study ends with recommendations to engage residential loads in fast timescale demand response and suggests directions for future research. 


\section{ACKNOWLEDGEMENTS}

My truly deep and profound thanks and gratefulness are due to Allah the Almighty who bestowed me with patience and perseverance to complete this study.

I would like to express my sincere and profound gratitude to everyone who assisted me to complete this research. First and foremost, I wish to thank my supervisor, Dr. Ramesh Rayudu, who offered me encouragement and provided guidance and healthy questioning throughout the process. He helped me to improve my skills of critical thinking and academic research.

Again my thanks are due to Allah who endowed me with an exceptional and extremely supportive wife who has lived with me the ups and downs of my postgraduate experience and to her I will be eternally indebted. I also thank my adorable children Sara, Sufian, Salah, Mariam, and Noha who despite their young ages managed to show great understanding and patience.

I would like to express my gratefulness to my mom and dad, who always believed in me by encouraging me to finish this journey. Their love, support and prayers made me go on no matter how far the way seemed.

I would like also to express my gratitude to Nabil Adam from Transpower for his helpful suggestions and critiquing during building up the model in Digsilent. I would like also to thank the staff from Transpower and Meridian Energy who provided me with wind data not available to the public.

I appreciated the financial support I have received from Transpower to present my research in the Wind Energy conference held in Wellington, April, 2014.

For all of this, I am sincerely grateful.

This thesis is dedicated

To my family who fill my life with endless joy and immeasurable love 


\section{LIST OF PUBLICATIONS}

The following papers have been presented during the course of the research described in this thesis:

1. H. Alzaanin and R. Rayudu, Integrating Wind Power with Domestic Demand Response to Increase the Value of Wind, 2014 NZ Wind Energy Conference and Exhibition, Te Papa, Wellington, 14-16 April.

2. H. Alzaanin and R. Rayudu, Investigating the Potential of Residential Thermostatically Controlled Loads for Fast Demand Response, Electricity Engineers' Association (EAA) Conference and Exhibition 2014, Auckland, 18-20 June 2014 


\section{TABLE OF CONTENTS}

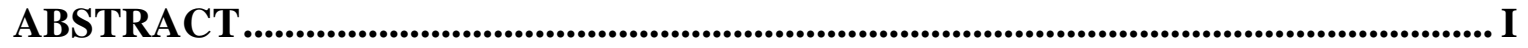

ACKNOWLEDGEMENTS .................................................................................. II

LIST OF PUBLICATIONS .......................................................................................

TABLE OF CONTENTS ................................................................................................ VII

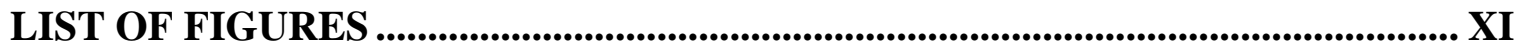

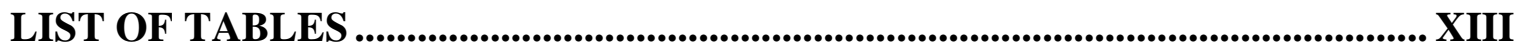

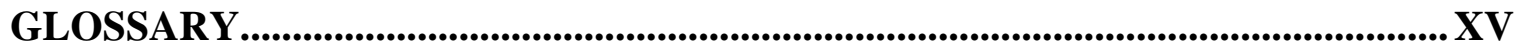

CHAPTER 1 INTRODUCTION

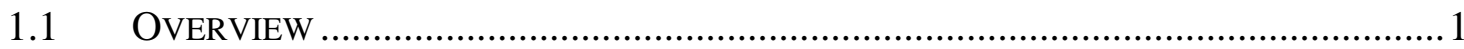

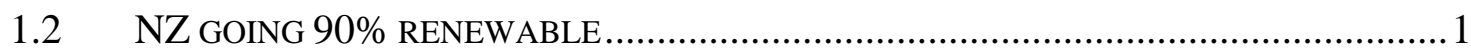

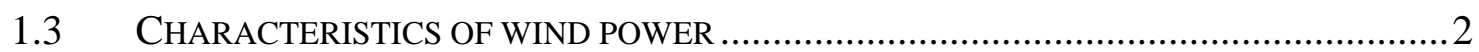

1.4 IMPACT OF LARGE-SCALE WIND INTEGRATION ON POWER SYSTEMS .......................

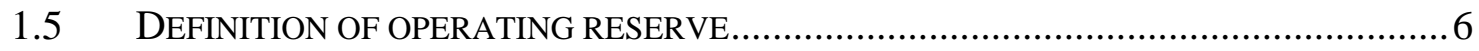

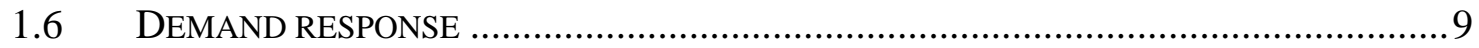

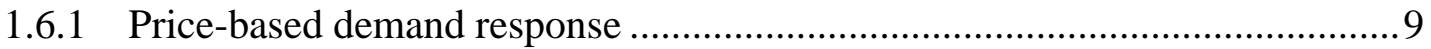

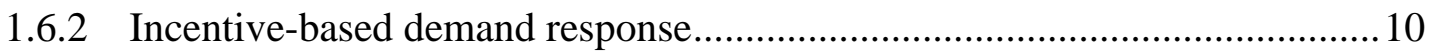

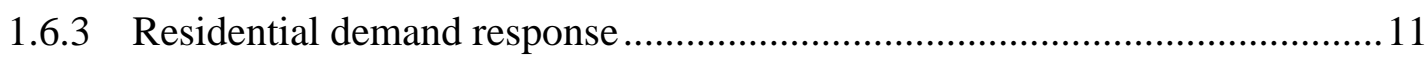

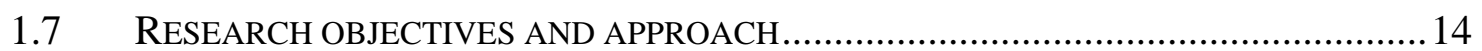

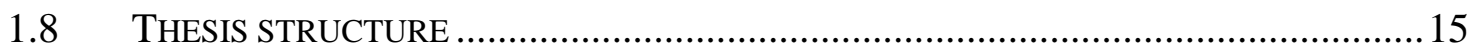

CHAPTER 2 NEW ZEALAND'S ELECTRICITY SECTOR ................................17

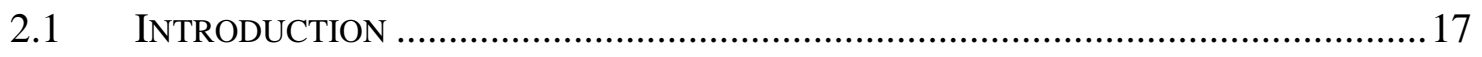

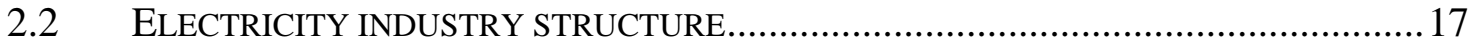

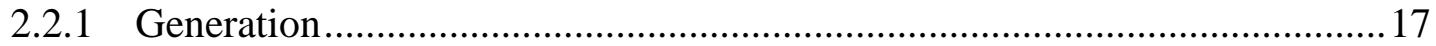

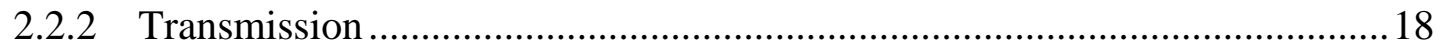

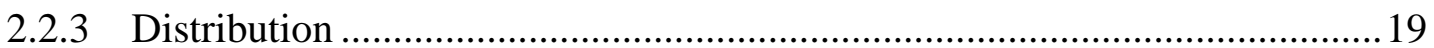

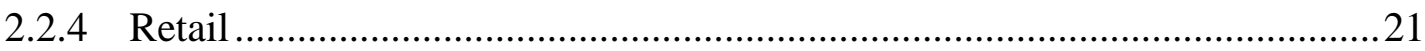

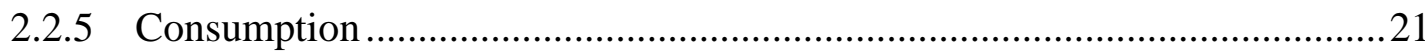

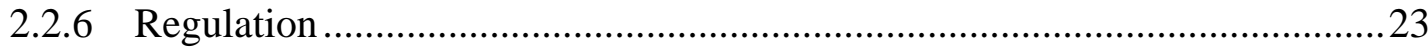

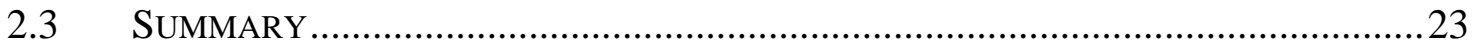

2.3.1 Demand response programs in New Zealand ............................................24

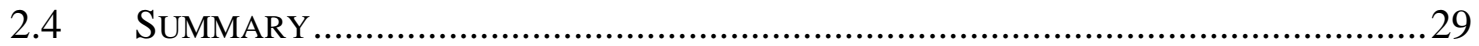


CHAPTER 3 LITERATURE REVIEW OF WIND INTEGRATION STUDIES .....31

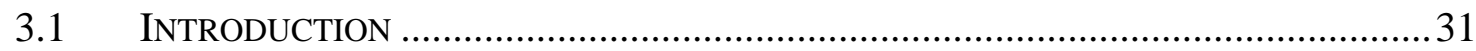

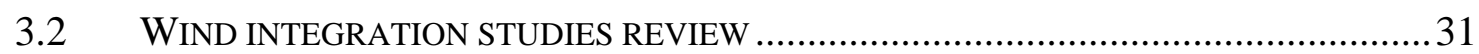

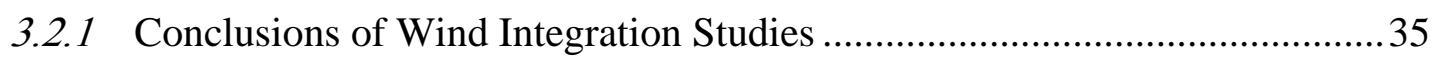

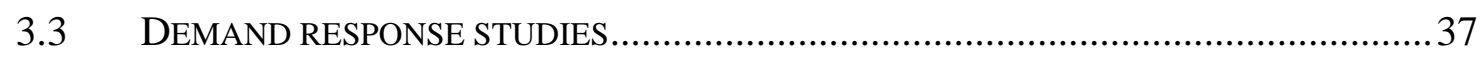

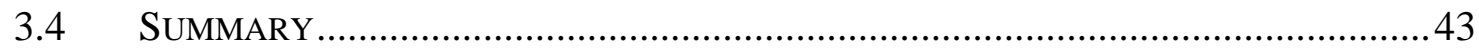

\section{CHAPTER 4 INTEGRATING RESIDENTIAL DEMAND RESPONSE WITH}

WIND POWER .44

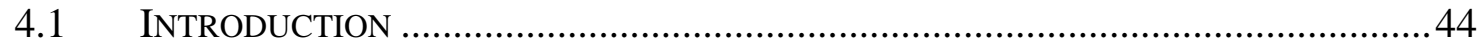

4.2 METHODOLOGY OF MODELLING RESIDENTIAL LOAD .......................................4

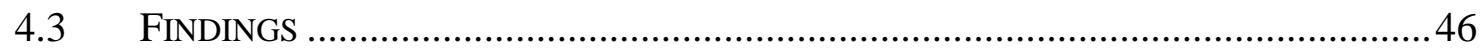

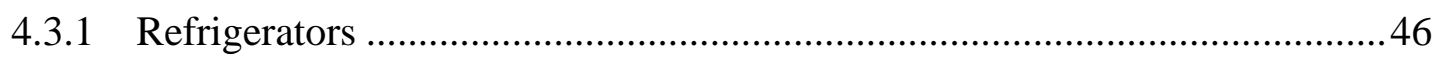

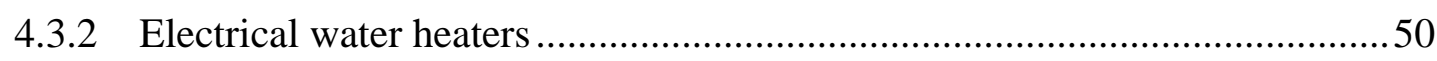

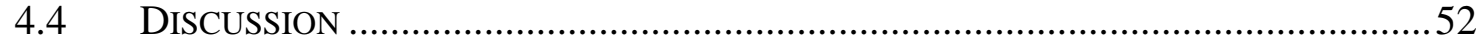

4.4.1 Potential of controlling modelled loads to provide Instantaneous Reserve ...54 SUMMARY.... 58

CHAPTER 5 INTEGRATING WELLINGTON REGION'S RESIDENTIAL LOADS WITH WEST WIND FARM WIND POWER ..............................................60

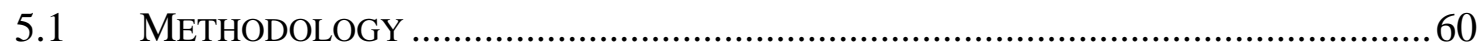

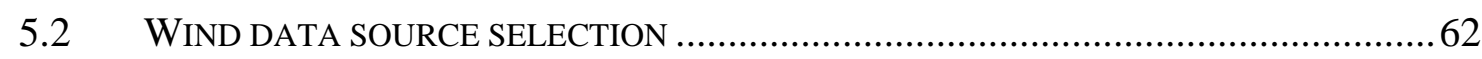

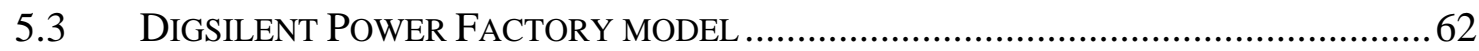

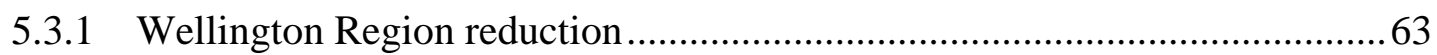

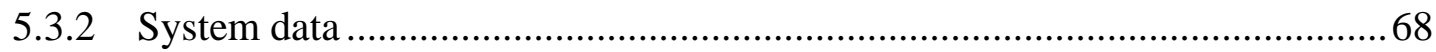

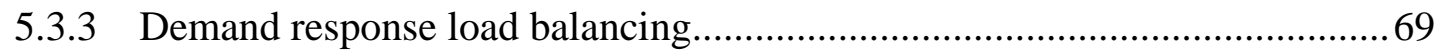

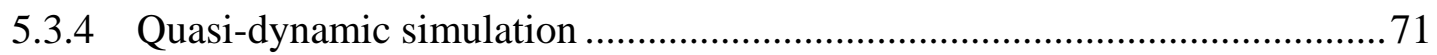

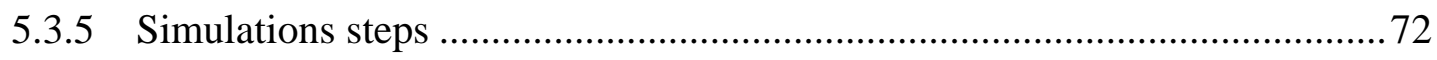

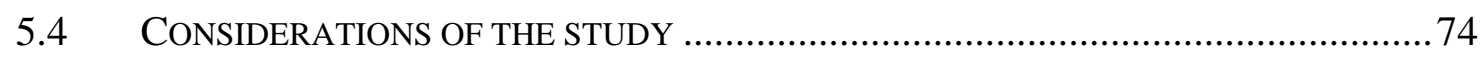

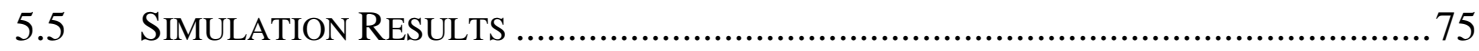

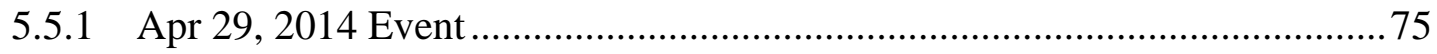

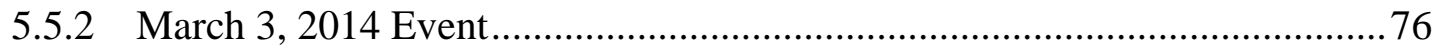

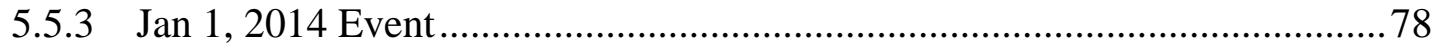

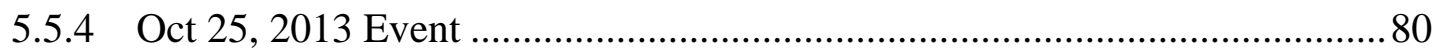




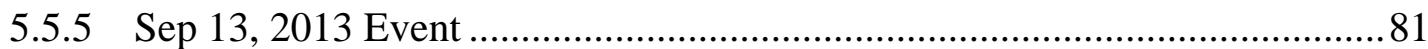

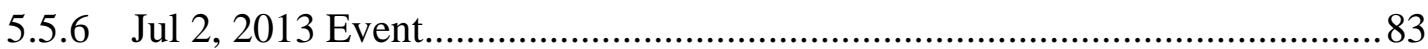

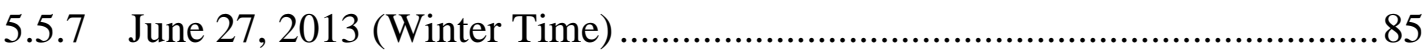

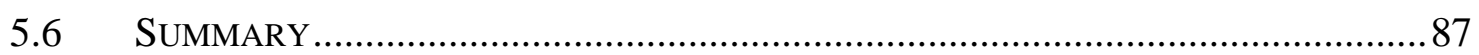

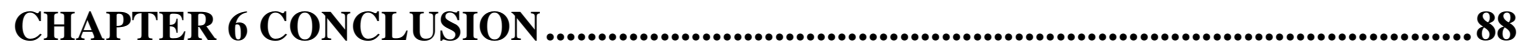

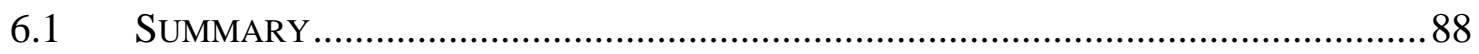

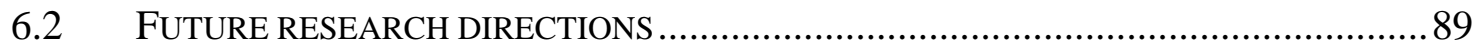

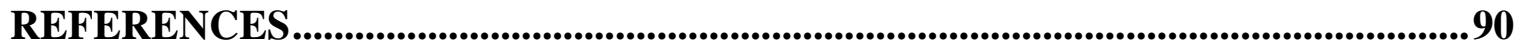




\section{LIST OF FIGURES}

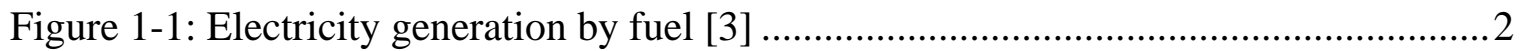

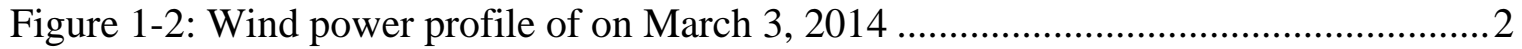

Figure 1-3: Impact of wind power on power systems [8] f............................................

Figure 1-4: Examples of Operating Reserves and how they are related [12] ..................... 7

Figure 1-5: Cost of increased flexibility in power systems, general trend [13] ................. 8

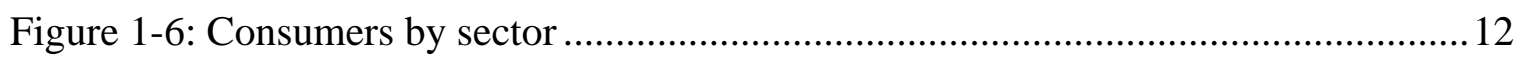

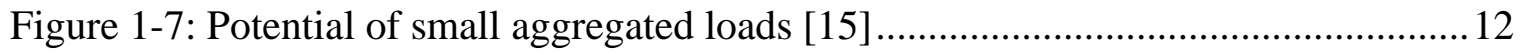

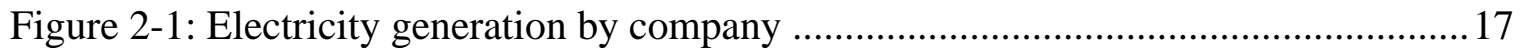

Figure 2-2: Percentage of New Zealand electricity generation from renewables............... 18

Figure 2-3: The North Island Generation Mix 2012 _....................................................... 18

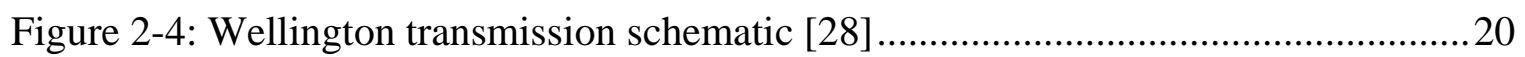

Figure 2-5: Monthly retail market share by parent company [23] .................................. 21

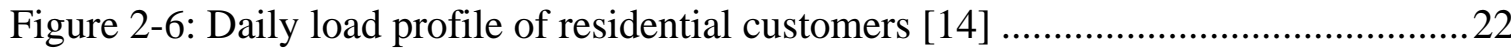

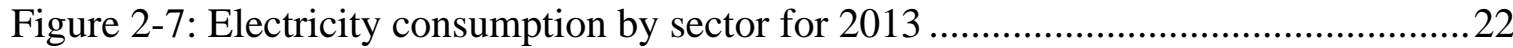

Figure 4-1: Residential electricity consumption ............................................................. 45

Figure 4-2: Duty cycle of refrigerators and freezers ...................................................... 47

Figure 4-3: Daily LC for refrigerators \& freezers in an average household......................47

Figure 4-4: Total load of refrigerators and freezers in New Zealand ................................48

Figure 4-5: DLC of refrigerator through delayed start of compressor................................48

Figure 4-6: The process of load reduction and load recovery in refrigerators...................49

Figure 4-7: General pattern of a daily load curve of an electrical water heater.................50

Figure 4-8: Total load of water heaters in New Zealand households ................................51

Figure 4-9: Example of a change in operation of controlled water heaters ......................51

Figure 4-10: Daily LC of modelled residential loads in New Zealand -2014 ...................52

Figure 4-11: DLC of household appliances Potential in 2014 ..........................................53

Figure 4-12: DLC of household appliances Potential in 2014 ........................................56

Figure 4-13: RDR Potential in 2020 towards Instantaneous Reserve...............................56

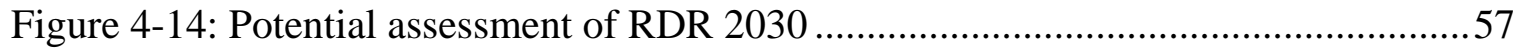

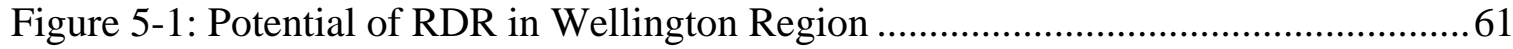

Figure 5-2: Wellington Region power system geographical diagram .............................65

Figure 5-3: Wellington Region Digsilent Model .............................................................67

Figure 5-4: West Wind $1 \mathrm{MW}$ time characteristic trigger .............................................69 
Figure 5-5: Central Park demand response slack generation modelling...........................70

Figure 5-6: Dynamic Response Power Frequency Controller ........................................ 70

Figure 5-7: Example of setting options for the quasi-dynamic simulation........................72

Figure 5-8: Balancing DWR with $100 \%$ of RDR on April 29, 2014 .............................. 74

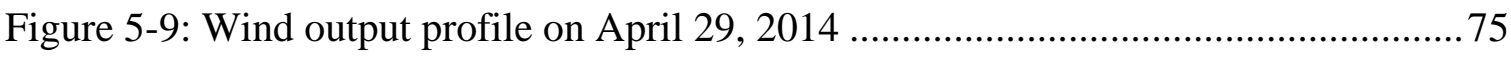

Figure 5-10: Balancing DWR with $100 \%$ of RDR on April 29, 2014........................... 76

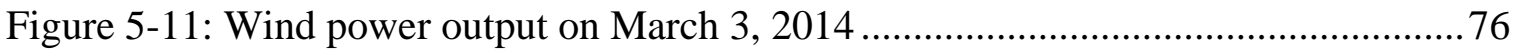

Figure 5-12: Balancing DWR with slack generation Mar 3, 2014 .................................77

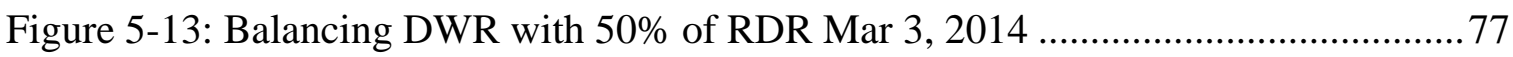

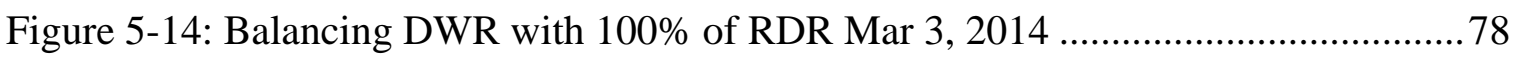

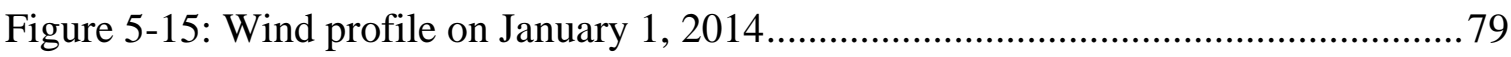

Figure 5-16: Balancing DWR with Slack generation on Jan 1, 2014 ..............................79

Figure 5-17: Balancing DWR with 100\% of RDR on Jan 1, 2014 ............................... 80

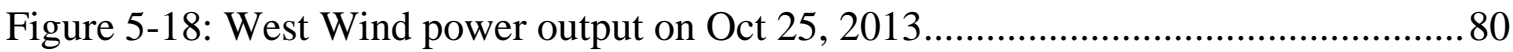

Figure 5-19: Balancing DWR with Slack generation on Oct 25, 2013 ...........................81

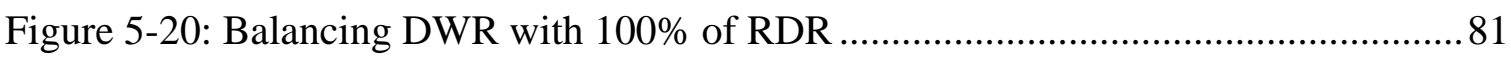

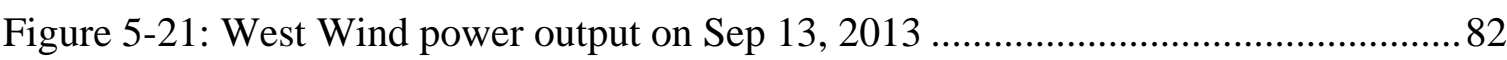

Figure 5-22: Balancing DWR with slack generation on Sep 13, 2013 ........................... 82

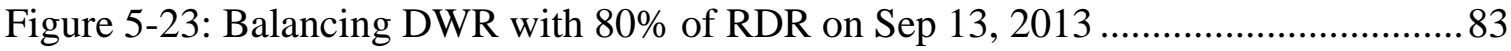

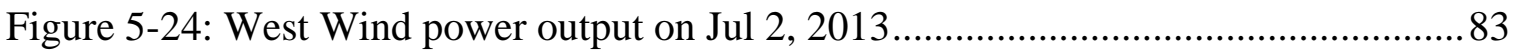

Figure 5-25: Balancing DWR with Slack generation on Jul 2, 2013............................. 84

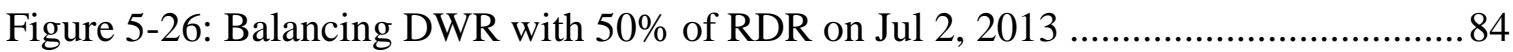

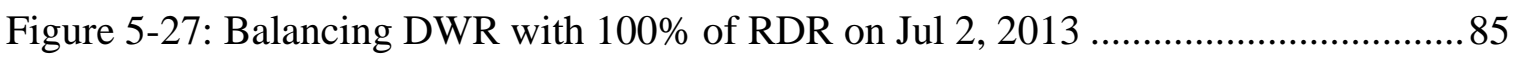

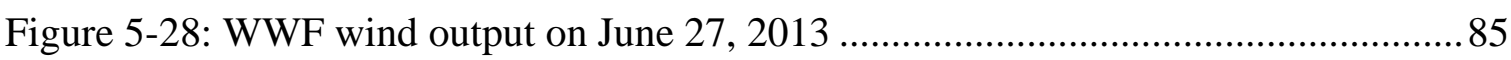

Figure 5-29: Balancing DWR with Slack generation June 27, 2013 .............................. 86

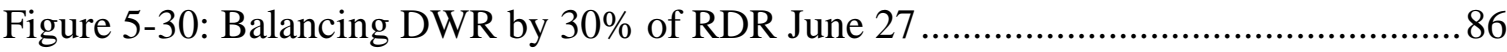




\section{LIST OF TABLES}

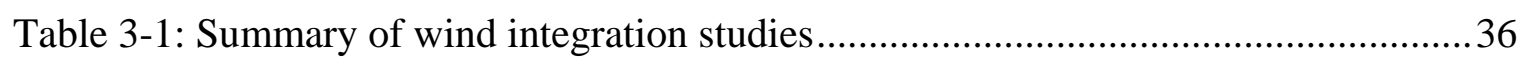

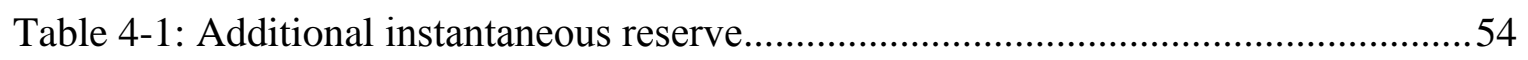

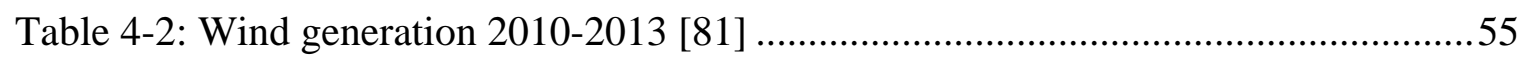

Table 4-3: Contribution of RDR towards additional Instantaneous reserve.......................58 


\section{GLOSSARY}

Abbreviations

DLC Direct Load Control

DR Demand Response

HVDC High Voltage Direct Current

LC Load Curve

RDR Residential Demand Response

WDR Wind Demand Ramp 


\section{CHAPTER 1 INTRODUCTION}

\subsection{Overview}

The purpose of this study is to assess the current level of demand responsiveness among domestic refrigerators, freezers, and water heaters and their potential to balance wind fluctuation and contribute towards additional instantaneous reserve resulting from the high penetration of wind in the New Zealand power system. The potential contribution may mitigate the impact of wind variability and assist to maintain the New Zealand power system flexibility when integrating large amounts of wind power into the grid. Flexibility is defined as the ability of a system to cope with uncertainties and variations in the generation and the demand, while maintaining the system reliability at minimum additional cost [1]. This chapter gives first an overview of the recent developments in the electric power industry in New Zealand that motivated the present work. It then discusses briefly the main characteristics of wind power which influence the flexibility of the power system. Strategies to maintain power system flexibility are reviewed with special focus on the role of demand response (DR) as a flexibility source. Research objectives and approach are listed. This chapter concludes with a brief outline of each chapter of the thesis.

\section{$1.2 \quad \mathrm{NZ}$ going $90 \%$ renewable}

The New Zealand Government has announced a target of generating 90\% of required electricity from renewable sources by 2025 , up from around $75 \%$ today. Achieving this aim requires a high increase in renewable generation, especially wind power. According to [2], wind is expected to be a main source of electricity, generating at least $20 \%$ of New Zealand's electricity by 2030 , up from $6 \%$ of generation today.

Figure 1-1 [3] shows the electricity generation by fuel till 2030.

Wind power has great potential for New Zealand's sustainable energy future. Increased wind generation will create a greater variety than currently exist in the sources of generation, mitigate the impacts of dry years on the power generation from hydro inflows. A number of factors are more likely to enhance the penetration of wind in New Zealand. New Zealand enjoys an abundance of wind due to its westerly air flow and long coastline, and to the mountainous geography of NZ [4]. The availability of land on which to sit wind farms, cost effective wind technology to generate power, cleanness of wind energy, and increased capacity and efficiency of wind turbines are other factors which facilitate higher integration of wind power in the NZ power system [2]. Therefore, wind power is regarded 
as one of the most promising renewable energy technologies for New Zealand power system.

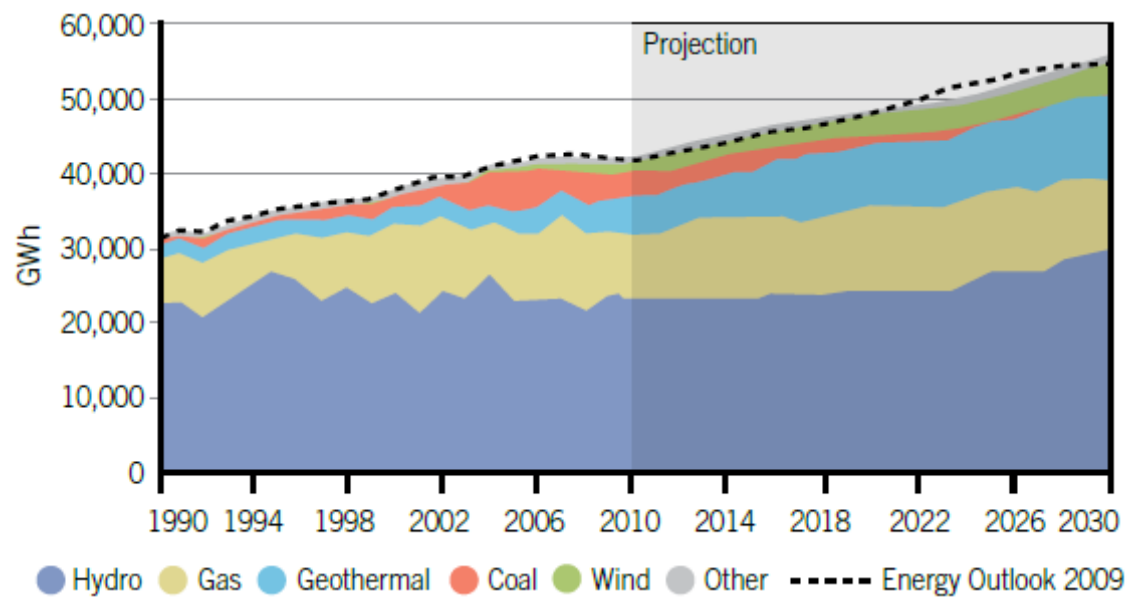

Figure 1-1: Electricity generation by fuel [3]

\subsection{Characteristics of wind power}

Wind power is naturally variable on different time scales ranging from seconds and hours to months and seasons and there is no control over the timing or level of generation output. Dramatic changes could happen in a single day, which significantly increase the difficulties in the operation of the power system. Figure 1-2 [5] represents West Wind power output plotted with 1-minute resolution on 3/3/2014.

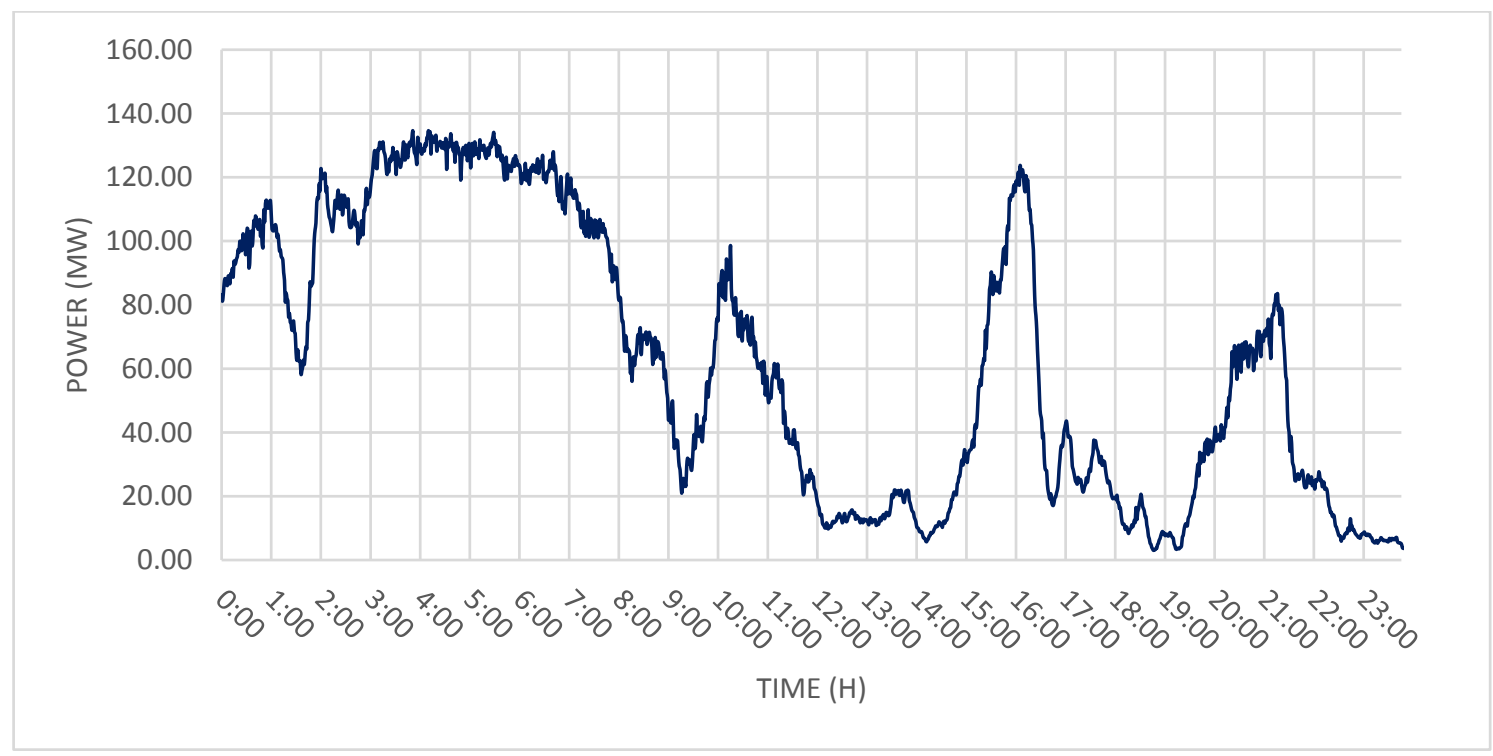

Figure 1-2: Wind power profile of on March 3, 2014

In this example, the difference between daily maximum power and daily minimum power is over $125 \mathrm{MW}$. Starting at about $130 \mathrm{MW}$ at 3:00 am it took about 6 hours for the wind 
power to decrease to around $20 \mathrm{MW}$. The wind power increased to about $100 \mathrm{MW}$ later. Then, in less than two hours, the wind generation decreases to less than $10 \mathrm{MW}$. Then, again it starts to increase from $6 \mathrm{MW}$ to $120 \mathrm{MW}$. There are smaller up and down movements with durations ranging from minutes to hours interspersed in between that create local peaks and valleys. For the electric system to operate reliably, generation must match load all the time. When an event like this occurs where the wind power may be decreasing simultaneously with an increase in load, the situation aggravates.

The existing power system is already designed to have sufficient flexibility to deal with variability and uncertainty in demand and to respond to unplanned generation outages and hence can host moderate amounts of variable renewable with little to no changes [6]. Variability and uncertainty arising from demand levels, hydro inflows and failures of generation units and network facilities are familiar to the electric power industry [7]. However, the deployment of wind power to supply the electricity industry at large scale has a more significant impact on the power system. The impact of large-scale wind integration on power systems is discussed in the following section.

\subsection{Impact of large-scale wind integration on power systems}

Wind power influences power system operational security, reliability, and performance. Figure 1-3 [8] captures the major areas in the planning and operation of the power system at different timescales which will be affected by the increased penetration of wind power: Balancing, adequacy of power and grid.

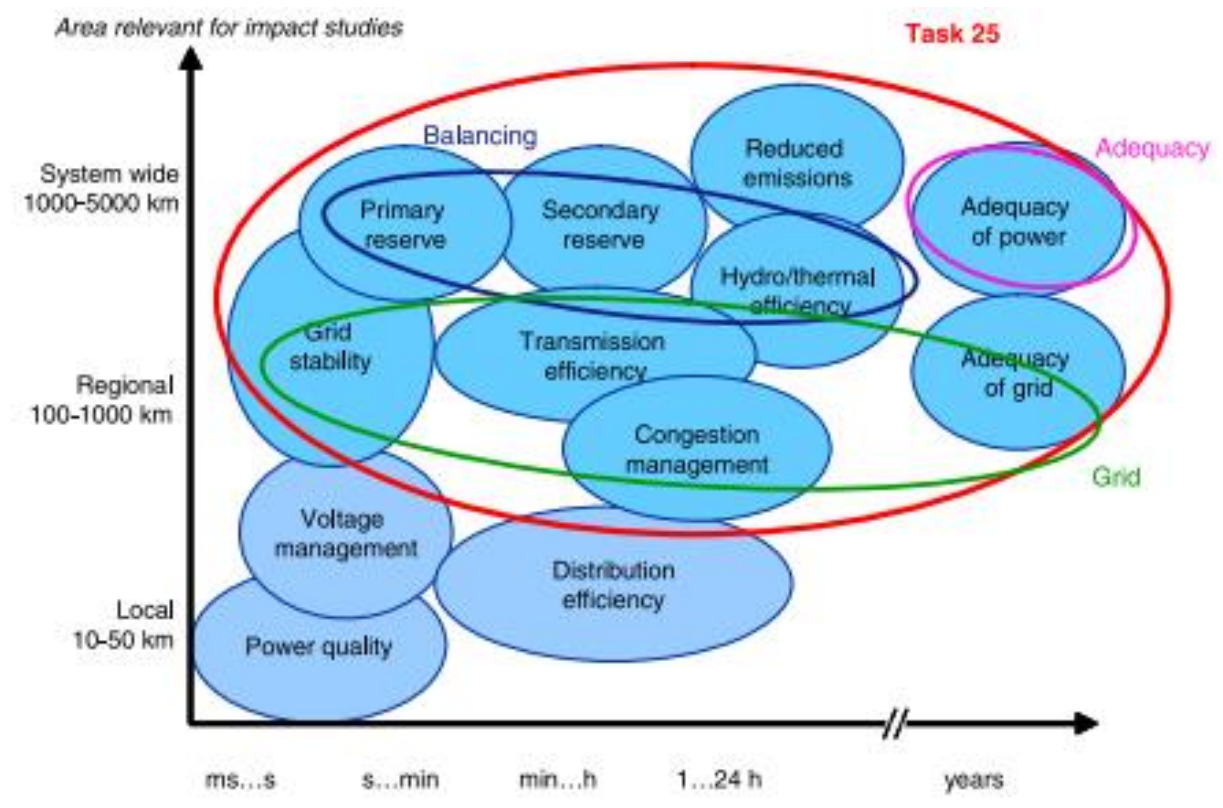

Figure 1-3: Impact of wind power on power systems [8] 
Balancing covers the impacts on allocation and use of short term reserves (timescale: minute ... half an hour) and efficiency and unit commitment of existing power capacity (timescale: hours ... days). In the timescale of hours to days the positive impacts of wind power can also be seen, reducing the use of fossil fuels thus saving the operational costs of the power system as well as decreasing the emissions. The unpredicted part of the variations of large area wind power should be combined with any other unpredicted variations the power system sees, like unpredicted variations in load. These power adequacy is associated with static conditions of the system. It is about the total supply available during peak load situations (timescale: several years). The estimation of the required generation capacity needs to include the system load demand and the maintenance needs of production units (reliability data). The criteria that are used for the adequacy evaluation include the loss of load expectation (LOLE), for instance. The issue is the proper assessment of wind power's aggregate capacity credit in the relevant peak load situations - taking into account the effect of geographical dispersion and interconnection. Wind generation will provide some additional load carrying capability to meet expected, projected increases in system demand. This contribution can be close to the average power produced by wind power at times of peak load, when the penetration of wind power is not high, and the capacity value of wind will decrease as wind power penetration increases. Aggregating large areas has a positive impact on the capacity credit of wind power.

Challenges for the case studies include developing representative wind power production time series across the area of study, taking into account the (smoothed out) variability and uncertainty (prediction errors) and then modelling the resultant power system operation. For high penetration levels of wind power, the optimization of the integrated system should be explored. Modifications to system configuration and operation practices to accommodate high wind penetration may be required. Not all current system operation techniques are designed to correctly incorporate the characteristics of wind generation and surely were not developed with that objective in mind. For high penetrations the surplus wind power also needs to be dealt with, for example by increasing the flexibility in the generation mix, transmission to neighbouring areas, storage (e.g. pumping hydro or thermal) or even demand side management (avoiding wind power curtailment). There is a need to assess wind power integration at the international level, for example to identify the needs and benefits of interconnection of national power systems. The impacts of wind power on transmission depend on the location of wind power plants relative to the load, and the correlation between wind power production and load consumption. Wind power 
affects the power flow in the network. It may change the power flow direction, and reduce or increase power losses and bottleneck situations. There are a variety of means to maximize the use of existing transmission lines like the use of online information (temperature, loads), FACTS (flexible ac transmission systems) and wind power plant output control. However, grid reinforcement may be necessary to maintain transmission adequacy and security. Grid extensions are commonly needed if new generation is installed in weak grids far from load centres. The issue is generally the same be it modern wind power plants or any other power plants. The cost of grid reinforcements due to wind power is therefore very dependent on where the wind power plants are located relative to the load and grid infrastructure, and one must expect numbers to vary from country to country [4, $11,7]$. With current technology, wind power plants can be designed to meet industry expectations such as riding through voltage dips, supplying reactive power to the system, controlling terminal voltage, and participating in SCADA (supervision control and data acquisition) system operation with output and ramp rate control.

The variability of renewable energies raises operational problems on power grids. To maintain power system reliability, resources assigned to achieve grid balance must be able to quickly respond to the excess or loss in variable generation. In addition to these common challenges, integration of large scale wind generation into the New Zealand power system creates more challenges due to its unique characteristics. These are listed in [9]:

1. New Zealand has a hydro dominated power system. Hydro plant can provide substantial operating flexibility to assist in managing wind variability. However, hydro does have storage and energy limitations.

2. The New Zealand power system has no interconnections to other power systems to draw from due to its island geography.

3. New Zealand's power system is long and stringy in nature as the generation and load are connected through long transmission lines. This is an important point when considering transmission issues associated with connecting new wind farms.

4. There are large wind output variations in relatively small period of time.

The large-scale wind power integration increases the level of uncertainty and variability in the system. A comprehensive review of the new requirements that intermittent generation may impose on power systems can be found in [8]. In order to integrate large penetrations of wind power without compromising the system security, more flexibility services are required to cope with the predicted and unpredicted changes in demand and supply.. A main 
strategy to enhance power system flexibility when hosting large amount of wind power is to increase the operating reserve so that the system can handle more uncertainties. Operating reserves are defined next.

\subsection{Definition of operating reserve}

Operating reserve is traditionally designed to provide upward reserve which is required to handle an unforeseen increase in demand or an unexpected decrease in generation and downward reserve which is required to cope with an unforeseen decrease of demand [10]. Power system operators secure different amounts and types of operating reserves to maintain supply-demand balance and keep the system frequency stable. The integration of wind power generation requires additional upward and downward reserves to assist in generation and load balance and frequency control because of the possible overestimate or underestimate of the wind generation and future loads [11]. The author of [12] differentiated the types of operating reserves according to their response speed, response duration, and frequency of use. These reserve types are summarised in Figure 1-4. Spinning reserve refers to the extra generating capacity that is available by increasing power output of generators that are already connected to the power system. The non-spinning reserve is the extra generating capacity that is not currently connected to the system but can be brought online after a short delay. The replacement reserve known as contingency reserve is reserve power provided by generators that require a longer start-up time (typically thirty to sixty minutes). It is used to relieve the generators providing the spinning or non-spinning reserve and thus restore the operating reserve. Finally, the frequency-response reserve (also known as regulating reserve) is provided as an automatic reaction to a loss in supply. It occurs because immediately following a loss of supply, the generators slow down due to the increased load. To combat this slowing, many generators have a governor. By helping the generators to speed up, these governors provide a small boost to both the output frequency and the power of each generator. 


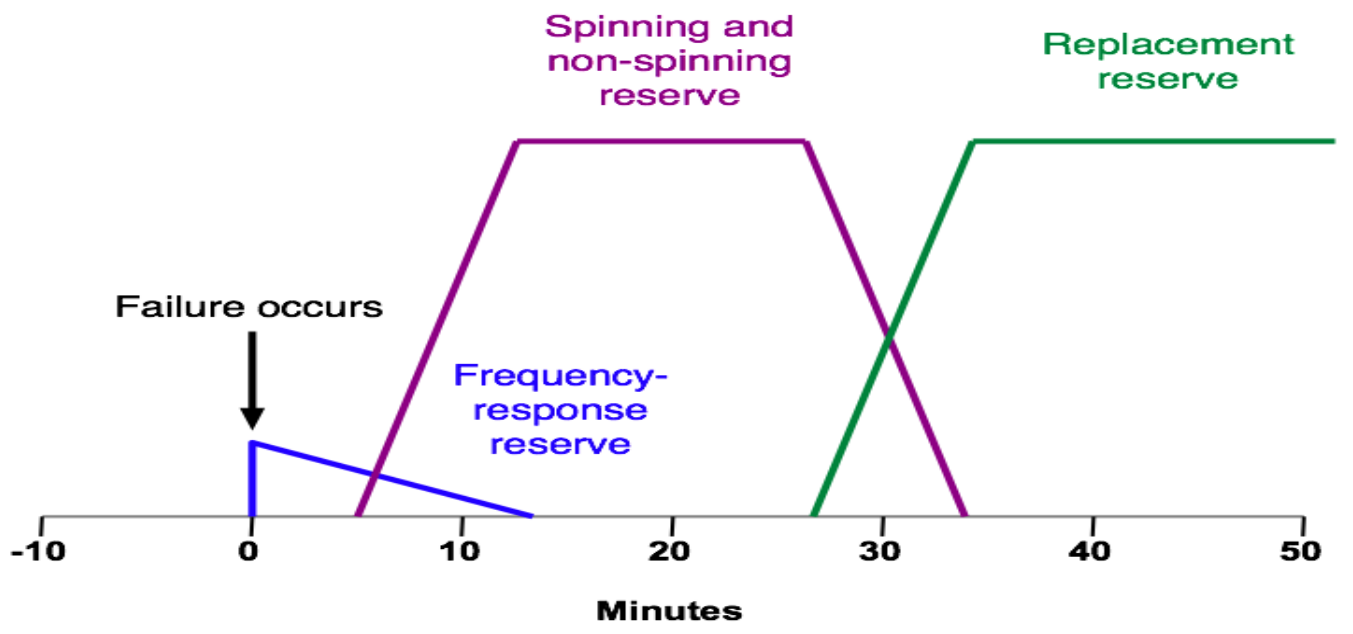

Figure 1-4: Examples of Operating Reserves and how they are related [12]

Operating reserve in the New Zealand power system has been defined and investigated by [9]. The researchers of [9] carried out a study to investigate the system impacts and costs of integrating wind power in New Zealand. One of the objectives of their study was to quantify the amount of additional operating reserves needed and their cost effective provision in order to capture most of the variation in wind power output to maintain system balance and security. Their study investigated the impact of increased wind penetration levels on three types of operating reserves: instantaneous reserve (spinning reserve), frequency keeping reserve and standing reserve (non-spinning reserve). Frequency keeping reserve refers to the reserve utilised to manage the frequency in the North and South Islands within the normal band of $50+/-0.2 \mathrm{~Hz}$. In order to meet this objective, the system operator procures frequency keeping quantities of $+/-50 \mathrm{MW}$ from frequency keeping stations in each island. On the other hand standing reserve is used for absorbing less frequent but relatively large load-supply imbalances. Instantaneous reserve which will be the focus of this study is defined as the reserve provided to manage the risk of the loss of infeed from the largest single plant in a contingency event. They further classified instantaneous reserve into fast instantaneous reserve which should be available within $6 \mathrm{sec}$ and sustained for a minute, and sustained instantaneous reserve which needs to be available within $60 \mathrm{sec}$ and sustained for 15 minutes. The authors of [9] found that for low wind penetration in 2010, hydro remains the primary source of operating reserves. However, due to the limited expansion of New Zealand's hydro capacity expected in the future, other flexibility resources should take part to manage the variability of wind generation. Additional 
operating reserves will be needed to manage the uncertainty in wind generation output in high penetration scenario.

Numerous studies have shown that high penetration of fluctuating renewable energy is possible, but this requires constant changes in planning and operation of transmission networks as well as resources which can balance fluctuations and respond to contingencies. Power systems have many flexibility sources for integrating greater amounts of variable generation into the grid. Figure 1-5 [13] provides a conceptual supply curve which shows the main sources of flexibility and their cost rates.

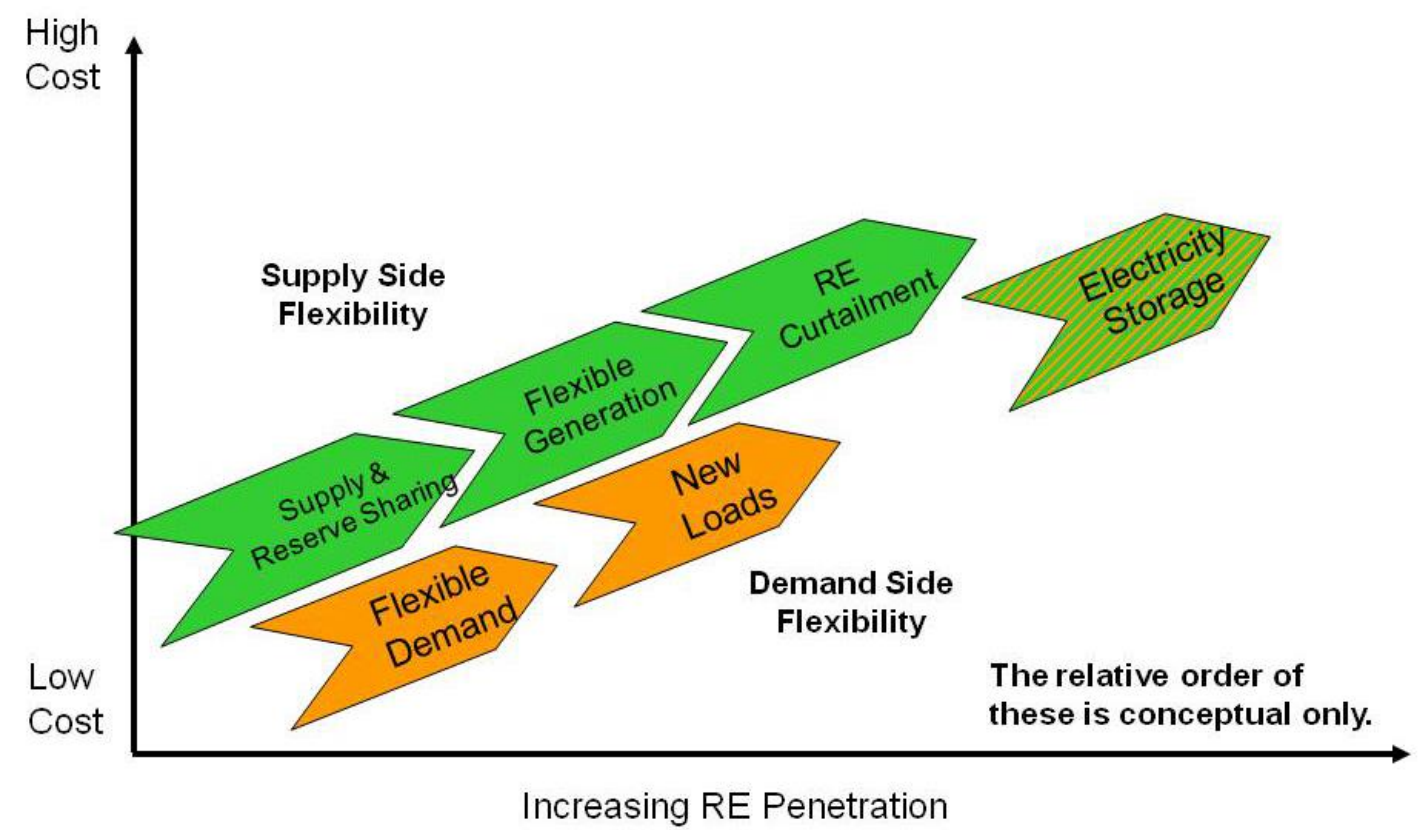

Figure 1-5: Cost of increased flexibility in power systems, general trend [13]

Supply from power plants have traditionally provided nearly all system flexibility. Flexibility options in power supply include conventional generation systems, such as coal, gas, oil and renewable sources. Energy storage can be seen as both generation and demand in the system. Also, power system transmission and distribution networks are a key enabler of flexibility in the system, allowing the spatial sharing of flexibility resources. The use of interconnections between neighbouring systems to enhance system security has been a common practice. Interconnections can increase flexibility by allowing balancing of a system in coordination with other system operators. In Denmark and Germany where wind power is a main source of electricity, their power systems are managed by utilising large flow of power across national boundaries. This flow ensures demand is met during periods of low renewable generation and also to allow extra power supply to be used elsewhere during periods of high renewable generation. However, due to the isolated location of New 
Zealand, importing and exporting power is not a feasible option. Power systems can also utilise flexible demand response to maintain their flexibility and security. The focus of this study is on examining the potential of demand response as a source of contributing towards instantaneous reserve provision in the New Zealand power system when hosting large amount of wind with the aim of maintaining system reliability Next section provides a brief background about demand response capabilities of providing reserve to maintain power system flexibility.

\subsection{Demand response}

Stakeholders are recognizing that flexible demand will be increasingly valuable in managing the intermittency of renewables in the future and that the participation of the demand side has potential to bring considerable benefits to the electricity market. The author of [14] commented that demand response is a critical feature to be developed for an efficiently functioning electricity grid in an isolated country like New Zealand, which is aspiring for a high intermittent renewable penetration. From the perspective of wind power integration and increasing system flexibility, demand response offers the most interesting prospects [15]. Demand response can usually be very fast to react, which means that it can be used for a wide variety of system services starting from instantaneous reserves all the way to long-term capacity adequacy. Technically, demand can provide better reliability response than generation since full response is usually achieved immediately by tripping the load [12]. [16] defined demand response as "changes in electric usage by end-use customers from their normal consumption patterns in response to changes in the price of electricity over time, or to incentive payments designed to induce lower electricity use at times of high wholesale market prices or when system reliability is jeopardized." Demand response includes all intentional modifications to consumption patterns of electricity of induce customers that are intended to alter the timing, level of instantaneous demand, or the total electricity consumption. Demand response has existed in various forms for decades. Demand response programs fall into incentive based demand response and price based demand response which has many subcategories. These demand response subcategories are described in the US Federal Energy Regulatory Commission Reports [16]

\subsubsection{Price-based demand response}

Price-based demand response involves using changing prices to induce changes in customers' consumption of electricity. 


\subsubsection{Real Time Pricing}

This is a dynamic tariff which reflects real time costs. Prices offered to customers typically vary in either 1 hour or 15 minute blocks, and are either based on day ahead market prices, or reflect the true real time market prices for electricity.

\subsubsection{Time of Use Pricing}

It is widely offered to all customer types. Customers pay different prices per unit of electricity during different blocks of time throughout the day. Time of Use Pricing is used to encourage load shifting to bring about peak clipping and valley filling and produce a more desirable load shape.

\subsubsection{Critical Peak Pricing}

This type is used to shift or reduce loads during critical peak events. Events are limited in number and events typically last a number of hours. Customers receive advance notification of an event - often 24 hours' notice is given but some programs also operate with shorter notification periods. Critical Peak Pricing is often used in conjunction with Time of Use Pricing tariffs. Significantly increased prices are charged during the peak events, but customers are rewarded with reduced on-peak rates at non-event times. The authors of [17] have investigated the impact of 15 programs which introduced some form of incentives to compensate residential customers for reducing demand which varied considerably based on the pricing-based strategy. While time-of-use pricing scheme resulted in 3-6\% rate reduction, critical-peak pricing achieved higher reductions (13-20\%).

\subsubsection{Incentive-based demand response}

Incentive-based demand response consists of payments to customers to incentivise load reductions at times of system stress or high electricity prices [16]. The various programs of incentive-based demand response are reviewed in [18] and [19].

\subsubsection{Direct load control}

Direct load control (DLC) programs refer to programs in which a utility or system operator remotely shuts down or cycles a customer's electrical equipment on short notice to address system or local reliability contingencies in exchange for an incentive payment or bill credit. Operation of DLC typically occurs during times of system peak demand. For decades, DLC has been used on domestic loads such as air conditioners and water heaters, typically to 
achieve peak reductions in demand. Ripple Control of water heaters has been used in New Zealand since 1960s [14].

\subsubsection{Interruptible service}

Customers on interruptible service receive a rate discount or bill credit in exchange for agreeing to reduce load during system contingencies. If customers do not curtail, they can be penalised

\subsubsection{Emergency demand response program}

This scheme provides an incentive payment to customers for reducing their loads during reliability-triggered events, but curtailment is voluntary. Customers can choose to forgo the payment and not curtail when notified. The level of the payment is typically specified beforehand.

In this study, DLC strategy refers to the scheme when the utility or system operator remotely controls customer's appliances on short notice to contribute to system additional Instantaneous reserve resulting from the variability of large amount of wind power integration. Most of the DLC programs are offered to large commercial and industrial customer, and residential demand response is a largely unexploited resource [20]. Improved technologies in communication and control provide new opportunities for tapping the residential demand response to play a role in meeting some of the challenges emerging from higher penetration of variable generation in the power system.

\subsubsection{Residential demand response}

Residential demand response can play an important role in the effort to achieve an efficient and reliable power system with high penetration of renewable energy sources [21]. In New Zealand, most of the cost effective control methods are targeted towards large industrial and commercial loads due to their large consumption of electricity and to the simplicity of controlling and interacting with a small number of large consumers by sector. Figure 1-6 provides information about the estimated electricity consumption per sector and the percentage of consumers. The estimated electricity consumption by sector shows that residential loads constitute the highest magnitude of demand (35\%) and the highest percentage of the number of consumers $(85 \%)$. One generally thinks of large industrial and commercial facilities as the best candidates for demand response programs because these 
customers consume large amounts of electricity and, subsequently, are able to curtail a substantial amount of power when a demand response event is called.

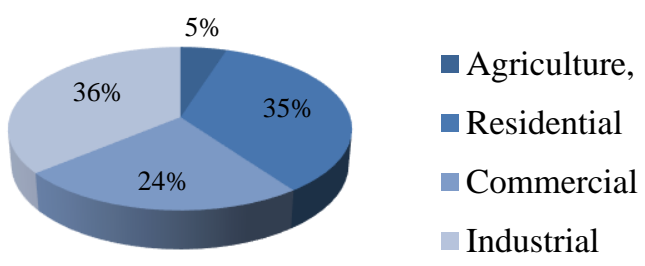

Estimated Electricity Consumption

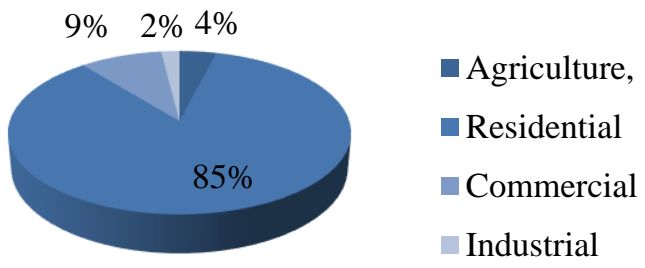

Percentage of Consumers by Sector

\section{Figure 1-6: Consumers by sector}

However, there are many benefits to using aggregations of small residential loads. First of all, small residential loads are more reliable in aggregate than larger loads. As shown in Figure 1-7 [15], if there are six generators each providing 100MW with reliability $95 \%$ the probability for the six to work together is $74 \%$, and the probability for only five generators to work together is $97 \%$. On the other hand if there is an aggregation of 1200 small loads with $500 \mathrm{KW}$ each and reliability rate $90 \%$, this will give $540 \mathrm{MW}$ but not less than 520MW.

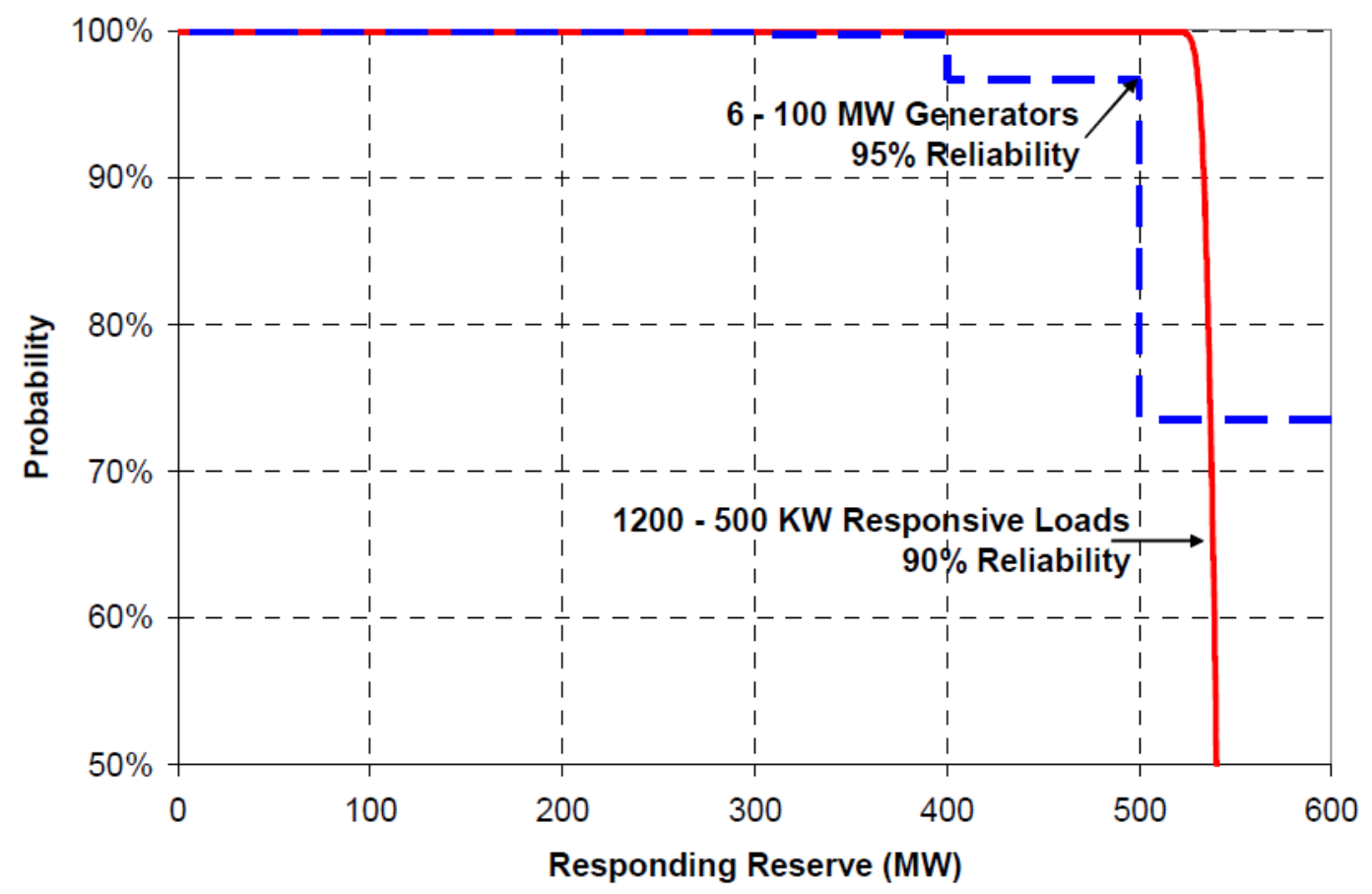

Figure 1-7: Potential of small aggregated loads [15]

The small residential loads are also spatially distributed not centred in limited area, and thus there is a huge resource potential. At the same time, if loads are to become responsive, 
the overall satisfaction of consumers should not be affected. The author of [12] listed the following characteristics of suitable loads which can participate in providing reserves to the power system

\subsubsection{Storage}

It is difficult to store power or energy directly. So, any load that has some storage in its operation process or if some energy can be injected to it, then it can be a good candidate to supply reserves. Thermal storage loads such as building heating/cooling, water heating, refrigeration and compressed air, water pumping are best examples of load that can serve as instantaneous reserves.

\subsubsection{Control capability}

The responsive load must be controllable such that it is able to respond to curtailment requests from the utility company.

\subsubsection{Notification requirements}

Power system contingency should be diagnosed as soon as possible. Thus, load that requires short notification time are best suited for instantaneous reserves. Thermal loads, water pumping, air compression can be used as reserves because they generally do not require advance notification curtailment.

\subsubsection{Response speed}

The load used as contingency reserve must accomplish the given task as soon as it has been notified, without wasting anytime. Studies have shown that load response can exceed generator response. Thermal loads can provide full response instantaneously.

\subsubsection{Size}

The size of each responsive load is small. However, the aggregate size needs to be large enough to be useful. Aggregate size is a very important index to offer more reliability resource for instantaneous reserve

\subsubsection{Minimal cost}

When responsive loads are used as the instantaneous reserve provider, saving is made in the investment to build the generator and transmission devices. Moreover, controller and 
communication device needs to be installed at the load side. When responsive load work as instantaneous reserve provider, the price compensation for customer is also considered. Therefore, household appliances which are thermostatically controlled represent an excellent target for load control due to their ability to store energy in the form of temperature. These loads are often controlled by hysteretic thermostats. Those loads can be interrupted for limited periods of time without noticed loss of end-use function. Examples of household appliances are refrigerators, freezers, and water heaters. These appliances are selected also because of their stable power demand throughout the years with very slight seasonable variations. One way to implement DLC is through interruptions of appliances operation for a short time in a way that does not disturb the consumers' comfort and which require minimal customer's intervention. This strategy will be investigated in this study to quantify the potential of residential demand response gained from controlling refrigerators, freezers, and water heaters to balance the fluctuation of wind and contribute towards the additional instantaneous reserve at times when large amounts of wind are being integrated into the grid.

\subsection{Research objectives and approach}

This study aims to investigate to what extent responsive demand provided from controlling household appliances can act as a source of flexibility and provide instantaneous reserve to facilitate the integration of wind generation in the New Zealand power system. Household appliances including refrigerators, freezers, and water heaters are ideal candidates due to their considerable saturation rates and the possibility of instantaneous control [22]. It specifically examines the potential for residential responsive loads for electric water heaters, freezers, and refrigerators to participate in short timescale energy markets through contributing towards the additional instantaneous reserve during three scenarios for wind penetration in $2014,2020,2030$. Then, the potential of the studied residential loads to balance the intermittency of wind will be demonstrated on Wellington Region Electrical Network. Specifically, this case study will show the extent the responsive residential loads in Wellington region can mitigate the variability of the wind power generated from West Wind Farm in Wellington during seven selected days during the years 2013-2014. This research does not presume to estimate precisely the amount of load available to respond to system required instantaneous reserves in 2020, 2030 rather it presents an approximate initial calculation of their potential. 


\subsection{Thesis structure}

According to the objectives presented above, the thesis is organised in five chapters. Chapter 2 gives a thorough review of the electricity supply system in New Zealand and the trends of demand response offered in New Zealand electricity market. Chapter 3 reviews the main findings from the state of the art wind integration studies and the impact of wind integration upon operating reserve. It also reviews studies which investigated the role of demand response to mitigate the variability of wind. Chapter 4 assesses the current level of demand responsiveness among domestic loads for certain household appliances and evaluates the aggregated effect of these loads and the margin which could be derived from them to meet the requirements of the additional instantaneous reserves based on three scenarios for wind penetration in 2014, 2020, 2030. Then, the potential of the studied residential loads to balance the intermittency of wind will be demonstrated by conducting a small case study which modelled the extent the responsive residential loads in Wellington Region network can mitigate the variability of the wind generated from West wind Farm in Wellington. Chapter 5 concludes this work and proposes directions for future work. 



\section{CHAPTER 2 NEW ZEALAND'S ELECTRICITY SECTOR}

\subsection{Introduction}

This chapter gives a thorough review of the electricity supply system in New Zealand. The first section reviews the six distinct components of New Zealand electricity sector: generation, transmission, distribution, retail, consumption and regulation. The second part reviews a number of DR initiatives and their purposes in New Zealand electricity market. The information in this chapter were synthesised from different sources as documented below.

\subsection{Electricity industry structure}

\subsubsection{Generation}

Generation companies generate electricity at power stations, selling the electricity generated via the wholesale market to retailers while physical electricity is injected into either transmission lines or distribution lines. In 2013, 41,876 GWh of electricity was generated in New Zealand [23]. Numerous companies generate power, but $92 \%$ of electricity is generated by five companies: Contact Energy, Genesis Energy, Meridian Energy, Mighty River Power and Trust Power as shown in Figure 2-1

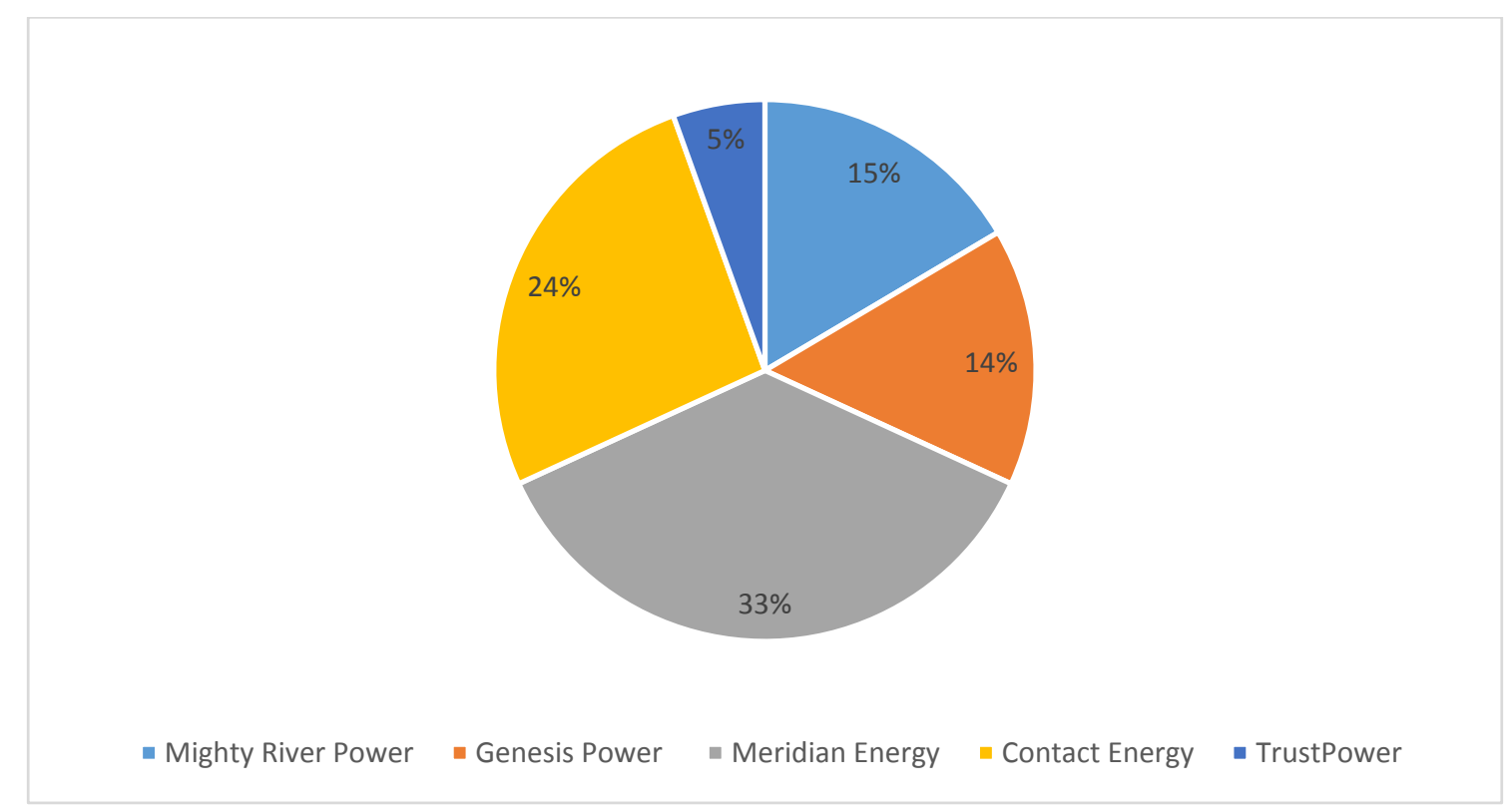

Figure 2-1: Electricity generation by company

The electricity generated in 2013 was $53 \%$ hydroelectricity, $20 \%$ natural gas, $14 \%$ geothermal, 8\% coal and 5\% wind [23] as depicted in Figure 2-2. 


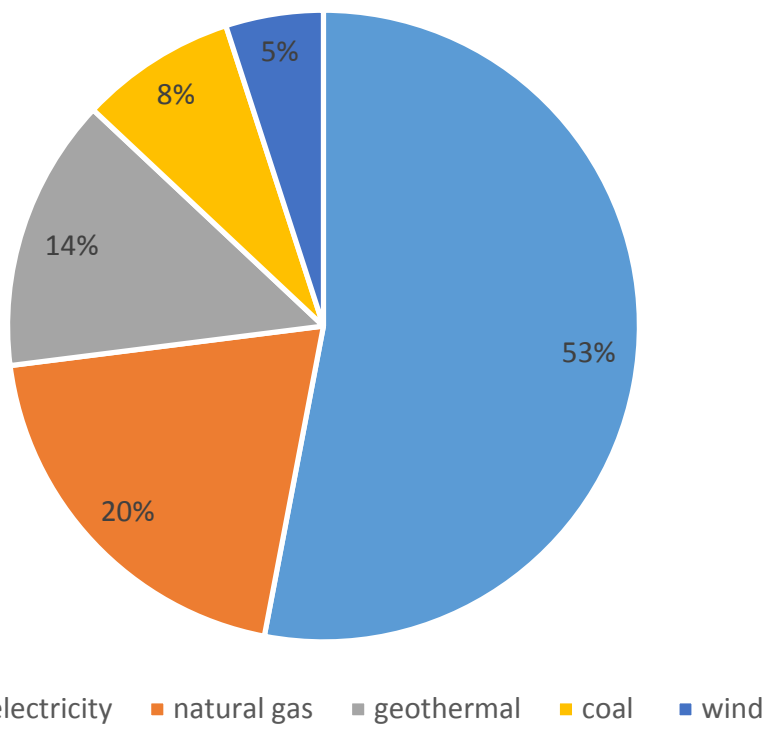

Figure 2-2: Percentage of New Zealand electricity generation from renewables

In 2013, New Zealand generated 41,876 gigawatt-hours (GWh) of electricity: 24,200 (GWh) for North Island and 17,676 (GWh) for South Island [4]. Comparing the two main islands, nearly all South Island's electricity is generated by hydroelectricity - 98\% in 2012 [4] and the rest is generated by wind power. The North Island meanwhile has various sources of generation sources as shown in Figure 2-3.

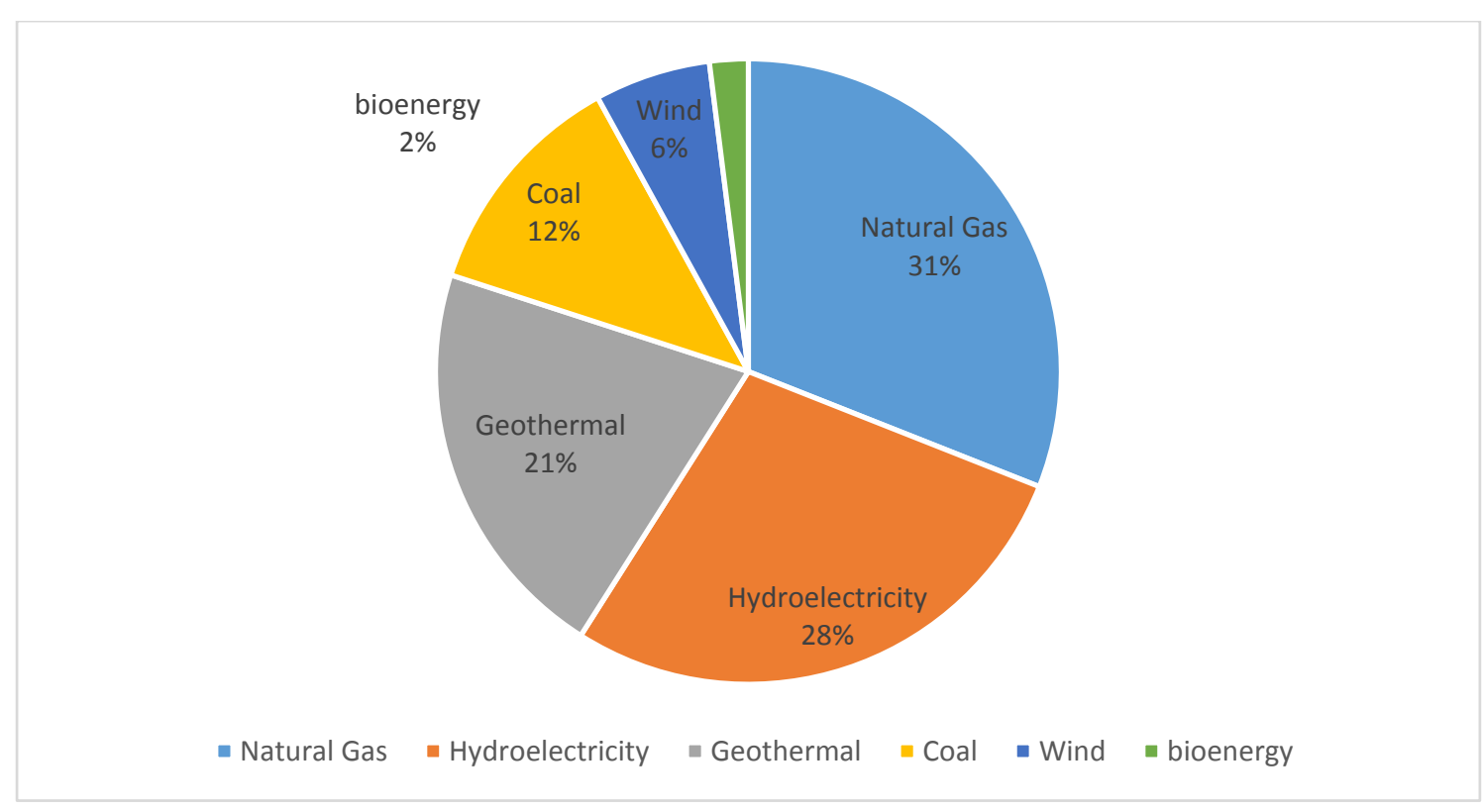

Figure 2-3: The North Island Generation Mix 2012

\subsubsection{Transmission}

Transpower operates the national transmission grid, which conveys electricity from most of the major power stations around the country to local distribution lines [24]. It also 
conveys electricity directly to major users such as the New Zealand Aluminium Smelter [25]. As system operator, Transpower manages the real-time operation of New Zealand's power system by keeping the right amount of energy flowing 24 hours a day, 7 days a week. New Zealand's national electricity transmission grid connects its generating facilities to its demand centres. The grid contains 11,803 kilometres of high-voltage lines and 178 substations [24]. Electric transmission lines are the high voltage power lines that transport power from the generation stations to the key distribution points around the country. The backbone of the grid in each island is the network of $220 \mathrm{KV}$ transmission lines. These lines connect the larger cities and power users with the major power stations. Lower capacity $110 \mathrm{KV}, 66 \mathrm{KV}$ and $50 \mathrm{KV}$ transmission lines connect smaller towns and cities and smaller power stations, and are connected to the $220 \mathrm{kV}$ core grid through points of interconnection at major transmission substations [26]. Transpower commissioned the Pole 3 upgrade of the High Voltage Direct Current link between the North and South Islands during 2013, now with a capacity of $1200 \mathrm{MW}$. Up to $1000 \mathrm{MW}$ of surplus power generated in the South Island can be transmitted to the North Island [23]. Much of New Zealand's electricity is generated from lakes and rivers in the South Island while most of the electricity demand is in the North Island, particularly the Auckland region [26]. Transpower ensures that its network is capable of transmitting power between the two islands. It works in collaboration with electricity generation companies as well as distribution companies.

\subsubsection{Distribution}

Electricity from Transpower's national grid is distributed to local lines companies and large industrial users via 180 grid exit points at 147 locations. Large industrial companies, such as New Zealand Steel at Glenbrook draw directly from Transpower substations and not the local lines companies' local grids [27]. There are 28 distribution companies each serving a set geographic area. Distribution of electricity to local consumers is the responsibility of one of about 30 local line companies. Each company supplies electricity to a set geographic area based on the grid exit points they draw from [27].Wellington Electricity is the distribution company in Wellington Region as depicted in Figure 2-4 [28]. 


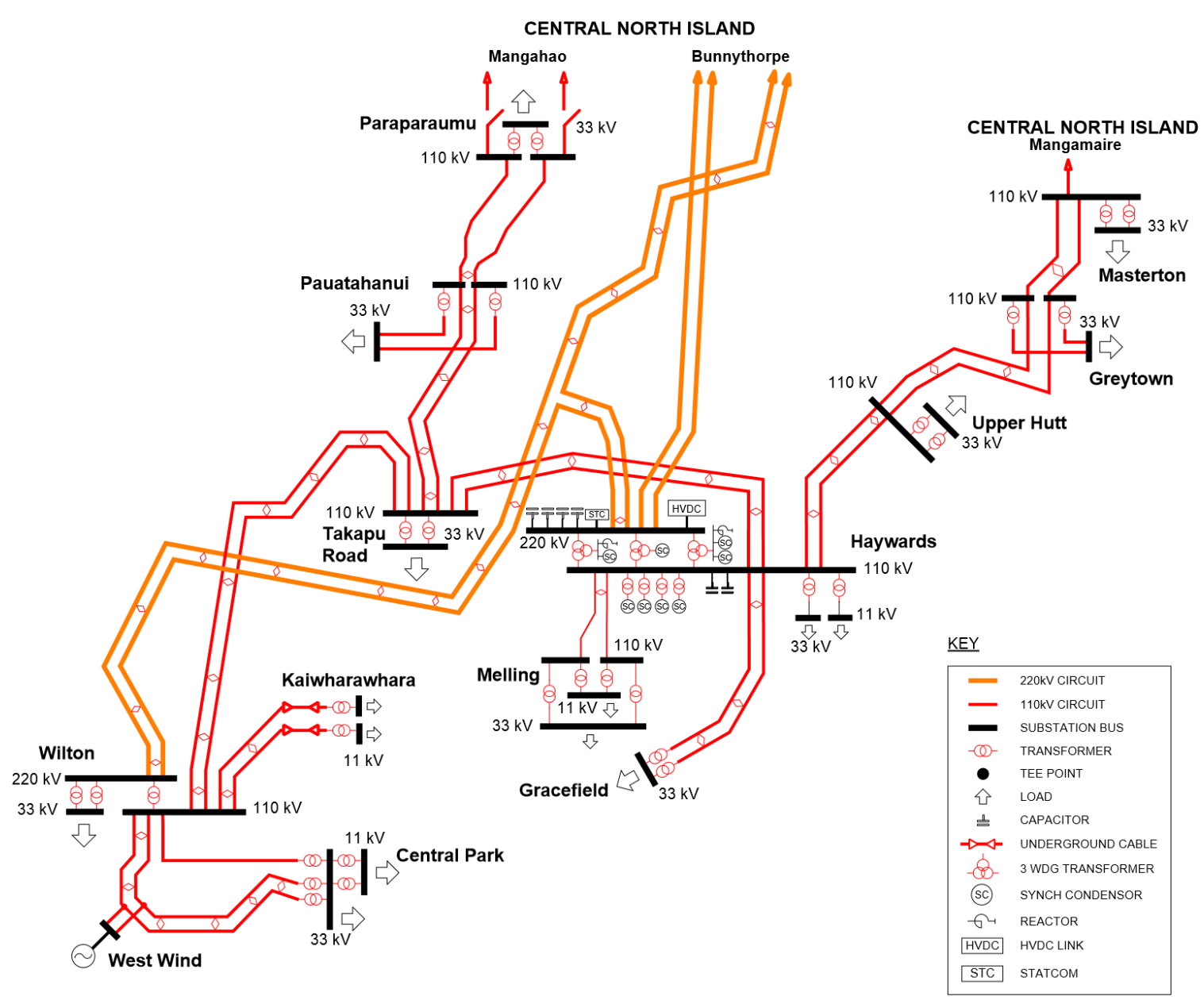

Figure 2-4: Wellington transmission schematic [28]

The local line companies draw electricity from one or more grid exit points at various voltages between $11 \mathrm{kV}$ and $110 \mathrm{kV}$. Some medium-sized industrial consumers draw directly from the subtransmission grid, and smaller power stations up to around $60 \mathrm{MW}$ in size usually connect to the sub-transmission grid for distribution and connection to the national grid. Sub transmission and distribution voltages differ from area to area. Most areas use $33 \mathrm{kV}$ sub transmission and $11 \mathrm{kV}$ distributions [25]. Distribution voltage lines run from zone substations to the streets of consumers, and to some large local businesses, such as supermarkets, schools, large farms. Three phase power is available in all urban and most rural areas [27]. Single phase supply utilizing only two phases or single wire earth return systems are used in outlying and remote rural areas with light loads. Distribution networks transport power to consumers through a network of overhead wires and underground cables. In total, there are over $150,000 \mathrm{~km}$ of distribution lines in New Zealand. The distribution networks also include substations which convert electricity to lower voltages [23]. Almost all consumer premises in New Zealand are connected to a distribution network. 


\subsubsection{Retail}

Retail companies buy electricity from generators and then sell it to consumers. Numerous companies' retail electricity, including many generating companies, but $95 \%$ of the retail sector is dominated by five companies: Contact Energy, Genesis Energy, Mercury Energy (the retail division of Mighty River Power), Meridian Energy and Trust Power [25]. Retailers buy electricity at connection points to the grid and on-sell it to consumers at individual customer connection points. The retailer is responsible for the installation of appropriate metering, meter reading, billing and payment collection. The retailer pays distribution companies for distribution service which includes transmission charges paid by distributors to Transpower, and also buys electricity from the wholesale electricity market [25]. In most cases, the consumer is billed only by the retailer. Figure 2-5 shows the market share of retailers based on monthly numbers of customers at 31 December 2013[24].

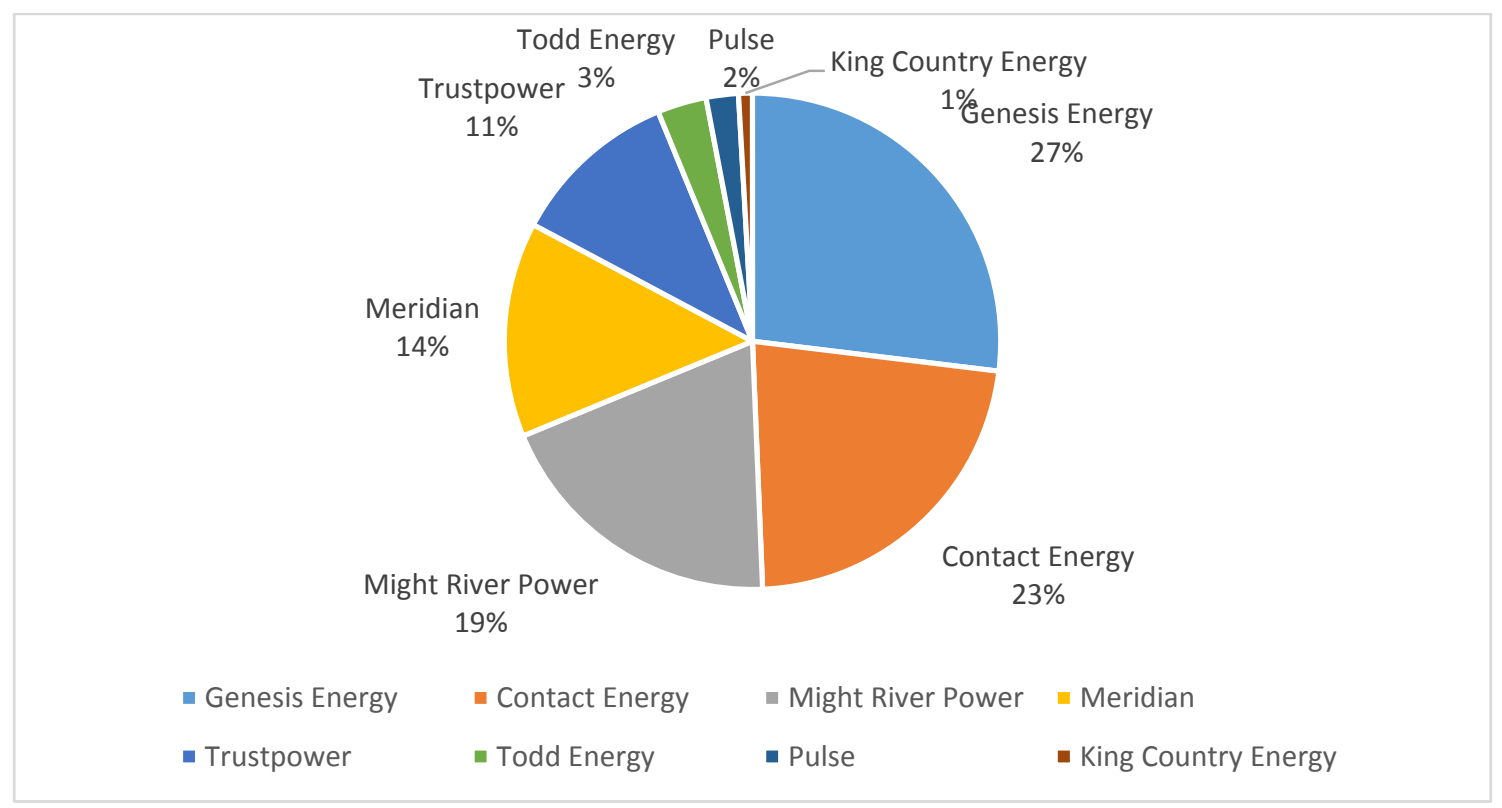

Figure 2-5: Monthly retail market share by parent company [23]

\subsubsection{Consumption}

Nearly two million consumers take electricity from the distribution networks or the transmission network and buy electricity from retailers for their use [23]. Consumers range from typical households, which consume on average 8-9 MWh per year, to the Tiwai Point Aluminium Smelter, which consumes 5,400,000 MWh per year [25]. Electricity consumers range from large industrial sites down to individual households. Demand for electricity varies from moment to moment and supply must change to meet change in demand. Consumption follows strong daily and seasonal patterns. At low demand times 
such as a summer night, total demand may be as low as 2,600 MW, whereas at peak times especially during winter evenings, it can exceed 6,500 MW. While electricity use has historically been highest on cold winter evenings, some regions now have a summer time peak demand as a result of increasing use of farm irrigation and domestic air-conditioning [14]. Figure 2-6 shows an average demand profile for a domestic consumer for a 24-hour period during winter in New Zealand [14]

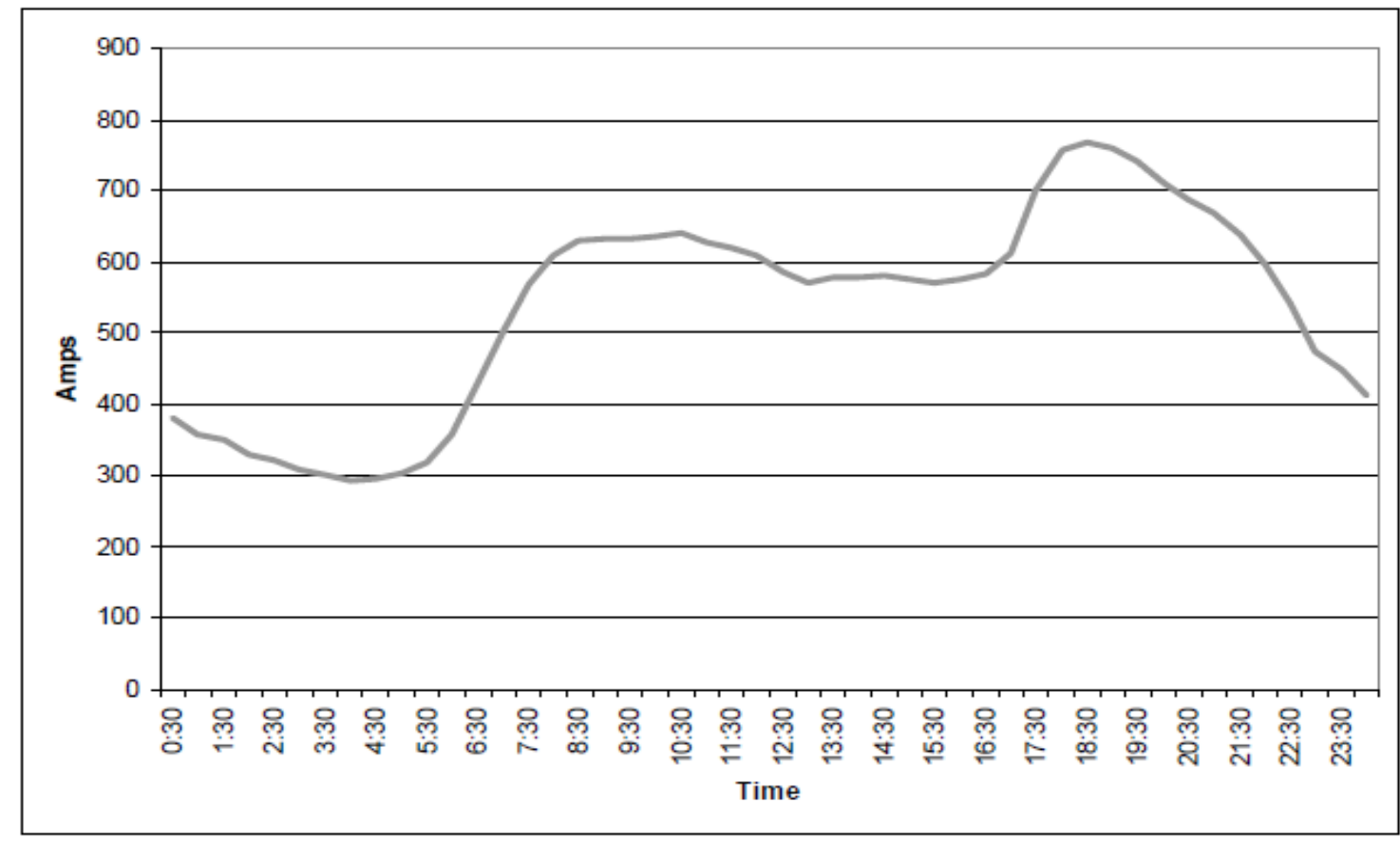

Figure 2-6: Daily load profile of residential customers [14]

Ministry of Business and innovation New Zealand [23] reported that in 2013, New Zealand consumed a total of $38,998 \mathrm{GWh}$ of electricity. Residential consumption decreased by $1.7 \%$ in 2013 to $12,307 \mathrm{GWh}$. Technological energy efficiency improvements and changes in household behaviour could be behind this fall. There were over 1,994,000 connections to the national electricity network on in 2012 , with $86 \%$ being residential connections whose electricity consumption constitute $35 \%$ as shown in Figure $2-7$

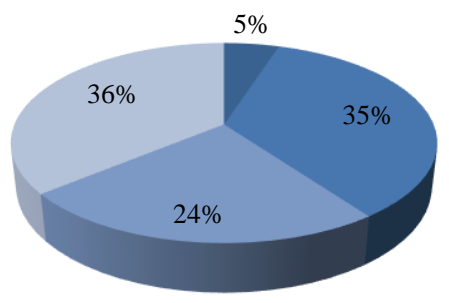

- Agriculture,

- Residential

- Commercial

Industrial

Figure 2-7: Electricity consumption by sector for 2013 


\subsubsection{Regulation}

New Zealand's Electricity Authority is responsible for management of the electricity industry, while Transpower as System Operator manages the electricity system in real time to ensure generation matches demand. Electricity Authority has regulatory oversight of the retail and wholesale markets, and transmission contracts [29]. The Authority contracts out the services required to run the electricity market. Electricity is traded at a wholesale level in a spot market. The market operation is managed by several service providers under agreements with the Electricity Authority. Electricity spot prices can vary significantly across trading periods, reflecting factors such as changing demand and supply [29]. Spot prices can also vary significantly across locations, reflecting electrical losses and constraints on the transmission system. Generators submit offers through a Wholesale Information and Trading System. Each offer covers a future half-hour period called a trading period and is an offer to generate a specified quantity at that time in return for a nominated price [29]. Transpower uses a scheduling, pricing and dispatch (SPD) system to rank these offers in order of price, and selects the lowest-cost combination of offers (bids) to satisfy demand. The market pricing principle is known as bid-based security-constrained economic dispatch with nodal prices. The highest-priced bid offered by a generator required to meet demand for a given half-hour sets the spot price for that trading period. During each half hour period Transpower publishes a new real-time price every five minutes, and a timeweighted 30-minute average price. The real-time prices are used by some large directconnect consumers to adapt their demand. The final prices are calculated normally noon the following day, using the offer prices as established two hours before the trading period and volumes as established during the trading period [26]. Differences between forecast, dispatch, real-time and final prices can be significant.

\subsection{Summary}

The share of electricity generated from renewable energy sources increased from $72.8 \%$ in 2012 to $75.1 \%$ in 2013. This was due to increased hydro and geothermal generation, and lower coal generation. On the supply-side, New Zealand generates a bulk of its electricity from hydro power. A unique feature of New Zealand hydro is the very low storage ability. Variability in rainfall results in variability of the amount of power that can be generated from the hydro power. In New Zealand, high electricity demand during the winter months coincides sometime with the dry years where generation capacity is limited and this increases the advantages of higher integration of wind in the NZ power system. The fact 
that residential sector consumes more than $35 \%$ of electricity and that the residential consumption contributes to $50 \%$ of peak may highlight the potential of dealing with the residential sector to improve system reliability and contribute to maintain balance between demand and supply, especially that these big numbers of small residential loads are spatially distributed as discussed in the distributing and retailing section.

\subsubsection{Demand response programs in New Zealand}

There are a number of demand response programs which are targeted towards four components of the NZ power system: transmission, distribution, retailing, and domestic consumption. Most of those demand response programs are incentive based [30].

\subsubsection{Transpower demand response initiative}

Transpower has used demand response since the 1990's to defer transmission investment [31]. Transpower most recent incentive-based initiative targets users who have flexible demand which facilitates participation by reducing their usage when called upon to do so, and receive a payment for their reduction. Two types are available, the first being security DR whereby the user is compelled to reduce consumption by a contracted amount when called upon to do so [32]. An availability payment is also made. The second type is price responsive DR in which the user may voluntarily opt in to a call. For both types the call from Transpower is made at least 2.5 hours in advance [33]. Communication is managed via the Demand Response Management System between Transpower and the Curtailment Service Provider using Alstom's DRBizNet platform [32]. The Curtailment Service Provider may be the consumer or a third party providing service on the consumer's behalf. In July 2013 Transpower announced that it had received a very positive response. Suppliers varied from commercial businesses, to larger industrials, and to retailers. Over $200 \mathrm{MW}$ was obtained representing about $8 \%$ of Upper North Island peak demand. In November 2013 the Commerce Commission approved expanding Transpower's demand response programme geographically to the whole of country to enable it to be tested throughout New Zealand. Transpower ultimately has a target of obtaining $10 \%$ of peak national demand through demand response [34]. The next target is small to medium size businesses offering 20 to $200 \mathrm{~kW}$ of demand response. This may eventually be extended to households. Alstom Grid's DRBizNet technology aims to target home appliance, such as fridges and freezers. This could occur through the introduction of smart appliances such as fridges, freezers, and 
thermostats which might link to a smart meter communicating with a customer service provider [32].

\subsubsection{Interruptible load}

Interruptible load is incentive based demand response strategy and is available for shedding or demand reduction to enable the power system to respond to the falling of the largest single supply asset by supporting the grid system frequency to avoid cascade failure [35]. There are two types of interruptible load according to the time and duration of response. The first is fast instantaneous response which arrests frequency fall, and it should be ready to shed within 1 second of the grid system frequency falling to or below $49.2 \mathrm{~Hz}$ and be sustained for at least 60 seconds [36]. The second is sustained instantaneous response which restores frequency and must be shed over the first 60 seconds of the grid system frequency falling to or below $49.2 \mathrm{~Hz}$ and be sustained until instructed by the system operator [36]. Interruptible load is shed automatically using frequency controlled relays. The quantity of fast response required on hand is calculated by the system operator's Reserve Management Tool. The required quantities of interruptible load are procured in the same way as the wholesale energy market. Availability and event payments are charged. An event charge is paid by who is responsible for causing the under frequency event [30]. The event charge is related to those who pay availability charges. On the demand side, interruptible load is provided by industrial and commercial end-users. Usually these end-users will provide their interruptible load via an aggregator who is contracted by Transpower to offer interruptible load into the reserves market. In return, the end-users receive payments for their Interruptible Load. For example, EnerNOC Inc. is an aggregator of interruptible loads under its Demand SMART NZ Interruptible Load Programme [37] . In 2012 this offered over $120 \mathrm{MW}$ of interruptible load to the instantaneous market in the North Island. It secures interruptible load in both North and South Islands for Genesis Energy [38] EnerNOC installs a data server at the client's facility enabling real-time monitoring and viewing of energy data. Upon detecting a frequency drop EnerNOC metering automatically initiates shedding of nominated load which is notified to the client via SMS or Email. Clients receive monthly payments.

\subsubsection{Demand response program at the retailer}

Demand response is used by retailers to manage load and therefore influence spot prices in an area, particularly if that area is constrained [30]. A retailer may contract with distributors 
to use ripple control to provide load shifting services for peak periods. This can also include locational load shifting between Grid Exit points. System agreements between a retailer and distributor may allow load controlling for the retailer's purposes if the distributor is not requiring control for security of its own network. This control affects the customer loads of multiple retailers. The interests of these retailers are usually aligned by load controlling. Ultimately, Advanced Metering Infrastructure (AMI) will allow a retailer to just control the load of its own customers.

Another significant form of demand response on the retailing level is related to the procurement of interruptible loads. The spot energy price is influenced by the availability of reserve. Generation plant, or HVDC transmission, may be constrained by a lack of reserve. Thus the provision of interruptible loads can help mitigate high prices on a retailer's load, as the spot energy price is influenced by the availability of reserve. Furthermore, from the perspective of a generator, sufficient reserve ensures dispatch enabling revenue from generation. For example, reserve in the receiving island can facilitate transfer on the HVDC link and thereby reduce prices. This creates an incentive for generator-retailers to contract for interruptible load. Another strategy used at the retailing level is price-based demand response and it requires the installation of smart meters to consumers and offer their domestic customers Time of Use (TOU) tariffs. Curtailable loads can be utilised to reduce wholesale electricity price spikes in the lower North Island. For example, industrial and commercial load in the lower North Island is being aggregated by EnerNOC, for Genesis Energy [38]. When the need arises, Genesis informs EnerNOC that DR capacity is required. In turn EnerNOC contacts their clients to reduce consumption or switch to back-up generation. The notice time is two hours and clients have the choice to opt out in a manner similar to Transpower's price responsive DR. EnerNOC installs meters that communicate to its Network Operations Centre. Clients then have real time energy monitoring via EnerNOC's Demand SMART web based portal. Notification to clients is via SMS, Email, or phone. Clients receive a capacity payment for being enrolled and an energy payment based on the amount of DR delivered.

\subsubsection{DR at the distribution level}

Ripple control to shed household hot water heating load has been used for many decades in New Zealand. It is a form of incentive based demand response known as Direct Load Control [14]. Today it remains the principal DR tool used by distributors. A distribution company responds by using ripple control to minimize their portion of their region's charge. 
Transpower charges distribution companies for the use of the national grid by including a Regional Coincident Peak Demand charge (RCPD) [29]. There are two regions in each island. Both upper island regions price on the 12 RCPD peaks in the measurement period, while the two lower island regions price on the top 100 RCPD peaks. For instance, Orion uses demand response for the purposes of deferring costs, and maintaining compliance with their security of supply standard. The use of demand response was an important tool in managing the restoration of supply during the 2010-2011 Canterbury earthquakes. Metering owners have installed approximately 110,000 smart meters, most of which contain inbuilt ripple receivers on the Orion network. Where appropriate, the remainder of the 190,000 network connections have standalone ripple receivers. The use of ripple control allows a 5-10\% reduction of peak demand corresponding to 30-60 MW. Customers with loads exceeding $300 \mathrm{kVA}$ are subject to peak demand period pricing. This enables a further $3 \%$ of peak demand reduction. Furthermore, it is estimated that the use of day-night pricing options has encouraged approximately $10 \%$ of load to be shifted from the daytime peak into the overnight. Thus peak demand has been reduced by a total of approximately $20 \%$. The transfer of load to the night is so successful that the signalling of night load switching is staggered to manage potential night time peaks. In addition, Orion has established a load curtailment scheme which provides irrigators with the option of being contracted to be the first to be cut-off in an emergency, thereby allowing better security of supply for more critical loads such as dairy sheds in an affected area. This demand response scheme uses ripple control to operate only irrigator relays. Irrigators are incentivised to participate with an interruptibility rebate [30].

Another DR strategy used at the distribution level is employed by The Lines Company (TLC) In order to accurately reflect the cost of supplying capacity [39]. TLC line charges are payable by connected consumers, both load and generation, according to the capacity each consumer requires and the assets in use to provide that capacity in remote rural connections. Demand Charging and Dedicated Asset Charges enable TLC to set prices that signal to the consumer the relative cost of reliable supply to their installation [39]. TLC has introduced a charging component based on the uncontrolled $\mathrm{kW}$ load of a customer during periods of load controlling. To better facilitate this approach, TLC is gradually rolling out its own advanced metering. For customers with this metering, the six highest two hour peaks in the measurement period when TLC is load controlling are averaged to determine a base variable capacity and associated charge. TLC have also introduced direct billing of line charges to consumers, and considers this approach more effective than using traditional 
retailer channels. The resulting separation of billing of line charges and of retailer energy charges should provide greater transparency of electricity pricing for consumers. TLC has an ageing network. The DR resulting from capacity pricing should also allow TLC to focus on renewing ageing assets to enhance security rather than having to use resources to increase network capacity.

Another company called Vector has launched an initiative offering installation of PhotoVoltaic (PV) panels combined with battery storage for domestic customers [40]. The installation includes a $12.3 \mathrm{kWh}$ Lithium ion battery pack, inverter, and control unit with a choice of 3, 4, or $5 \mathrm{~kW}$ capacity PV panels. The inclusion of battery storage enhances the benefits of PV which include: supply security, power quality management, mitigating the potential charging impact of electric vehicles on the network, and operation as a peak power supply. Distributed battery storage allows batteries to be charged at night, and then be used by the distributor to load shift power back into the network at peak times.

\subsubsection{Demand Response for domestic consumers}

Historically, DR operating in the NZ home has been limited to distributor's ripple control of hot-water and the homeowner's manual response to the retailer's traditional tariffs such as day/night rates [30]. NZ's use of ripple control is already wide-spread and provides a substantial benefit. The introduction of Home Energy Management Systems which refers to any product or service that monitors, controls, or analyses energy in the home has great potential to introduce more demand response strategies to the domestic sector. Home Energy Management Systems (HEMS) includes smart-meters, residential utility DR programs, home automation services, data analysis and visualization, auditing, and related security services. Utilities, customers and third-party vendors look to find the right balance between energy reduction, cost and customer satisfaction. In the US HEMS markets, there are utility and non-utility solutions [41]. Utility solutions include both the utility and the thousands of homes enrolled in the HEMS program. The utility benefits greatly from these services, and usually also has to pay for the entire solution [41]. Non-utility solutions focus solely on the home customer and integrate various smart-home services, which fall under the broad definition of HEMS mentioned above. The detailed economic analysis used for utility customers is replaced with a smart marketing campaign targeting the needs of homeowners vendors often enter the home with a security solution and then offer HEMS as an add-on sale. Homeowners can purchase the HEMS hardware in the mid-hundreds to low-thousands range, and pay between $\$ 15$ and $\$ 60$ per month for energy management, 
automation and security services. In the technical components of a HEMS system are listed as comprising of sensing devices, measuring devices, smart appliances, enabling ICT, and energy management systems [42]. Challenges to implementation are summarized as cost, lack of standards, low consumer awareness or interest, choice of ICT, and degree of system intelligence. With more developments in the HEMS systems, it is hoped that responsive loads in the residential sectors in New Zealand will be an active role in providing flexible demand to contribute towards balancing wind power and providing system reserves.

\subsection{Summary}

Many forms of demand response, both incentive and price based, have been identified operating at all levels of the electricity structure in New Zealand These demand response strategies provides many benefits to the power system in New Zealand including deferral of asset investment, reduced environmental impact, improved security of supply, and better integration of variable renewable generation [30]. DR from residential sector seems to be an untapped resource which may have huge potential especially with the latest technological development in ICT with increasing penetration of wind power in New Zealand, the amount and cost of reserves will increase in the future. A possible alternative is utilizing residential responsive loads to balance wind fluctuation and to provide operating reserve. This study assesses the potential of suitable loads of household appliances including refrigerators, freezers, and water heaters to provide instantaneous reserve and mitigate the demand-generation imbalance resulting from wind variability. 


\section{CHAPTER 3 LITERATURE REVIEW OF WIND INTEGRATION STUDIES}

\subsection{Introduction}

One of the fastest developing renewable energy resources in most power systems around the world, including New Zealand, is wind power. Due to the variable and to the uncertain nature of wind, the impact of wind power generation on electric systems is an area of interest in the electric utility industry. Issues associated with the integration of wind power into power system have been characterized as either engineering issues, operational issues or planning issues [43]. Engineering issues include harmonics, reactive power supply and voltage regulation, frequency control, fault level, island operation. Operational issues include the effect of variable renewable energy on (conventional) networks, operating reserve requirements, unit commitment and economic dispatch. Planning issues concern the appropriate modelling and evaluation of intermittent wind resources compared to conventional resources. The first section of this chapter reviews the state of the art wind power integration studies and the impact of wind integration on power system operations in the future. There will be a special reference to the additional operating reserves needed to balance the fluctuation of wind to maintain system reliability and flexibility. The second section reports on studies about utilising demand response as a resource to facilitate wind integration by mitigating the variability of wind, and thus enhance power system reliability.

\subsection{Wind integration studies review}

Wind generation may require system operators to carry additional operating reserves. This section reviews published studies about European and US power systems and wind power integration. In Europe, according to its function, operating reserve is divided into primary control reserve, secondary control reserve, and tertiary control reserve [44]. Primary control reserve is activated within seconds, while secondary control reserve is activated within minutes. Tertiary control reserve implies changes in generation or load on a contractual, market or regulatory basis, activated for a period of time, e.g. 15 minutes. The first study to be reviewed about wind integration focuses on the Nordic countries. Estimate for the operating reserve requirement due to wind power in the Nordic countries is reported in [45]. The reserve requirement for the system, due to wind power, was determined by combining the wind power variation with varying electricity consumption. The increase in reserve 
requirement is mostly seen on the 15 minutes to 1 hour time scale. The operating reserves in the Nordic countries should be increased by an amount corresponding to about $2 \%$ of wind power capacity when wind power produces $10 \%$ of yearly gross demand and $4 \%$ when wind power produces $20 \%$ of yearly gross demand. Simulations of increasing wind power in the Nordic electricity system show that wind power would mainly replace coal fired production and increase transmission between the areas within the Nordic countries and from Nordic countries to Central Europe. In the Nordic countries, the analyses of three years of hourly wind generation data together with the earlier studies show that the capacity credit of wind power is close to the average power produced. Wind power can contribute to power system adequacy

In Ireland, the All Island Grid Study was published in 2008 and examined the Irish system's ability to integrate various penetrations of wind generation [46]. Ireland is an island system with one 400-MW interconnector in operation and a 500-MW interconnector under construction. Six plant portfolios were examined to meet the load forecasted for 2020 . Portfolio 1 contains $2 \mathrm{GW}$ of wind; portfolios 2, 3 and 4 contain $4 \mathrm{GW}$ of wind; portfolio 5 contained $6 \mathrm{GW}$; and portfolio 6 contained $8 \mathrm{GW}$ of wind generation. The study incorporated a refined implementation for spinning and replacement reserves. The definition of a unit capable of meeting the replacement reserve standard was an off-line unit with a start-up time of less than 60 minutes and online units whose capacity was not allocated to the spinning reserve requirement. The requirements for spinning and replacement reserve were based on a mixture of existing and proven requirements and newer techniques for the provision of reserve for wind generators. Spinning reserve demand is calculated as being the size of the largest online unit plus an additional demand for wind generation. Reserve is allocated in such a way as to keep the average risk of having a load shedding incident in each hour the same for all hours of a year and includes the effect of generator outages and load and wind forecast errors. System modelling for the year 2020 assumed that $100 \mathrm{MW}$ of spinning reserve can be obtained through interconnection. Another $50 \mathrm{MW}$ of reserve is assumed to be provided from interruptible contract loads. Of the remainder, a constraint of a maximum of $50 \%$ of reserve demand can be provided by pumped storage. Instantaneous reserve is required more frequently as the amount of wind increases in the portfolio, significantly so in portfolio 6 . The variable generation requires extra instantaneous reserve as well as the loss of the largest conventional unit.

In Germany, the most prominent integration study is the DENA study [47] which looked into a scenario whereby there would be $15 \%$ wind energy penetration expected by 2015 (34 
GW). The forecast errors for wind energy give rise to an additional requirement for regulating and reserve power capacity to guarantee the balance between infeeds and loads at all times. In the calculation of the reserve requirements, the probability distribution of the forecast errors of the wind power infeeds as well as those of the forecast errors of the load demand were considered. Despite an assumed improvement in the predictability for wind energy, the required regulating and reserve power capacity increases disproportionately as the installed wind capacity increases. The wind-related regulating reserve and power capacity requirement depends on the level of the predicted wind infeed, The regulating and reserve power capacity required for the following day can be determined in dependency on the forecasted wind infeed level. This provides an average day ahead regulating and reserve power capacity. For 2015, additional maximum 7,064 MW of positive regulating and reserve power capacity is needed, of which on average 3,227 MW has to be contracted day ahead. In 2003, the corresponding values were 2,077 MW maximum and 1,178 MW on average. Additional maximum 5,480 MW of negative regulating and reserve power capacity is needed.

The author of [48] describes Manitoba hydro's plans to incorporate wind power over the next 20 years and the associated wind integration costs. Additional reserves are required because of wind volatility and wind generation forecast error. Reductions in wind generation are of the most concern because other generation must be increased to counter balance the shortfall in wind generation. The wind integration impacts and related costs were studied over low, medium, and high water supply conditions. Manitoba hydro is in a unique position that it can with its hydro system enhance the value of intermittent wind power by shaping and firming it into a firm product. Wind power impact with a penetration level of $23 \%$ of installed capacity or $15 \%$ or yearly production was calculated to be up to 3.44 MW on frequency-controlled reserves covering $99 \%$ of variations and up to $226 \mathrm{MW}$ on fast and slow reserves. This reflects that the longer the time horizon is the larger the increase in reserve requirements will be.

Impact of wind generation on the operation and development of the UK electricity systems has been studied by [49]. In order to deal with unpredicted variations in demand and generation, the system operator requires appropriate automatic response, to neutralise rapid variations from a few seconds to a few minutes, and reserves to deal with slow variations over time horizons from several minutes to several hours. On average, the UK system operator commits about 600MW of dynamic frequency control, while about $2400 \mathrm{MW}$ of various types of reserve is required to manage the uncertainty over time horizons of the 
order of 3 to 4 hours. These values could be significantly changed in the future with increase in wind penetration levels considering that wind generation is both variable and unpredictable. The reserve requirements are driven by the assumption that time horizons larger than 4 hours will be managed by starting up additional units, which should be within the dynamic capabilities of gas fired technologies. The increase in demand for continuous frequency regulation was found to be relatively small for modest increases in wind power connected. However, at high wind penetrations the reserve levels equivalent to $25 \%$ of wind installed capacity will cover even the extreme variations in wind output.

In the United States., the first two major wind power integration studies were performed in the states of New York [50] and Minnesota [51]. In New York, the study evaluated 3,300 MW of wind power on the 33,000 MW peak load NYISO system. The study concluded that an additional $36 \mathrm{MW}$ of regulating reserve was required on top of the current $175-250$ MW procured today. This is a result of analysing the standard deviation of 6-second changes in load net of wind compared with that of load alone. The standard deviation with wind increased from $71 \mathrm{MW}$ to $83 \mathrm{MW}$, presenting a $12 \mathrm{MW}$ increase. The total standard deviation is multiplied by three to ensure that the total regulation requirement is sufficient to cover $99.7 \%$ of all instances, thus giving the $36 \mathrm{MW}$ increase. In Minnesota [51]., the study evaluated $15 \%, 20 \%$, and $25 \%$ wind power as a percentage of total annual demand (3441 MW, $4582 \mathrm{MW}$, and $5688 \mathrm{MW}$ of wind on a system with a peak demand of roughly 20,000 MW). High penetration of wind in the system will require frequent switching of generators, allocation of more ramping capability to account for wind variability, and more regulation capacity. All of these services are associated with additional costs.

In the literature, many studies assess the impacts of wind in terms of the increased cost of managing the system with significant wind generation. The authors of [52] reported and commented on studies conducted by utilities in the U.S. They states that the main concern of these studies is the impacts of wind on power system operation and the associated integration cost. The main approach of these researches is by starting with the physical behaviour of the system without wind, and then discussing how that physical behaviour is affected by wind power. In these studies, the impacts of wind on conventional generation are usually analysed over three key time frames that correspond to system operation. The first is the regulation time frame from seconds to minutes. The second is the load following time frame from 10 minutes to few hours, which is mostly relevant to ramping capability of power system. The third is the scheduling of unit commitment time frame which can range from several hours to a few days. This period is for planning the required quantity of 
generation and load following capability. Wind integration studies are performed on these time frames with wind capacity penetration of 3\%-20\%. At these wind penetration levels, the impact on regulation and load following appear to be modest in no more than $0.2 \$ / \mathrm{MWh}$, and the unit commitment time scale appears to be more prominent which may cost up to $6.57 \$ / \mathrm{MWh}$. In the California ISO 2007 wind integration report [53], the California ISO estimates that the target of California to reach a renewable integration level of $20 \%$ can increase load following capacity requirements up to $3470 \mathrm{MW}$, and rampingup and ramping-down requirements by up to $40 \mathrm{MW} / \mathrm{min}$ for up to $20 \mathrm{~min}$, compared to their current levels.

The Eastern Wind Integration and Transmission Study (EWITS) evaluated the operational impacts of various wind penetrations, locations, and transmission build-out options for most of the U.S. Eastern Interconnection [54]. The study included three scenarios of $20 \%$ wind energy with each representing different primary locations of the wind, and one $30 \%$ wind energy scenario. High penetrations of wind generation ranging from $20 \%$ to $30 \%$ of the electrical energy requirements of the Eastern Interconnection are technically feasible with significant expansion of the transmission infrastructure. New transmission will be required for all the future wind scenarios in the Eastern Interconnection. Without transmission enhancements, substantial curtailment of wind generation would be required for all the $20 \%$ scenarios. Transmission helps reduce the impacts of the variability of the wind, which reduces wind integration costs, increases reliability of the electrical grid, and helps make more efficient use of the available generation resources.

\subsubsection{Conclusions of Wind Integration Studies}

\section{Although different wind integration studies categorise the impacts of wind from different aspects, there is considerable consistency between their results and insights. These wind impacts can be classified according to the time scales in which they are involved as summarised in}

Table 3-1 
Table 3-1: Summary of wind integration studies

\begin{tabular}{|c|c|c|c|}
\hline Time scale & Domain & Elements affected & $\begin{array}{l}\text { Requirement } \\
\text { to mitigate impacts }\end{array}$ \\
\hline $\begin{array}{l}\text { Milliseconds } \\
\text { to seconds }\end{array}$ & $\begin{array}{l}\text { Wind plant } \\
\text { interconnection }\end{array}$ & Dynamic stability & $\begin{array}{l}\text { Better design of wind } \\
\text { plant }\end{array}$ \\
\hline $\begin{array}{l}\text { Seconds to } \\
\text { minutes }\end{array}$ & Regulation & Primary regulation & $\begin{array}{l}\text { Improve Participation of } \\
\text { wind farms }\end{array}$ \\
\hline $\begin{array}{l}\text { Minutes to } \\
\text { hours }\end{array}$ & Load following & Ramping rate & $\begin{array}{l}\text { Increase ramping } \\
\text { capability }\end{array}$ \\
\hline Hours to days & $\begin{array}{l}\text { Generation } \\
\text { scheduling; } \\
\text { Day-ahead } \\
\text { market }\end{array}$ & $\begin{array}{l}\text { Generation pattern of } \\
\text { conventional generation; } \\
\text { Transmission and } \\
\text { distribution efficiency; } \\
\text { Wind utilisation }\end{array}$ & $\begin{array}{l}\text { Increase spinning and } \\
\text { standing reserve; } \\
\text { Improve forecasting; } \\
\text { Efficient market design; } \\
\text { Possibility of } \\
\text { curtailing wind }\end{array}$ \\
\hline Years & $\begin{array}{l}\text { Expansion } \\
\text { planning }\end{array}$ & $\begin{array}{l}\text { Generation adequacy; } \\
\text { Flexibility adequacy; } \\
\text { Transmission adequacy }\end{array}$ & $\begin{array}{lr}\text { Optimise } & \text { generation } \\
\text { mix; } & \text { Increase } \\
\text { transmission investment }\end{array}$ \\
\hline
\end{tabular}

In conclusion, large volumes of wind generation bring extra generation, uncertainty and variability to the original power system. The increase in reserve requirement is mostly estimated by statistical methods combining the variability or forecast errors of wind power to that of load and investigating the increase in the largest variations seen by the system. In order to handle these changes and accommodate wind generation effectively, sufficient reserve and ramping capability are required. As mentioned in Chapter 1, operating reserve to maintain power system flexibility can be provided from various resources: flexible 
generation, demand side management, storage, and interconnections. An important issue is that increase in reserve requirements does not necessarily mean need of new investments.

\subsection{Demand response studies}

By increasing the penetration of renewables in power systems, demand side participation become more important. In order to meet these demand peaks, utilities usually resort to increasing generation capacity and distribution assets by building new power plants, and installing larger transformers, transmission lines, and distribution cables. Such changes require expensive investments, and the operational costs of peaking power plants are very expensive. Instead of trying to increase generation, transmission, and distribution capacity, demand response programs try to mitigate demand in various ways [15]. Demand response has been actively considered for power balancing. Participation of demand response can be achieved by active consumer participation in real-time to maintain balance between generation and demand with two-way communication [33]. It is well known that DR increases system reliability and flexibility to manage the variability and uncertainty of some renewable energy resources, decreases the cost of operation, and enhances system efficiency. Furthermore, the authors of [55] found out that more frequent and short switching on and off of suitable residential loads are more acceptable than infrequent and long curtailment. As stated previously, in electric systems reserve must be available at very short notice and availability must be given during a certain time span; therefore, an appropriate way for residential loads to fulfil these requirements is by employing direct load control.

The author in [56] analysed different household appliances and their potential to delay their load consumption. He concludes that $5 \%$ to $20 \%$ of these devices would use a delay option in the future. There is no standardized methodology to calculate demand response potentials. Many known publications focus on a certain amount of power that can be blocked for a given period of time. Values for demand response potentials in different studies are highly diverse due to their dependency upon the considered country, the time of day, the season, and the way that the influence on the load is implemented. The possible duration of the load modification is often stated as a measure for the available energy that can be shifted over time. The authors of [57] shows the benefits of applying time-of-use and real-time-pricing in a small domestic test system in Ireland, where wind generation is becoming more important. Ireland aims to source $40 \%$ of its electricity needs from renewable energies by $2025,86 \%$ of which will be supplied by wind power. Authors in 
[58] proposed a methodology for the generation of demand side offers in large customer facilities and a real application to a university customer in Spain. They found that demands can offer ancillary reserves without problems under normal as well as contingency situations. Authors in [59] analysed the process of getting reserve from demand in the New England market. They found out that demand is able to provide reserves within 30 minutes, some within 10 minutes. Thus, some demands overfulfill the requirements set for thermal generators. Other works confirm the ability of demands to react faster than many quick start units do. The work of [60] analyses the reactions of air conditioning in a hotel complex. Many of the analysed demands were capable of numerous shorts and as well to less frequent prolonged curtailments. The authors of [61] showed that using air-conditioning load control as rotating reserve, instead of peak management programs, can triple load reduction. We suggest that the full air-conditioning load can be completely interrupted during a major grid event. Although air conditioners are not available to supply reserve year round, their availability highly correlates with grid demands. This study shows a close correlation between errors in short term energy demand and the contingency reserve because when air conditioning loads increase, the need for available reserve increase and this illustrates the advantage in using air conditioners to supply contingency reserve. If the current demand forecast is in error and underestimates the current load, the grid operator must commission additional power plants to handle the load. By using air-conditioners instead of generation to provide reserve, generation can be saved for electricity supply rather than for providing ancillary services. Air-conditioners motor compressors can be interrupted for several minutes without affecting the services provided.

The potential of air conditioners is supported by [61] who showed that existing utility loadmanagement assets can provide spinning reserve to main power system reliability from air conditioners. In the first phase of this demonstration project, the research target marketed Using aggregated demand-side resources to provide spinning reserve as demonstrated in this project will give grid operators at the California Independent System Operator and Southern California Edison a powerful new tool to improve reliability, prevent rolling blackouts, and lower grid operating costs. Southern California Edison air-conditioning load-cycling program, called the Summer Discount Plan to customers on a single Southern California Edison distribution feeder and developed an external website with real-time telemetry for the aggregated loads on this feeder and conducted a large number of shortduration curtailments of participating customers' air-conditioning units to simulate 
provision of spinning reserve. In the second phase, they conducted load curtailments within four geographically distinct feeders to determine the transferability of target marketing approaches and better understand the performance of Southern California Edison load management dispatch system as well as variations in the air conditioners' use of Southern California Edison's participating customers; The major findings from the second phase of this demonstration are that demand response resources can provide full response significantly faster than required by power system reliability rules. Authors in [61] state that technically it may be more attractive for some loads to provide contingency reserve rather than peak reduction as this may be needed for various hours per day and various days in a row. In contrast, during a contingency, reserves may be needed only during a short time span until other reserves become operative. Authors in [62] analysed how direct load control can be used to give spinning reserve during a contingency. They performed a contingency analysis, selected the most severe cases, calculated with an economic model the amount of demand participation in direct load control and confirmed via simulation the economic and reliability benefits of demand giving reserve.

The author of [8] commented that an additional potential of reserve power could be made available from household customers, if a communication system is developed, which allows to control the domestic appliances. [20] reported that the control of fridges and freezers has a potential of maximum $3 \mathrm{GW}$ positive and negative balancing power. If washing machines tumble dryers and dishwashers are included, the potential would increase to $7 \mathrm{GW}$ during daytime. This however, would require a clear change in user behaviour. The study by [63] estimated the potential contribution of smart household electrical appliances to balancing European electricity grids. The study included the following appliances: air conditioners, circulation pumps for heating, dishwashers, thermal accumulators, freezers, refrigerators, ovens, stoves, dryers, electric water heaters and washing machines. First, the study compiled information on the hourly use profile and operating procedures of these devices through Europe, using studies and available data. According to the average daily profile, electricity demand at minimum load is, at most, between 200 and $850 \mathrm{~W}$. Afterward, the equipment was sorted by two management approaches: change in start-up time (smart timing of appliance cycles) and temporary interruption (interruptions of appliance cycles). In the first case, the user sets both the startup time and the latest time at which the operation must be finished. Washer and dryer use can be postponed by 3 to 6 hours, dishwashers from 3 to 8 hours, and refrigerators/freezers from 15 to 30 minutes and other appliances from 15 minutes to one hour. 
In the second case, for some electrical appliances, the cycle can be temporarily interrupted for a certain length of time and under certain conditions. However, this is not suitable for all appliances. Washing machines could be interrupted for 15 minutes, dryers for 30 minutes, dishwashers for 15 minutes, refrigerator / freezer for 15 minutes and other appliances for 5 minutes. Every appliance was qualitatively evaluated with four criteria: appliance power, availability, flexibility of load to be shifted and customer acceptance. These results were applied according to a grouping of five European regions, consisting of countries exchanging electricity generation and balancing service between them. A flexible capacity was estimated between $100 \mathrm{~kW}$ and $150 \mathrm{~kW}$ for 1000 residential customers (100 $\mathrm{W}$ to $150 \mathrm{~W}$ per customer).

Using these appliances could reduce fossil fuel demand for European grids by $4.5 \%$, Customers accept the idea of delaying use of dishwashers for long periods. However, these appliances are not widely available; Cold-generating appliances, such as refrigerators and freezers, can be fully automated. Washing machines and dryers are interesting options, but require more user interaction. Utilising this potential will contribute to reduce the balancing potential of wind power.

The study by [64] is part of the Project Power Shift Atlantic project. Researchers at University of New Brunswick developed a platform for aggregation and management of electric water heaters in order to supply ancillary services. Because of their thermal storage capacity, water heaters have the capacity for up-regulation or down-regulation when integrated with a virtual power plant. The aggregated water heater loads are distributed to supply ancillary services or reduce peak load with no effect on the customer consumption profile. The thermal status of every water heater is estimated using available data from smart electricity metres and other sensors. A smart meter measures the power demand of a residence; the smart grid communications infrastructures sends the information to the model unit, which extracts the power consumption of each water heater, its water usage and internal temperature, based on thermal models of each heater. The load forecast unit estimates future consumption for every water heater, using the water usage profile model and applying the thermal model on power measurement during the forecast window. A multi-agent control system adds the consumed power of several water heaters to calculate demand forecast available capacity for ancillary services.

The authors of estimated the potential of using water heaters to supply regulation service to power grids. In this study, the authors characterized the thermal behaviour of a typical 
water heater, the water usage profile and monitoring of a typical control population. With this model, they developed a direct control for the bottom element of the heater. According to the developed algorithm, each water heater receives a set point every minute. The conclusion of their study is that, according to the proposed approach, approximately 33,000 water heaters are needed to provide a 2-MW regulation service 24 hours a day. However, if water heaters only provide regulation from 6:00 to 24:00, approximately 20,000 will be needed.

An analysis by the authors of [65] shows the environmental and economic value of using water heaters to balance renewable energy. The authors used wind generation and market data to analyse balancing needs and determine the potential for load usage. They compared the consumption curves for interactive water heaters with market price data. In this study, a 400 litre water heater represents the equivalent of a $26 \mathrm{kWh}$ battery. The analysis concludes that it is possible to reduce the operating cost of a water heater by $50 \%$ using electricity only off-peak and only when there is wind production. According to this hypothesis, $25 \%$ of the energy consumed for heating water would be simultaneous with wind generation could come exclusively from wind generation.

The authot of [20] reported that a detailed investigation of demand response potentials in Germany is given, stating a year-round flexible load potential of about $3 \mathrm{GW}$ in the industry, $3 \mathrm{GW}$ in the commercial sector, and $4 \mathrm{GW}$ in the residential sector, which sums up to about $13 \%$ of the yearly maximum load. Additionally, seasonal potentials of $5 \mathrm{GW}$ of air conditioning load and up to $18 \mathrm{GW}$ of shiftable electric heating load are mentioned. The authors of [66] have evaluated that the demand response potential in Germany could be more than $30 \mathrm{GW}$, although a major portion totalling $20 \mathrm{GW}$ would not be available outside the heating season. Demand response would enable the system to cost-effectively balance $48 \mathrm{GW}$ of wind power in the system. [67] has analysed possibilities for demand side management in the household sector. His analysis concentrates on ventilation systems, refrigeration and water heating. He concludes that storing heat in different applications offers a large potential for integrating variable renewables. However, the results lack an economic component.

[68] have analysed how domestic hot water heating cylinders could offer demand response for price changes anticipated in the electricity market. This was inspected in relation to the anticipated significant wind power penetration in Ireland. The authors of [69] presented a case using the IEEE standard 30-bus test system. Two wind farms are connected to the system and the effects of multi-tariff rates and demand response are investigated. Demand 
response is assumed to respond to variations in wind power output, and it appears to offer significant savings in the system operation to increase the value of wind power. The author of [70] demonstrated the effects of the response by millions of household refrigerators and freezers to frequency signals. He found out that these residential loads are able to keep the system frequency more stable than a conventional spinning reserve. The effect is especially pronounced with higher shares of wind generation. The author of [71] shows that a population of thermostatically controlled loads can be managed to serve as virtual storage to follow generation variability in renewable electricity generators or variation in demand from other loads. His study focused on how small thermostat set point manipulations can turn on and off only the thermostatically controlled loads nearing the upper or lower limits of temperature set points. The 1-minute actual wind power data was collected by the National Renewable Energy Laboratory. It was found out that regulation service can be provided to offset supply or demand changes without compromising the comfort level of end users. In the simulation, controlling 60,000 air conditioners supplied the energy and power equivalent to $0.5 \mathrm{kWh}$. In the case study, approximately each $\mathrm{MW}$ of wind power required a 3.4 MW to balance in order to reduce error between the forecast and actual demand to its minimum. During the simulations, the maximum deviation of the temperature set point never exceeded $0.1 \mathrm{C}^{\circ}$, suggesting that this type of management would not compromise customer comfort. Changes can be small and still yield large aggregate changes in short-term demand. The method is tested to smooth short timescale fluctuations of a single wind farm. Similarly, the current study focus on investigating the potential of utilising refrigerators, freezers and water heater to contribute towards additional instantaneous reserve resulting from higher penetration of wind in the New Zealand Power system. It will also demonstrate the potential of these loads to offset and balance the fluctuations in wind power.

The authors of [72] have demonstrated and applied an advanced and theoretically stable stochastic control algorithm in order to simulate and assess the dynamic behaviour of domestic appliances contributing to primary frequency regulation using controllable domestic refrigerators. Simulations have been performed for a wide range of representative system conditions, resulting in a calculated value for the response contribution of a single appliance. The contribution of responsive demand to supporting frequency regulation has been used as input in a large-scale scheduling model, which, in addition to energy scheduling, incorporates frequency response requirements, while considering response contributions from conventional generators, wind generators and demand response. The 
results indicate that dynamic demand has the potential to generate considerable operating cost savings and carbon emission reductions in future systems.

\subsection{Summary}

The electricity markets are making a number of adjustments in order to integrate renewable energies. Indeed, variable production creates certain integration problems, which require increased levels of operating reserves. Furthermore, it is critical that these reserves have dynamic characteristics, which can support and encounter generation variability. While large power networks have countered capacity problems with increased production, demand response can be utilised to contribute to grid security and reliability. In this study, the main drivers for assessing the responsiveness of demand response are the need to compensate for the additional instantaneous reserve brought about by wind intermittency, and this provide an initial analysis of the flexibility potential available on the residential responsive loads. 


\section{CHAPTER 4 INTEGRATING RESIDENTIAL DEMAND RESPONSE WITH WIND POWER}

\subsection{Introduction}

The purpose of this study is to assess the current level of residential demand responsiveness among household appliances and their potential to contribute towards additional instantaneous reserve to balance the fluctuation of wind when higher rates of wind power are integrated in the NZ power system. This study first modelled the load profiles of refrigerators, freezers, and water heaters and statistically assessed the potential of controlling these residential loads using direct load control strategies to contribute towards the additional instantaneous reserve in the years 2014, 2020 and 2030. This was followed by conducting a scenario-based simulation study to showcase how the selected responsive loads in Wellington Region can contribute to balance the fluctuation of wind power generated by The West Wind wind farm during selected days in the years 2013-2014.

\subsection{Methodology of Modelling Residential Load}

As mentioned above, the purpose of this study is to assess the current level of demand responsiveness among domestic loads. Household appliances such as refrigerators, freezers, and water heaters generally can store energy due to their thermal mass. Thus, the service provided to the customer will not be affected when these loads are controlled by modifying their temperature set point by turning them on or off in advance or interrupting them for a short time. In order to assess the potential of controlling the loads of these household appliances, detailed consumption details of end users are required. There is no available data about load profiles of individual household appliances in New Zealand but rather the data consists of aggregated consumption. The first step was to develop load profiles for these household appliances which when combined represent approximately $50 \%$ of the total residential load in New Zealand as shown in

Figure 4-1. 


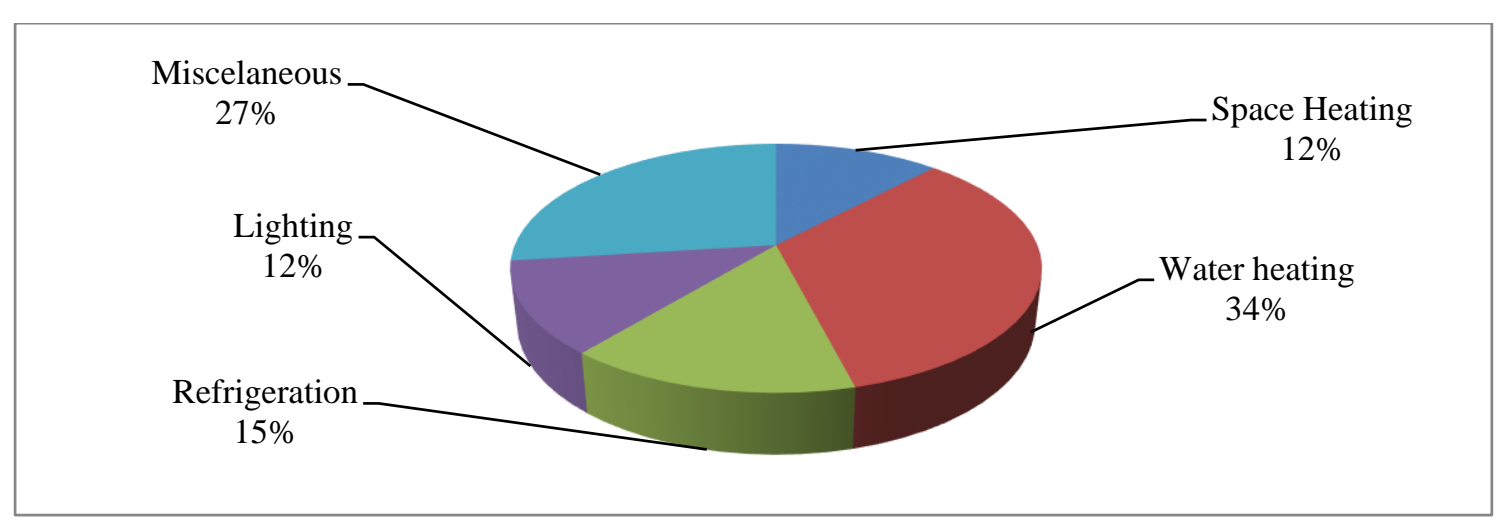

Figure 4-1: Residential electricity consumption

[73], [74], [75], [76], and [77] were the main data sources which have been used to build up the load curves for these appliances.

The equations used to generate the load profiles of these appliances were adopted from [73]. The theoretical background of the analysis in this chapter mainly focuses on three variables: the load curve per appliance and operation $(\mathrm{P})$ describing the typical power taken by an average appliance of this type per day or per operation, the probability of operation $(\alpha)$ and the number of the appliances of each type $(\beta)$ in Wellington Region. It considers the specific penetration rates $\beta \mathrm{k}$ of each appliance type in Wellington region, thus leading to the typical load curve for one average household $\boldsymbol{P}_{\boldsymbol{k}}(\boldsymbol{t})$. Altogether they define the average power demand for those appliances considered in this analysis, called the load curve $\mathrm{P}(\mathrm{t})$.

The first step was to develop load profiles for the refrigerator, freezer, and water heater (type $\boldsymbol{i}$ ) assuming this appliance is started at any time $\boldsymbol{j}$ during the 24 hours of a day in 15 minutes $\left(j=24(\right.$ hours $) * \mathbf{4}\left(\frac{1}{4}\right.$ per hour $\left.)=96\right)$ intervals as represented in Equation 4-1 where

$$
P_{i}(t)=\sum_{j=1}^{96} \alpha_{i}(t) P_{i j}(t) \quad \text { Equation 4-1 }
$$

Next, the average household power demand per appliance over the time of the day $P k(t)$ is then calculated by summing up the average power demand curves during the day of refrigerators, freezers, and water heaters by their ownership rate in New Zealand [74], using Equation 4-2

$$
P_{k}(t)=\sum_{i=1}^{n} \beta_{i} k P_{i}(t) \quad \text { Equation 4-2 }
$$


Then, the aggregate load curves for refrigerators, freezers, and water heaters are built up using the following equation where $\mathrm{K}$ refers to the number of households in New Zealand [76].

$$
P(t)=k P_{k}(t) \quad \text { Equation 4-3 }
$$

Finally, the residential resource available for direct load control from refrigerators, freezers, and water heaters was estimated for each hour throughout the day considering an aggregate load reduction with a fifteen minute maximum interruption time for each appliance.

\subsection{Findings}

\subsubsection{Refrigerators}

Refrigeration accounts for approximately $15 \%$ of the residential load in New Zealand [78]. Refrigerators including fridge-freezers and freezers have been modelled. Due to high penetration which is estimated to be 1.8 per household ( 0.68 for freezers and 1.31 for refrigerators) [74], the aggregate potential for these appliances is substantial. A main feature which makes refrigerators a strong candidate for direct load control demand response programs is that they have a stable aggregate load profile throughout the day regardless of the small variations resulting from changes in the ambient temperature in summer and winter and the frequency of door openings which increases in the evening around dinner time. Due to the thermal storage of the chilled contents, short interruptions in the power supply of refrigerators should not affect the service provided. Authors of [79] commented that fridge-freezers which compose the base load in the domestic sector have the potential of becoming responsive since interruptions of up to nearly two hours may not jeopardize the service provided by fridge-freezers. Refrigerators cycle on and off, according to thermostat set points between maximum and minimum temperatures. Once the internal temperature reaches the maximum temperature set point, the compressor starts and the refrigerator starts to cool. Once the refrigerator's internal temperature reaches the minimum required temperature set point, the compressor stops and the cycle then repeats. As shown in Figure 4-2, refrigerators were modelled as duty cycle. Duty cycles refers to the time when the refrigerator uses energy with a constant power demand of $0 \mathrm{~W} / 140 \mathrm{~W}$ in an active time of 15 minutes [73], and a period of inactivity for 45 minutes. The compressors' start-up probabilities were assumed to be evenly distributed during the day, which results in a constant aggregate power demand from refrigerators. 


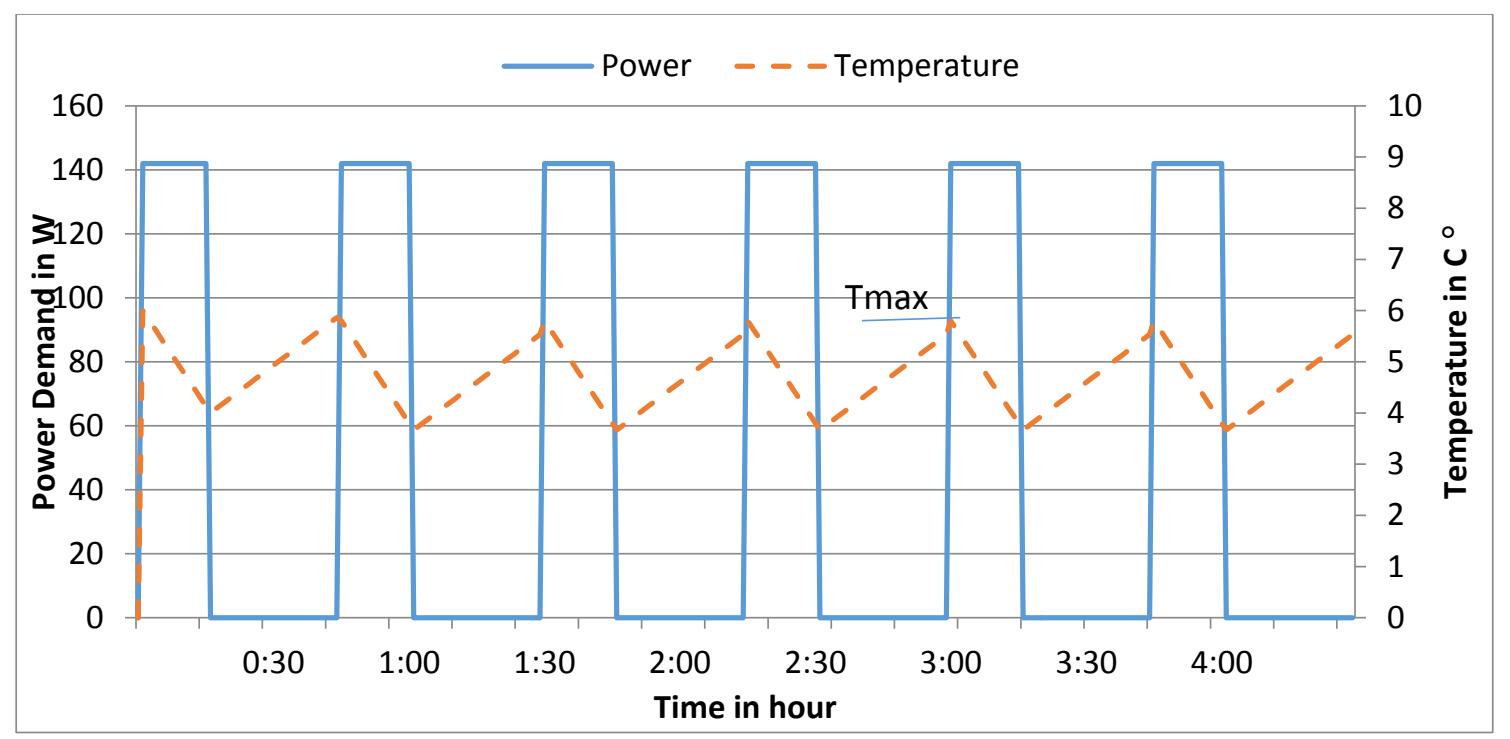

Figure 4-2: Duty cycle of refrigerators and freezers

Equation 4-1 above was used to calculate the average household power demand of refrigerators and freezers over the time of the day by summing up the average power demand curves during the day. The daily load curve of a refrigerator is between $40 \mathrm{~W}$ and $50 \mathrm{~W}$ and between $50 \mathrm{~W}$ and $60 \mathrm{~W}$ for the freezers as shown in Figure 4-3. These loads remain reasonably stable over the 24 hours of the day, peaking in the late evening through a combination of increasing ambient temperature and increased door openings.

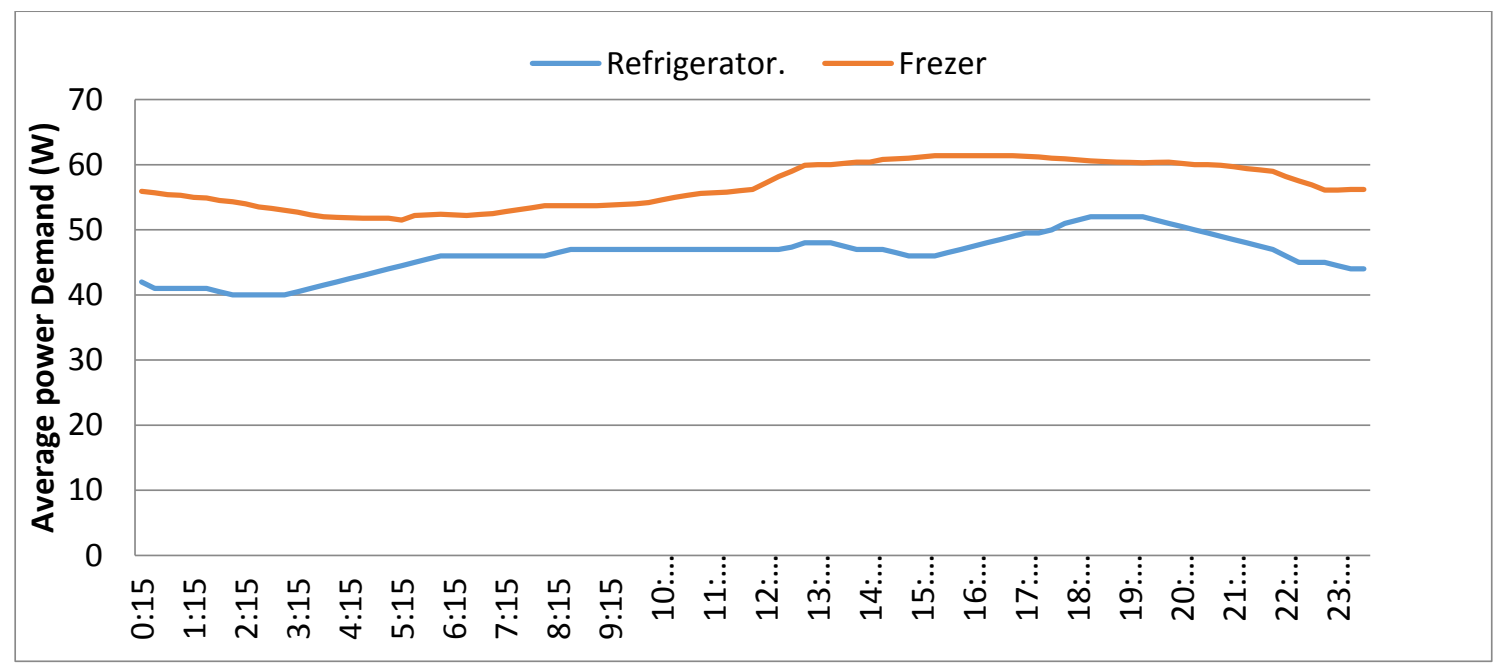

Figure 4-3: Daily LC for refrigerators \& freezers in an average household

The next step was to calculate the approximate total load for the refrigerators and freezers in the 1,700,000 New Zealand households [76] by using Equation 4-1 above. The saturation rate for refrigerators is 1.3 and 0.68 for freezers per household. This results in an estimated 2.2 million refrigerators and 1.1 million freezers in New Zealand. Their average total load will range from $160 \mathrm{MW}$ to $180 \mathrm{MW}$ as represented in Figure 4-4. 


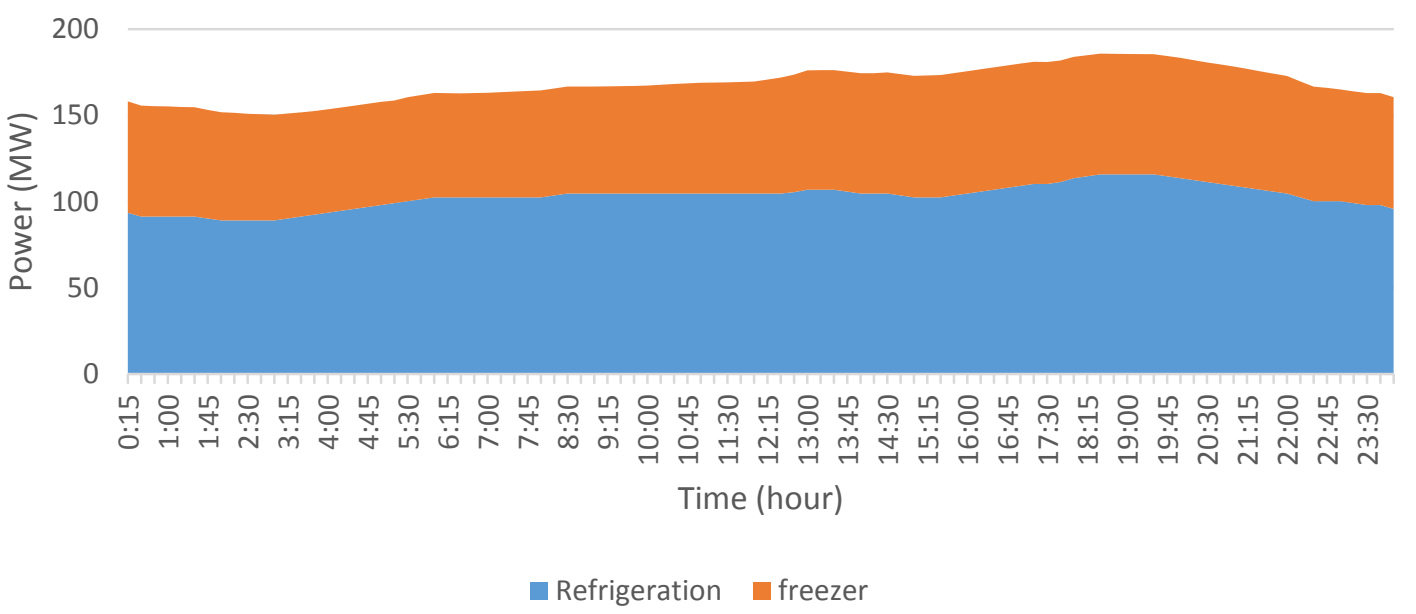

Figure 4-4: Total load of refrigerators and freezers in New Zealand

The possibility of delaying the compressor start-up or interrupting the compressor in every cycle makes them a very flexible demand response resource. The motor switches on when an upper thermostat set point is reached and remains on until the temperature reaches a lower set point. When a large number of devices are considered, the number of compressors running is almost constant. The scenario for control method for the refrigerator can be done through delaying the compressor in regular refrigerators or prolonging the cooling process in smart refrigerators as shown in Figure 4-5. Delaying or prolonging the cooling process for fifteen minutes, the temperature inside the container increases or decreases approximately $\pm 1.5^{\circ} \mathrm{C}[73]$.

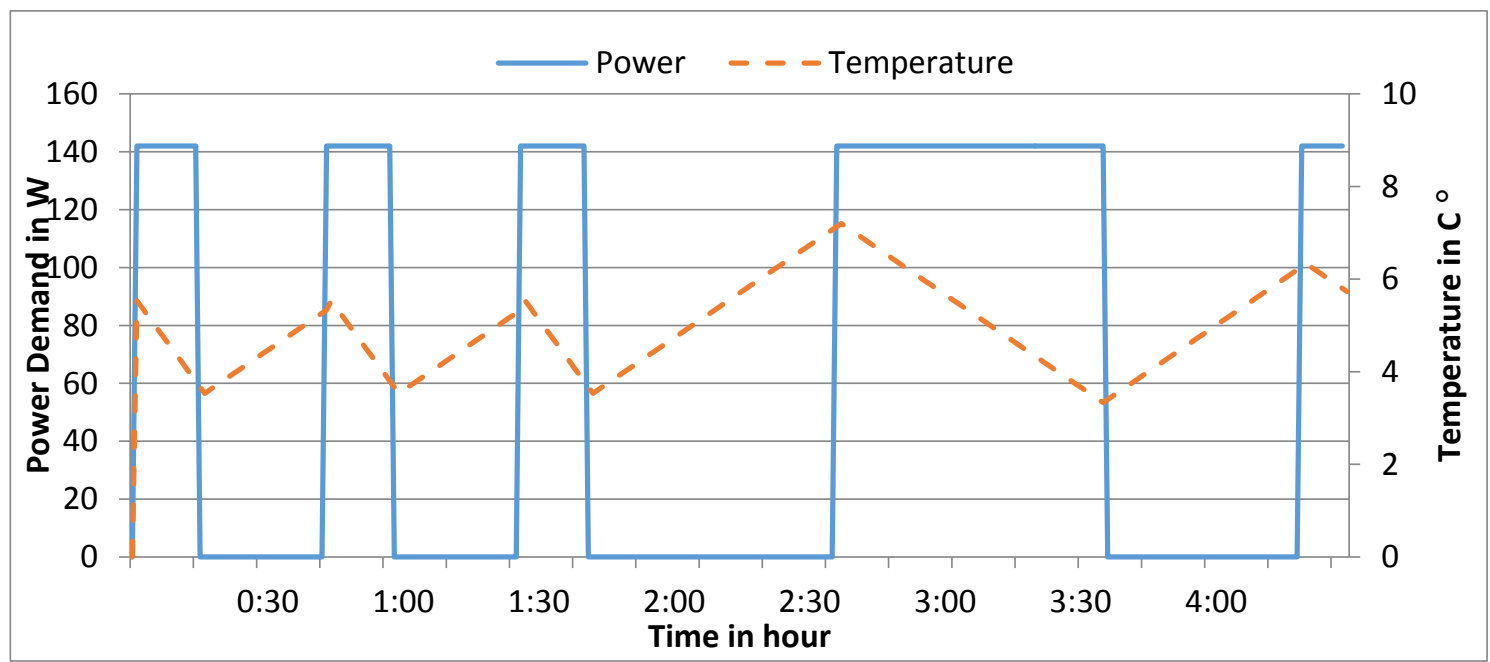

Figure 4-5: DLC of refrigerator through delayed start of compressor

When the temperature inside the disconnected refrigerator increases, it will reconnect gradually to keep the temperature within set limits. They will need energy to gradually restore their duty cycle length to the original pre-disturbance level, and they will recover 
the unserved energy later. This process of controlling a group of refrigerators and their recovery time is illustrated in Figure 4-6. First, a control signal can be sent by a third party to turn off a fraction of the refrigerators in the participating households. Then, these loads can be held off for " $m$ " time. After some time, they start to recover and operate again, and a control signal is sent to another group of refrigerators to be turned off for a certain amount of time in a way that does not affect the service. Each controlled group of refrigerators gets cycled through to extract prolonged capacity without negatively affecting individual customers.
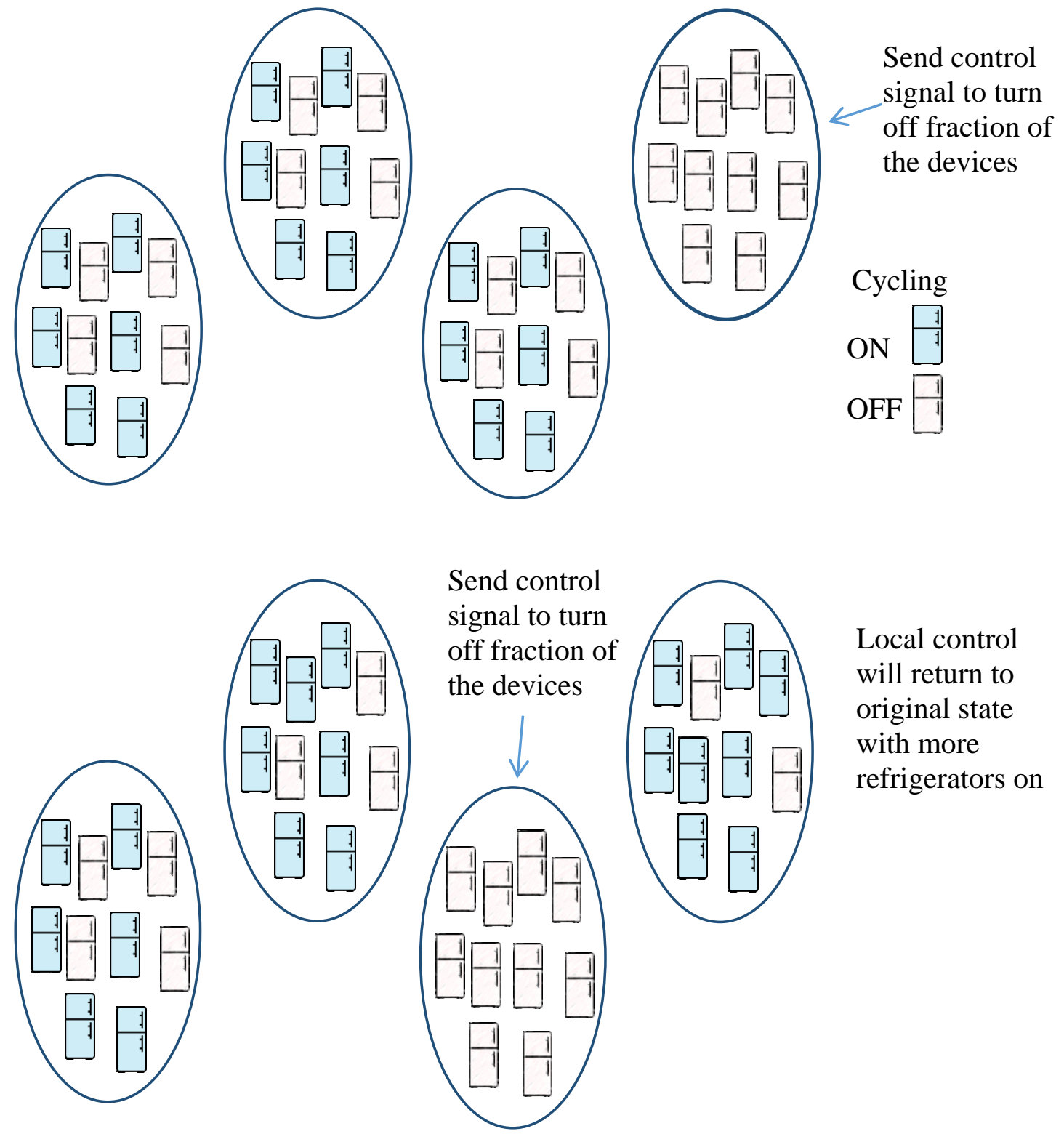

\section{Cycling \\ ON \\ $\mathrm{OFF}$}

Local control will return to original state with more refrigerators on

Figure 4-6: The process of load reduction and load recovery in refrigerators 
An assessment for the UK household refrigerators potential conducted by [70] shows a potential of $2000 \mathrm{MW}$ that could be saved by equipping the nation's household refrigerators with a "dynamic demand control"-technology that helps balancing out supply and demand on a short term basis. The timing of the activity of a number of fridges is altered without letting the fridge go outside the accepted temperature range. Time shifts from the order of seconds up to several minutes occur.

\subsubsection{Electrical water heaters}

Similar to refrigeration appliances, water heating is another substantial load in the residential sector. $88 \%$ of New Zealand homes use electricity as the primary fuel for water heating, and water heating accounts for approximately $34 \%$ of the residential load in New Zealand [78]. Electrical water heaters are usually controlled by a hysteretic thermostat which switches the heater ON and OFF depending on a measured temperature. Using Equation 4-2 listed in the methodology section above, the load curve for water heating is depicted in Figure 4-7 showing large peaks in both the early morning and early evening with low demand throughout the night. To illustrate, there is a usage peaking at around $7 \mathrm{am}$ before people heads to work, schools and universities and a smaller peak, at around 6-8 pm after finishing work.

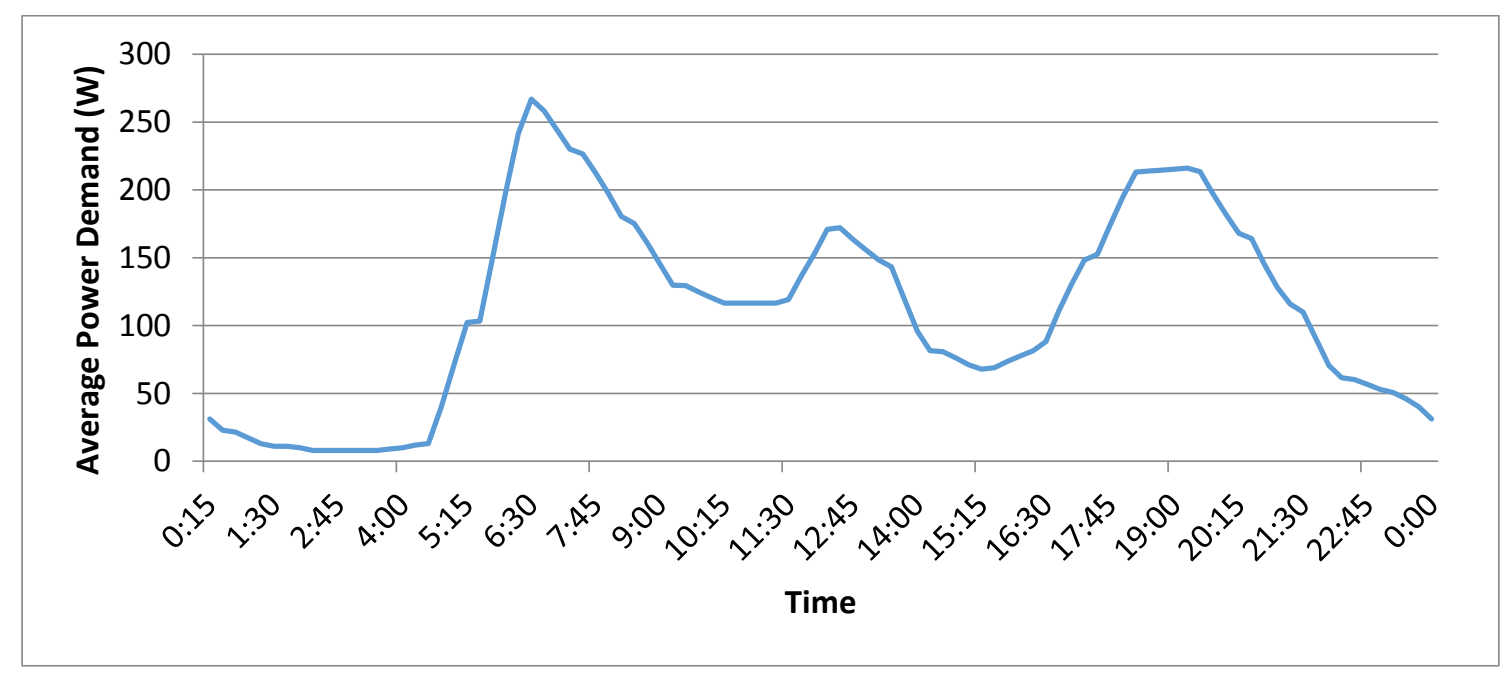

Figure 4-7: General pattern of a daily load curve of an electrical water heater

Next step was to calculate the approximate total load for the water heaters in the 1,700,000 New Zealand households [76] by using Equation 4-3 above. The saturation rate for electrical water heaters is .86 per household. This results in an estimated 1,360,000 in New Zealand. Their total load will range from 20MW to $340 \mathrm{MW}$ as represented in Figure 4-8. 


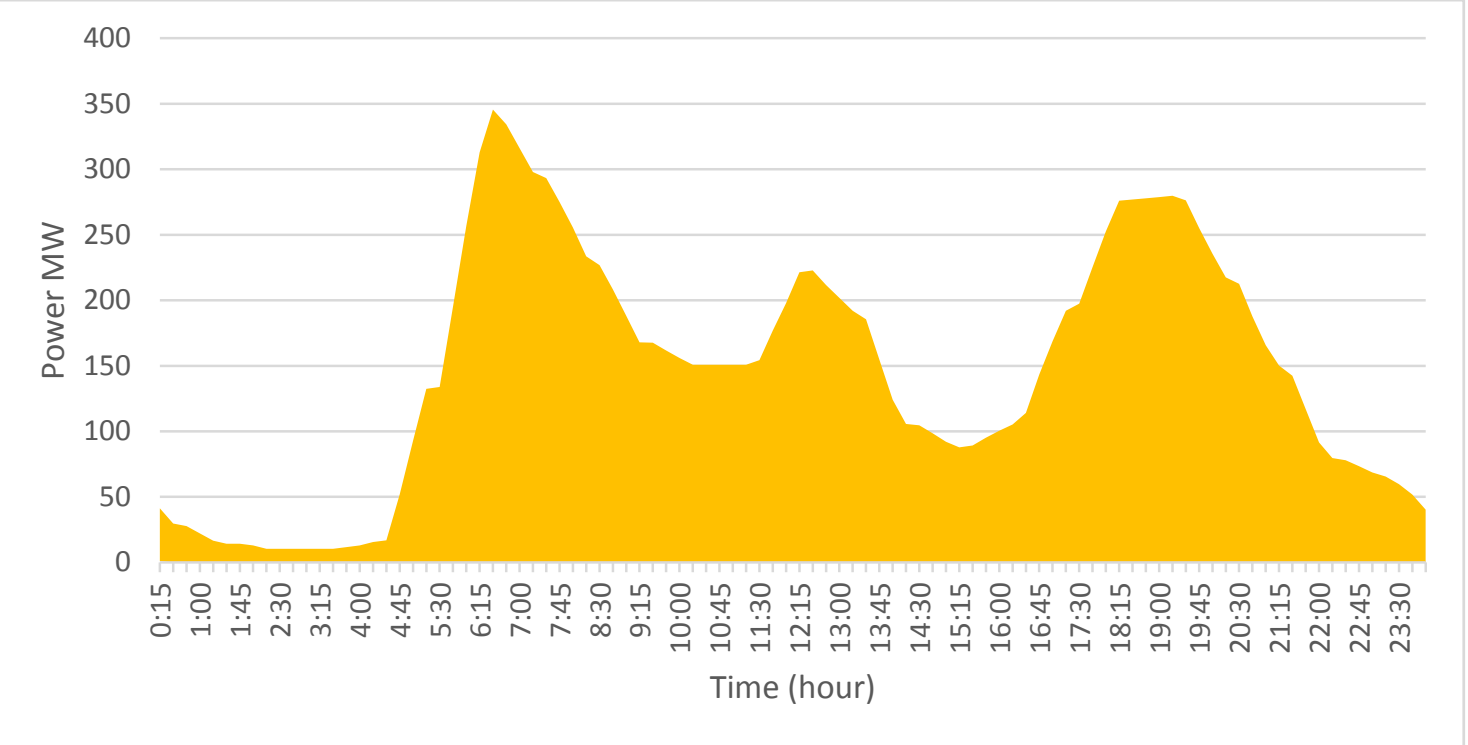

Figure 4-8: Total load of water heaters in New Zealand households

Electrical water heaters are suitable for short interruptions in their power supply with minimal impact on the customers' comfort level due to the thermal storage of the water and the storage tanks. For example, it is possible to delay the start of the heating phase or interrupting the heating phase for a certain time or reducing the power demand by choosing a lower desired water temperature. That can be achieved through sending a signal of shortage of power to the electric water heaters and thus trigger it to change its operation. Assuming a shift of 15 minutes, the operation probability will be changed. Reconnecting this group of water heaters to the system will cause a peak in demand during the payback stage similar to load recovery as shown in Figure 4-9.

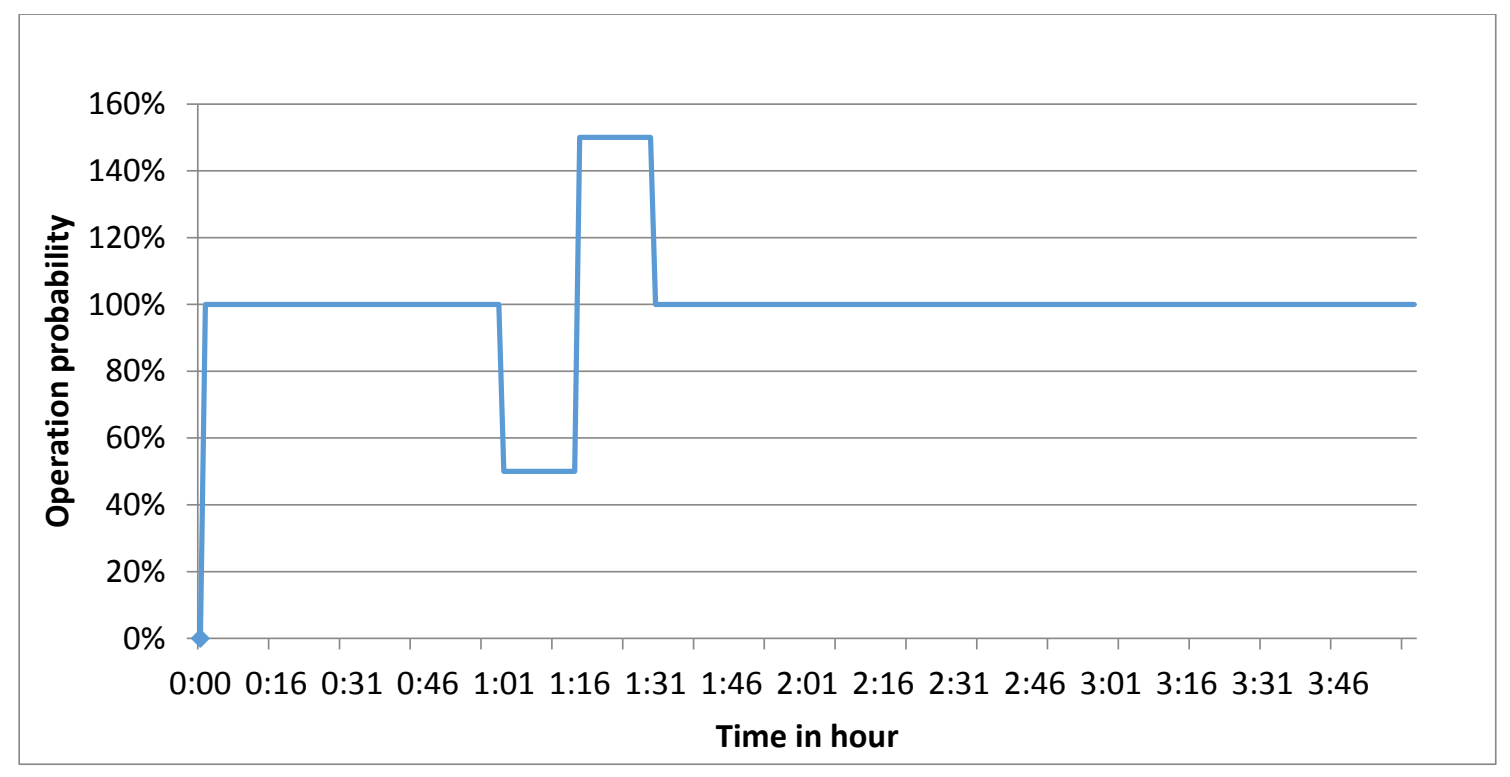

Figure 4-9: Example of a change in operation of controlled water heaters 
During load reduction, the demand of controlled water heaters is zero. For example, when $50 \%$ of the water heaters are turned off for 15 minutes, $50 \%$ of the restored demand is added to the uncontrolled demand for 15 minutes. Load reduction periods are followed by load recovery. The duration and the amount of the payback will depend on the type and duration of interrupted process and the type of storage. For example, let us assume we have 500 water heaters and that each water heater, when operating, has a load of $2 \mathrm{KW}$. Next, we assume a coincidence factor of 50 percent during the peak time, as only a half of the devices will use electricity simultaneously. This means that the load of 500 water heaters is $0.5 \mathrm{MW}(500 \times 50 \% \times 2 \mathrm{KW})$. If all 500 water heaters are switched off, the expected load reduction will only be $0.5 \mathrm{MW}$. If these are reconnected back to supply after half an hour, the load is likely to be $1 \mathrm{MW}(500 \mathrm{x} 2 \mathrm{KW})$. This is because the temperature in every water heater will be below the set levels and thermostat control is trying to reduce the temperature by having all water heaters use electricity. So, the total load of the group of controlled devices will increase during the load payback period. To counteract this load increase, some other appliances must be switched off.

\subsection{Discussion}

Individual household's power demand differs according to consumers' needs, behaviours, socio-economic background, family size, and age. Aggregation of the modelled loads of freezers, refrigerators, and water heaters has the potential to mitigate the irregularity in size and frequency of their power demand. The aggregated loads are represented in Figure 4-10.

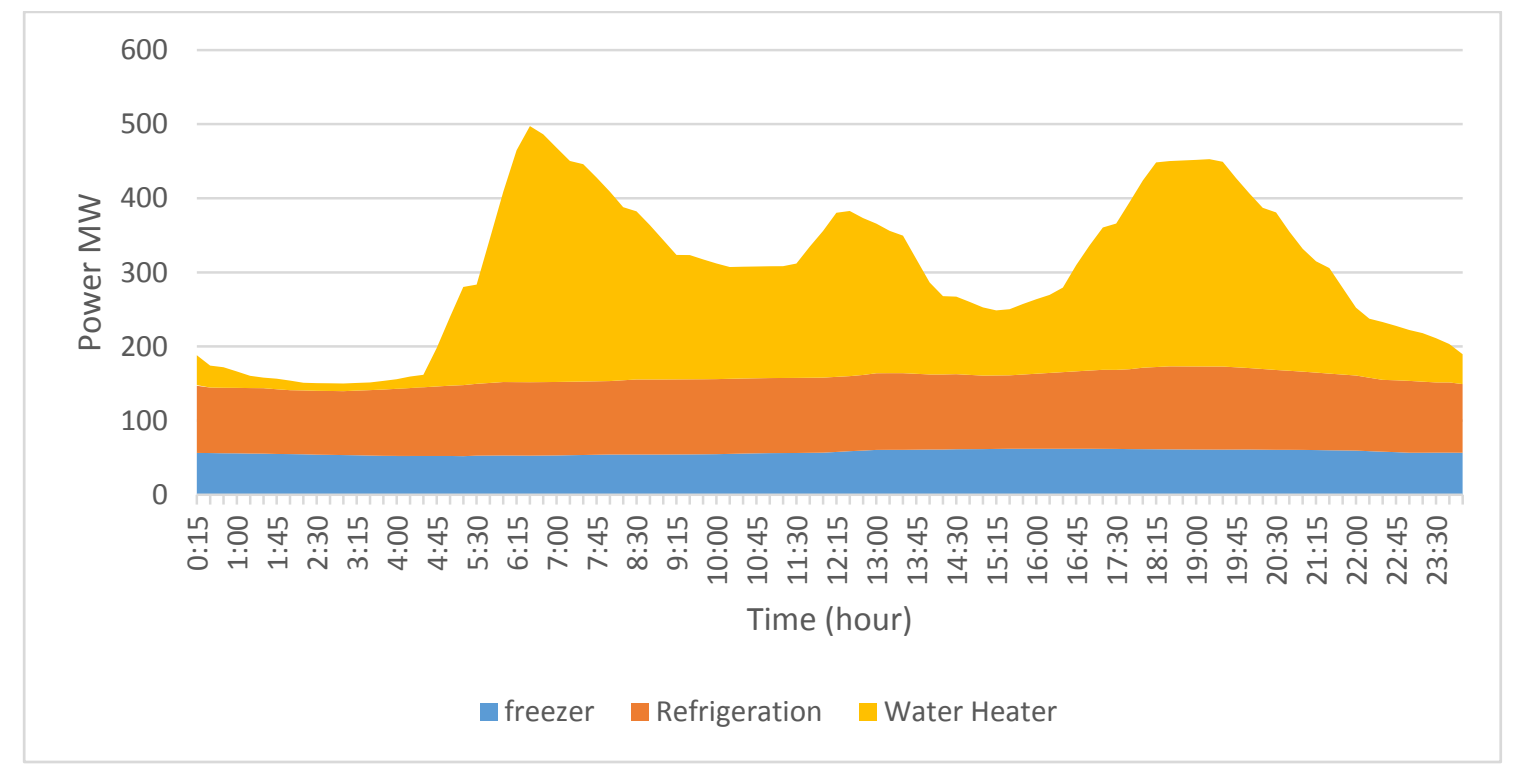

Figure 4-10: Daily LC of modelled residential loads in New Zealand -2014 
Direct load control is the most widely used demand response strategy in the residential sector in New Zealand. For decades, ripple control strategy has been used to control water heaters in New Zealand households for two hours, typically to achieve peak reductions in power demand. The purpose of this study is to illustrate and quantify available capacity of domestic responsive loads as a means to contribute towards instantaneous reserve provision resulting from higher wind power penetration. This study considers direct load control strategy of these domestic loads by interrupting their operation for fifteen minutes. Short interruptions of the appliances' duty cycles for fifteen minutes is more likely not to influence the service provided to the customers due to their thermal storage capability. A large resource is available throughout the day with a range of 152- $500 \mathrm{MW}$ available for interruption.

In [80], according to the survey up to $98 \%$ of the respondents would accept their refrigerators and freezers to be controlled but the key factor for their acceptance was the maintenance of control. In this study, assuming that $70 \%$ of the total households in New Zealand are willing to participate in a direct load control demand response program for the selected appliances, there will be an average of $300 \mathrm{MW}$ for interruption throughout the day which represents an average $3 \%$ of the power system demand in New Zealand. This is represented in Figure 4-11.

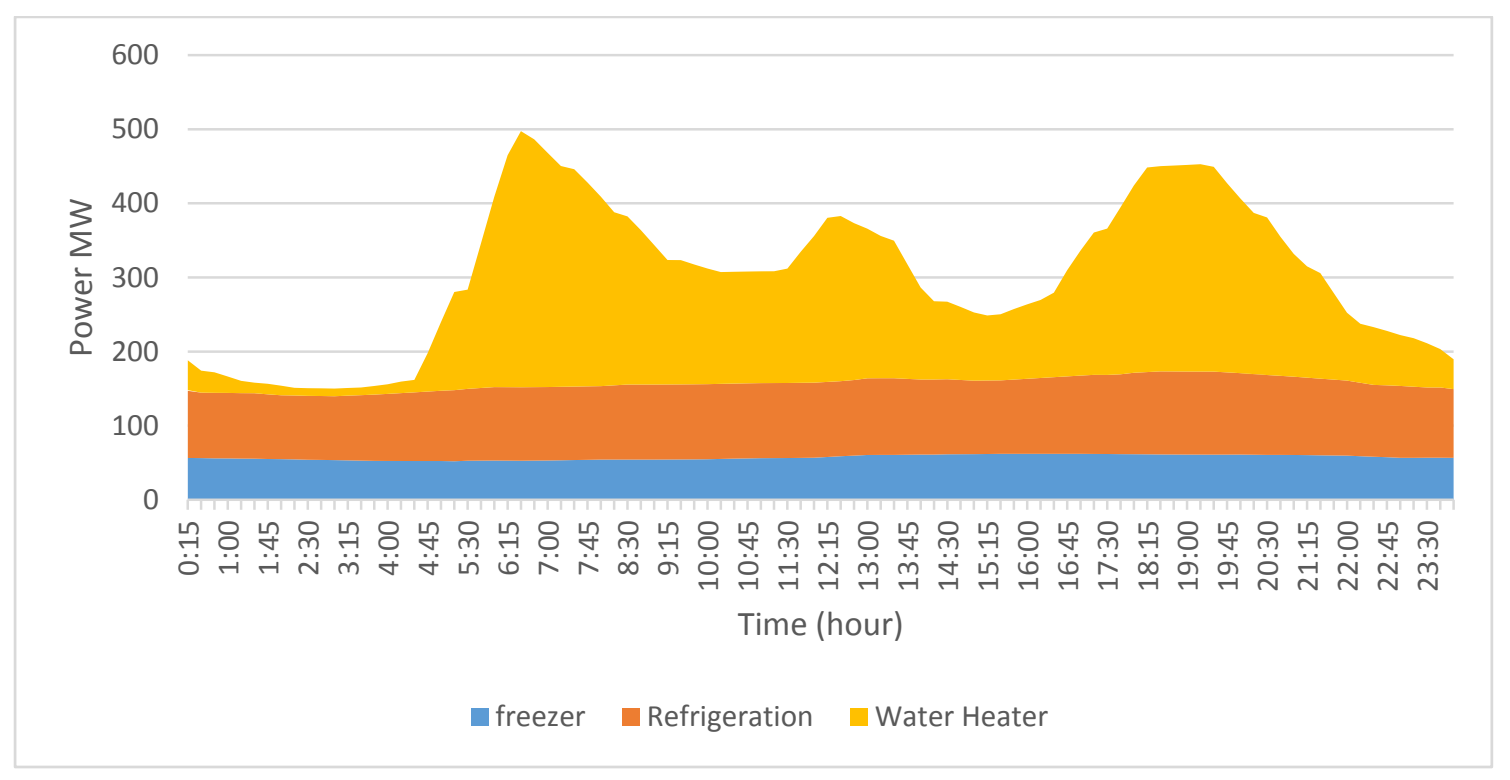

Figure 4-11: DLC of household appliances Potential in 2014

It can be thought of this resource as a power plant of $\sim 500 \mathrm{MW}$ during peak morning hours. The resource is largest in the morning due to the large potential delivered by water heaters. The results discussed are representative of a typical availability of interruptible loads. This 
potential may change slightly considering cold temperature in winter and temperature increase in summer. The residential demand response resources can also be thought of as a virtual generator. With the development of information technology and communication, consumers would not be involved in the control process of the participating loads. The household appliances can be remotely controlled by a third party. The third party could contract large amounts of residential customers, and then coordinate them in real-time for the provision of instantaneous reserve. This will require a coordinated intelligent operation of large numbers of these appliances, especially with the recent technology developments which currently facilitate a smart operation of these appliances. Simulations undertaken by [80] show that many European countries can benefit significantly from smart appliances operation. The study found out that the technological potentials depend on the user acceptance with regard to load-shifting, including, intermediate interruptions of the operation of appliances, or the use of freezers for temporarily storing energy. In order to use residential loads to provide instantaneous reserve, it is essential that they are controllable and that the response is predictable. Actual participation will depend on marketing effort, consumer education and the incentives offered.

\subsubsection{Potential of controlling modelled loads to provide Instantaneous Reserve}

One aim of this study is to estimate the amount of residential loads able to contribute to the additional instantaneous reserve which results from higher penetration of wind in the New Zealand power system in the years 2014, 2020, 2030. The authors of [9] found out that additional instantaneous reserve will be needed to manage the uncertainty in wind generation output. The quantity of additional instantaneous reserve needed was calculated in [9]. This study was conducted in 2008 and the reserve quantity needed for the years 2010 , 2020 and 2030 is summarised in Table 4-1.

Table 4-1: Additional instantaneous reserve

\begin{tabular}{|l|c|c|c|}
\hline & 2010 & 2020 & 2030 \\
\hline Installed wind power capacity (MW) & 634 & 2,066 & 3,412 \\
\hline Max. Instantaneous Reserve (MW) & 565 & 691 & 912 \\
\hline
\end{tabular}

The actual wind generation for the years $2010-2014$ is provided in

Table 4-2. 
Table 4-2: Wind generation 2010-2013 [81]

\begin{tabular}{|l|c|c|}
\hline Quarter ending & Generation (MW-hours) & \% of total generation \\
\hline March 2014 & 501,000 & 6.3 \\
\hline December 2013 & 519,000 & 5.0 \\
\hline September 2013 & 586,000 & 5.3 \\
\hline June 2013 & 455,587 & 4.7 \\
\hline March 2013 & 435,752 & 4.3 \\
\hline December 2012 & 589,440 & 6.4 \\
\hline September 2012 & 454,064 & 4.5 \\
\hline June 2012 & 497,784 & 5.1 \\
\hline March 2012 & 491,000 & 4.9 \\
\hline December 2011 & 472,000 & 4.6 \\
\hline September 2011 & 544,000 & 4.7 \\
\hline June 2011 & 483,000 & 4.4 \\
\hline March 2011 & 431,000 & 4.2 \\
\hline December 2010 & 413,000 & 3.9 \\
\hline September 2010 & 387,000 & 3.3 \\
\hline June 2010 & 407,000 & 3.8 \\
\hline March 2010 & 413,000 & 4.1 \\
\hline
\end{tabular}

Comparing the wind generation profile projected in the study conducted by [9] and the real generation data for the year 2010 shown in Table 2 above, we find that the 2010 projected generation is the real wind generation profile in 2014, especially considering that Mill Creek wind farm is planned to generate $60 \mathrm{MW}$ [82] by the end of 2014. Thus, the calculated additional operating reserve calculated for the wind generation in 2010 by [9] will be used in this study as the additional operating reserve needed for wind generation in 2014. The potential of RDR in 2014 to contribute towards the $656 \mathrm{MW}$ additional instantaneous reserve range from 150 to 497 when $70 \%$ of New Zealand households participate. In other words, RDR contribution rate will range from $26 \%$ to $86 \%$. This is illustrated in Figure 4-11. 


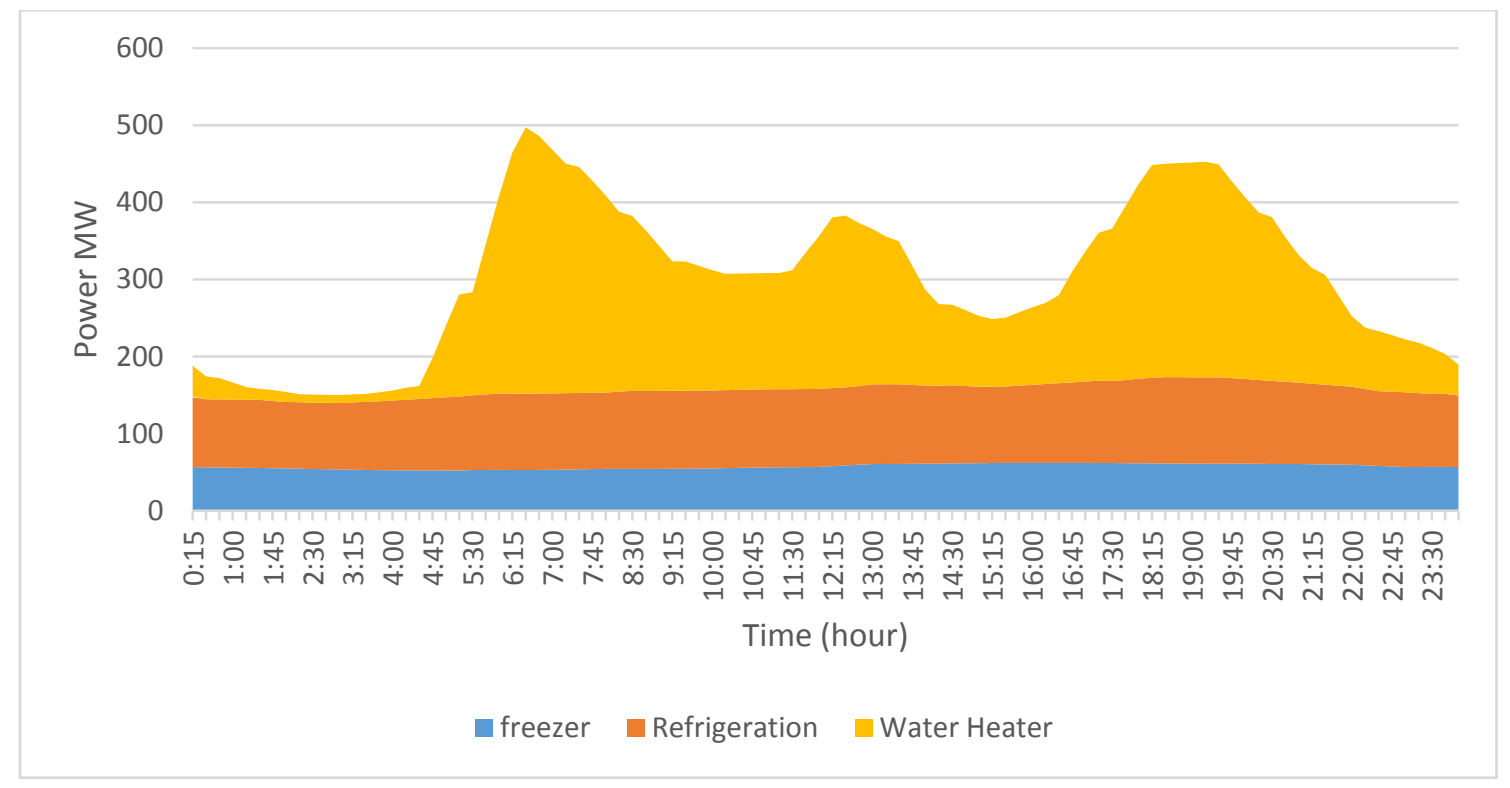

Figure 4-12: DLC of household appliances Potential in 2014

The estimation of the RDR availability in 2020 and 2030 is based on the assumption that these responsive loads will be fully controlled and be available at all times. Assuming a participation rate of $70 \%$ of New Zealand households, the maximum availability of the responsive loads of participating appliances to contribute towards the $691 \mathrm{MW}$ additional instantaneous reserve will be from $133 \mathrm{MW}$ to $565 \mathrm{MW}$. In this simulation, a consideration is given to the increase in efficiency of household appliances and to the slight increase in the number of households in 2020 which is expected to be $1,830,000$ according to [83]. The contribution rate of RDR ranging from 19\% - 82\% is depicted in Figure 4-13.

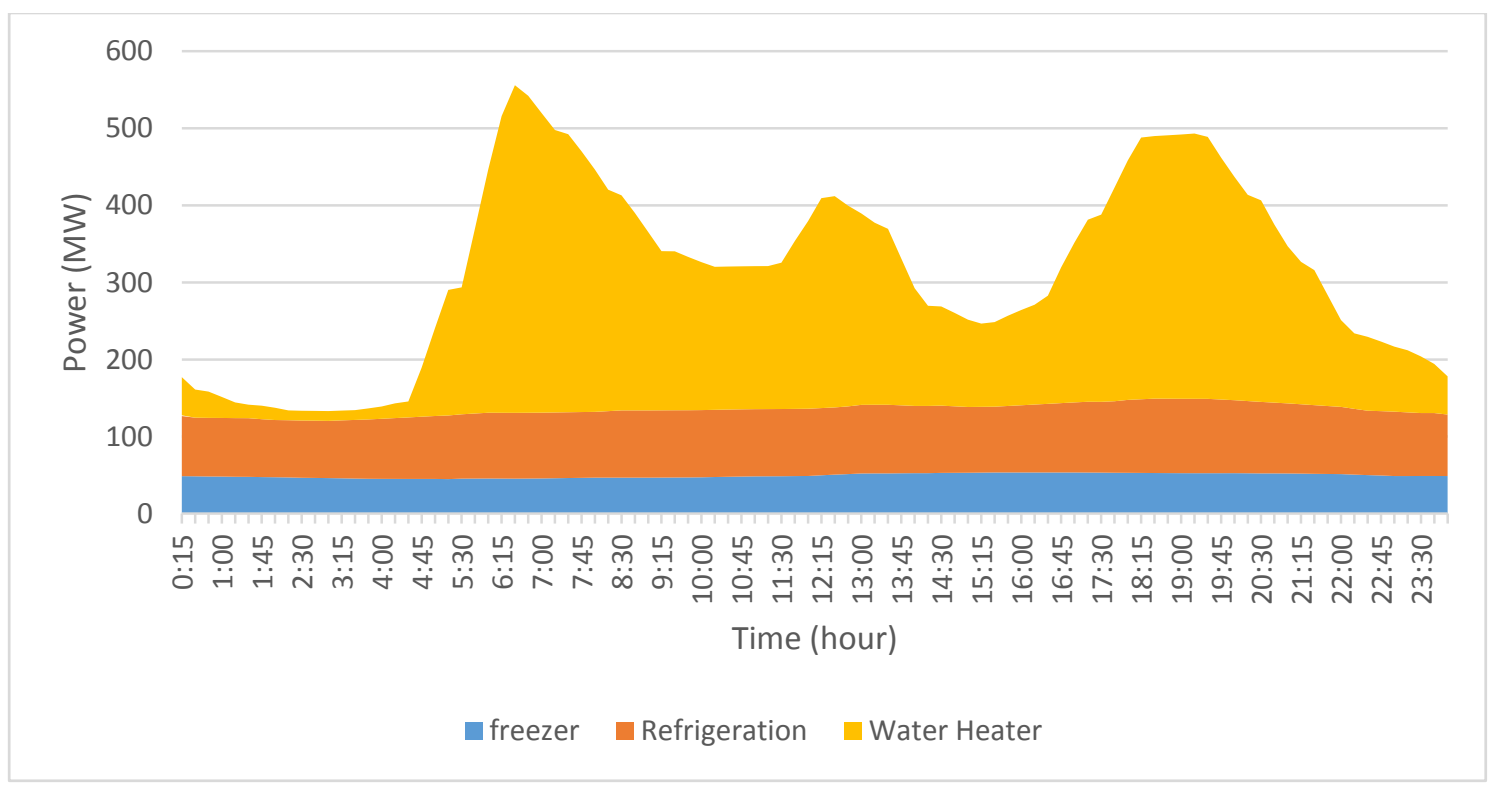

Figure 4-13: RDR Potential in 2020 towards Instantaneous Reserve 
In 2030, the potential of the modelled residential loads of these appliances is expected to provide $19 \%-70 \%$. The decrease in the contribution rate is due to the high increase of the additional instantaneous reserve needed with high penetration of wind and to the expected increase in efficiency of household appliances. However, as high uptake of heat pumps is expected to be around $50 \%$ by 2030 [74], they can be included in the direct control load demand response program to provide additional reserve. Also, electric vehicles are expected to be spread widely in New Zealand by 2030 .

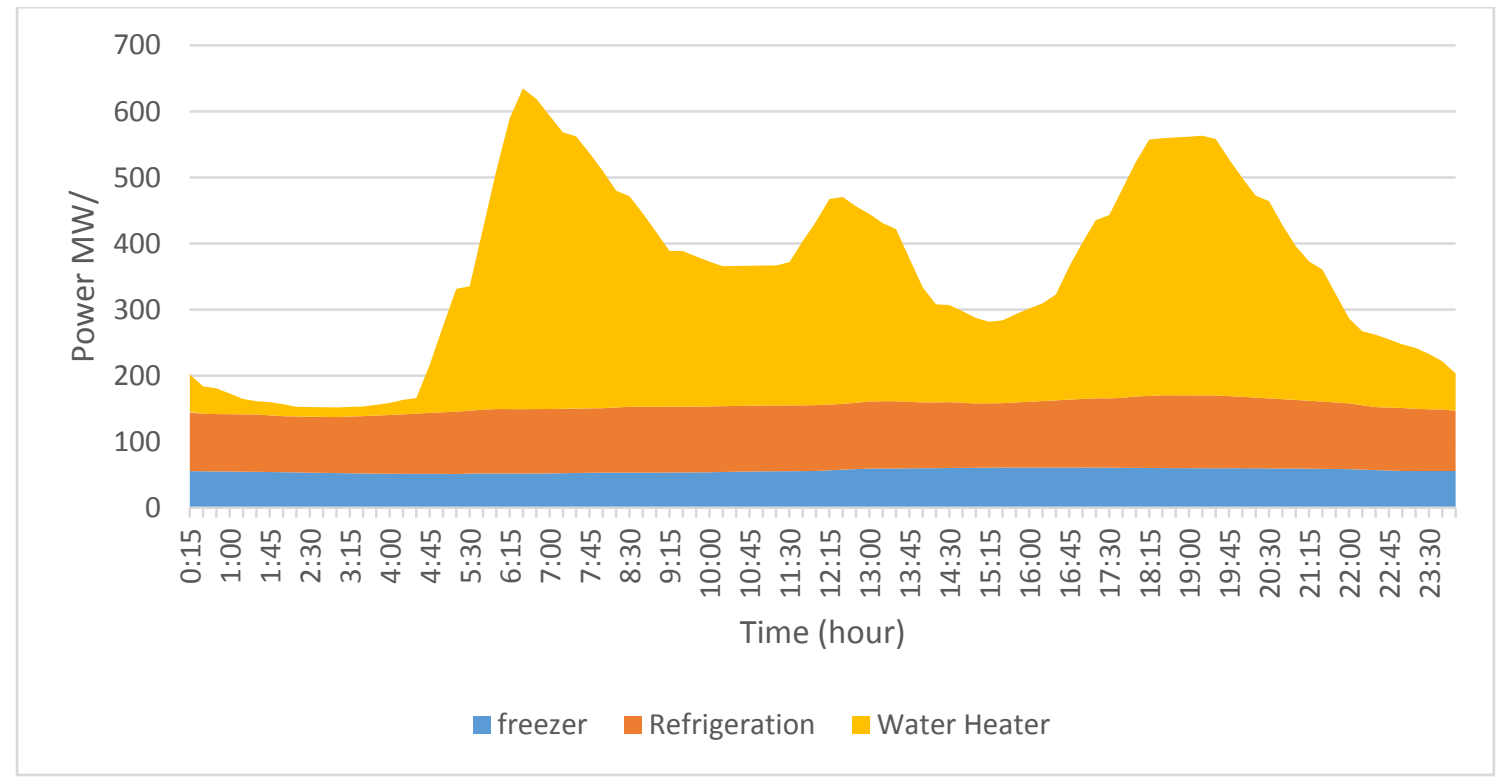

Figure 4-14: Potential assessment of RDR 2030

Although the time of maximum RDR resource availability may not align precisely with the times of maximum grid instantaneous reserve requirements, there is the potential for RDR resources to contribute to a significant fraction of the reserves requirement. Over the course of a day, the availabilities from the resources vary, and reach their maximums at different times. The statistical analysis of load capabilities predicts significant availability from enduse resources during the early morning and evening. Due to the 15 minute maximum interruption time of the responsive loads, their greatest potential lies in providing the instantaneous reserve when needed. The New Zealand electricity market is half an hour intra-day trading, direct load control could provide the necessary balancing until the next trading period. Table 3 summarises the maximum RDR potential contribution. 
Table 4-3: Contribution of RDR towards additional Instantaneous reserve

\begin{tabular}{|l|l|l|l|}
\hline & 2014 & 2020 & 2030 \\
\hline Installed wind power capacity (MW) & 634 & 2,066 & 3,412 \\
\hline Max. Instantaneous Reserve (MW) & 565 & 691 & 912 \\
\hline Max. RDR Potential Contribution & 480 & 550 & 635 \\
\hline
\end{tabular}

\section{Summary}

The modelled responses demonstrate a large potential resource from the residential demand side in terms of the supply of instantaneous reserves. Most of these loads will be operating continuously throughout the year and will overlap with the occurrence of wind power output down ramps. Demand response in the residential sector is most suited to providing instantaneous operating reserve delivered within 1 minute with a duration of 15 minutes. The system operator in New Zealand is recommended to provide an opportunity for residential demand side aggregators to participate in the market in future years. Further analysis is required into the benefit that such programs would offer to the system in terms of improved efficiencies and reliability. While the modelling provides an insight into typical amounts of reserve which could be made available through a direct load control program, further research is required in order to understand the precise nature of the response. At the end of the control period demand peaks will occur as the loads are reconnected and the energy is paid back. This is particularly the case for refrigeration loads and water heaters which will reclaim the shifted or interrupted energy over a relatively short period of time after reconnection. For low wind penetration in 2014, hydro remains the primary source of instantaneous reserves. The role of demand response in providing instantaneous reserves becomes more significant with the increased level of wind penetration in 2020 and 2030 scenarios due to the limited expansion of New Zealand's hydro capacity expected in the future. This analysis does not take into account the economics of participation or the effort required to enable the end-users effectively. More real data to confirm and refute the predictions of load capabilities must be gathered and analysed. These loads are expected to have sophisticated communication control systems in the near future, which will allow them to respond instantaneously to the operator requests. Finally, Results from this study indicate that the large potential for demand 
response in the residential sector in New Zealand requires further attention and should be considered a potential valuable resource in meeting the system needs in the future. 


\section{CHAPTER 5 INTEGRATING WELLINGTON REGION'S RESIDENTIAL LOADS WITH WEST WIND FARM WIND POWER}

\subsection{Methodology}

The variability of wind power generation is usually represented in the occasional wind down ramps and this has the potential to negatively affect the stability of the power grid especially with the expected increase of wind penetration. Wind power changes constantly where the power level moves up and down in a stochastic manner, and as a result cannot be treated as firm capacity for unit commitment purposes in long term generation scheduling. In current wholesale markets wind generators are treated as "Must Run (MR)" units so far as unit commitment is concerned. Wind generation is remunerated in a variety of ways in different markets (feed-in tariffs, price takers, tax break etc.) but rarely allowed to establish the system clearing price and receive the higher levels of remuneration available at the margin. Global wind power output is projected to increase from $130 \mathrm{TWh}$ in 2006 to over $660 \mathrm{TWh}$ in 2015 and $1490 \mathrm{TWh}$ in 2030 [1]. Wind power also experienced dramatic growth over the last decade; global installed capacity at the end of 2011 was around $240 \mathrm{GW}$, up from $18 \mathrm{GW}$ at the end of the year 2000. This increased trend will make wind the second-largest source of renewable electricity, after hydro in near future. NZ has set a target of $90 \%$ of renewable energy by 2025, given that NZ produced just over $75 \%$ of electricity using renewables in 2011. Given the high proportionate levels of wind capacity entering markets throughout the world, it is expected that the present wind generation capacity of over $600 \mathrm{MW}$ in New Zealand will further increase at least $1000 \mathrm{MW}$ by 2025 . It will be increasingly difficult to continue to schedule and dispatch wind units as MR units. Rather the trend to wind forming a significant proportion of capacity in many jurisdictions suggests that wind generators will have to be considered as "dispatchable" units. To achieve dispatchability wind generation will need to be "firmed" with generation or/and load resources. Different methods are used to balance the generation and load for different time frames. For longer time frames of days to weeks, operators may plan and commit different generating units to match the forecasted daily load profiles of weekdays and weekend. It is clear that the variability of wind power affects the system operations. This analysis will focus on utilizing RDR to balance the fluctuations of wind generation in 
the shorter time frames that could affect system operations in the sub-hourly and hourly time frames. The contribution of the RDR is investigated based on three scenarios. The load amount share from DLC demand response program in the Wellington Region is assumed to be equal to $0 \%, 50 \%$, and $100 \%$ of the available responsive loads to balance the fluctuation of wind generated from West Wind.

This section provides a showcase to illustrate the potential of integrating Residential Demand Response (RDR) with wind power. It specifically assesses the role of RDR extracted from the direct load control of refrigerators, freezers, water heaters, and heat pumps in Wellington Region to act as a possible reserve for balancing the fluctuation of wind power generated from the West Wind wind farm in eight selected days in the years 2013-2014. The value that responsive load resources can provide to mitigate the fluctuation of wind power generated from West Wind is investigated based on three scenarios. These scenarios are decided on the assumed contribution percentage of available responsive loads from $70 \%$ participation of wellington Region households.

Figure 5-1 presents the available loads from controlling refrigerators, freezers, water heaters, and heat pumps in $70 \%$ of Wellington Region households. A large resource is available throughout the day with a range of 20 - $55 \mathrm{MW}$ available for interruption. During the peak period, the power resource from those responsive loads can be thought of as a virtual generator of $55 \mathrm{MW}$.

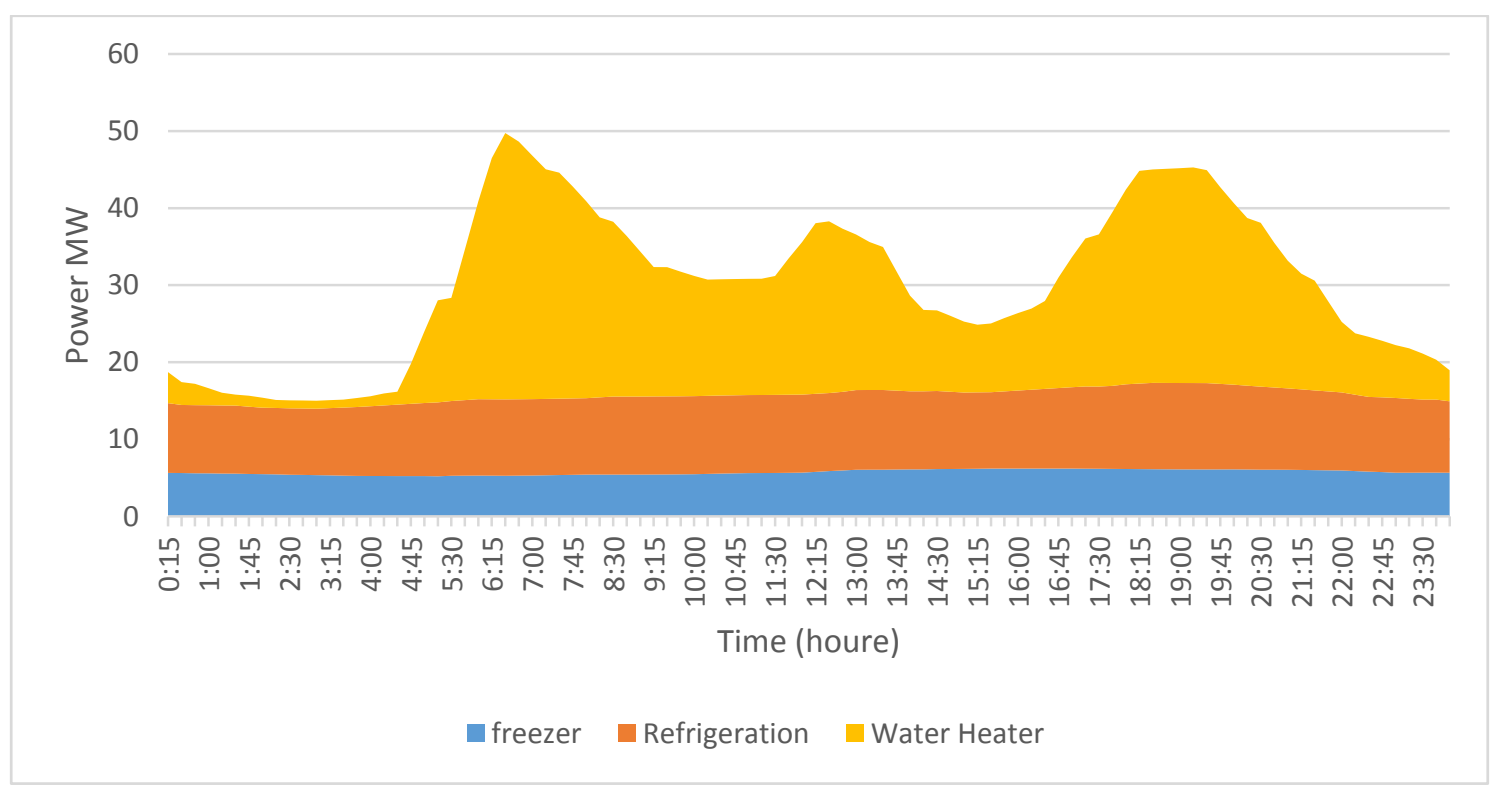

Figure 5-1: Potential of RDR in Wellington Region 
This simulation is performed using Digsilent Power Factory software. Below is a description of building the model and a report and analysis of the simulation results of integrating responsive loads with wind power on selected days.

\subsection{Wind data source selection}

Wind data in this study was acquired from Transpower which is comprised of recorded one minute resolution for eight days in 2013-2014 in different seasons. I averaged minute spot data to formulate hourly wind generation profile to provide a more accurate measure of the power generated over an hour than hourly spot data alone because it is best to select sources showing the greatest fluctuation of wind data. Wind power generally does not experience large changes in output from one moment in time to the next. It is therefore best to use an hourly measure of fluctuation, preferably arrived at through hourly averages of second or minute data, to assess demand response as a suitable resource for managing wind ramps. [84] defined a wind ramp as a monotonic change, defined as multiple serial step changes of the same direction, in wind power over a set of temporal step changes of recorded output. A step change is the difference between a record of power output and the prior record of power output along a time series of wind generation data; this difference, or change, can either be positive, negative, or zero. The length of each step change is a function of the defined time interval between singular or averaged data points, therefore a step change can be in seconds, minutes, or hours. A down-ramp begins at the point at which a step change in power output shifts from positive to negative. Wind down-ramps require dispatachable generation to have sufficient ramp up capacity to compensate for the lost wind power. One main aim of this study is to balance wind down-ramps by available load and responsiveness under a demand side management program.

In this study, the data for the system was balanced independent of RDR every 1 hour to cover for any inaccuracies in the data and model. The time period of 1 hour was chosen as it represents a reasonable time period for RDR to be the primary balancing mechanism for the wind fluctuations without impacting RDR participants negatively. A time period of 1 hour also allows a comfortable time frame for the system to balance the change in wind generation with low ramp rates and small effects on dispatch and the frequency keeper.

\subsection{Digsilent Power Factory model}

Digsilent Power Factory was chosen as the simulation software for this study due to the availability of the software and the accessibility of the power system models from 
Transpower. A full North Island Power System (NIPS) model was received from Transpower in Digsilent Power Factory format. The NIPS model had no dynamic models, limiting the study framework to load flow studies, rather than time domain analysis

\subsubsection{Wellington Region reduction}

Due to this study focussing on Wellington loads and West Wind generation, from the NIPS model, the Wellington region was isolated using the "Network Reduction" tool. The substations retained from the full NIPS model were Haywards, Wilton, Central Park, Kaiwharawhara, Takapu Rd, Pauatahanui, Melling, and Gracefield.

Consideration was given to extending the model to include Wellington Electricity substations. The model was kept at Transpower Grid Exit Point (GXP) level as it was determined that the load assumptions that could be made at Transpower GXP level were as valid as the load assumptions that could be made at the Wellington Electricity substation level. Therefore the increased complexity of adding Wellington Electricity substations to the model would provide little benefit to the study and was not implemented.

Figure 5-2 shows the Wellington Region power system retained in the Digsilent model geographically and 


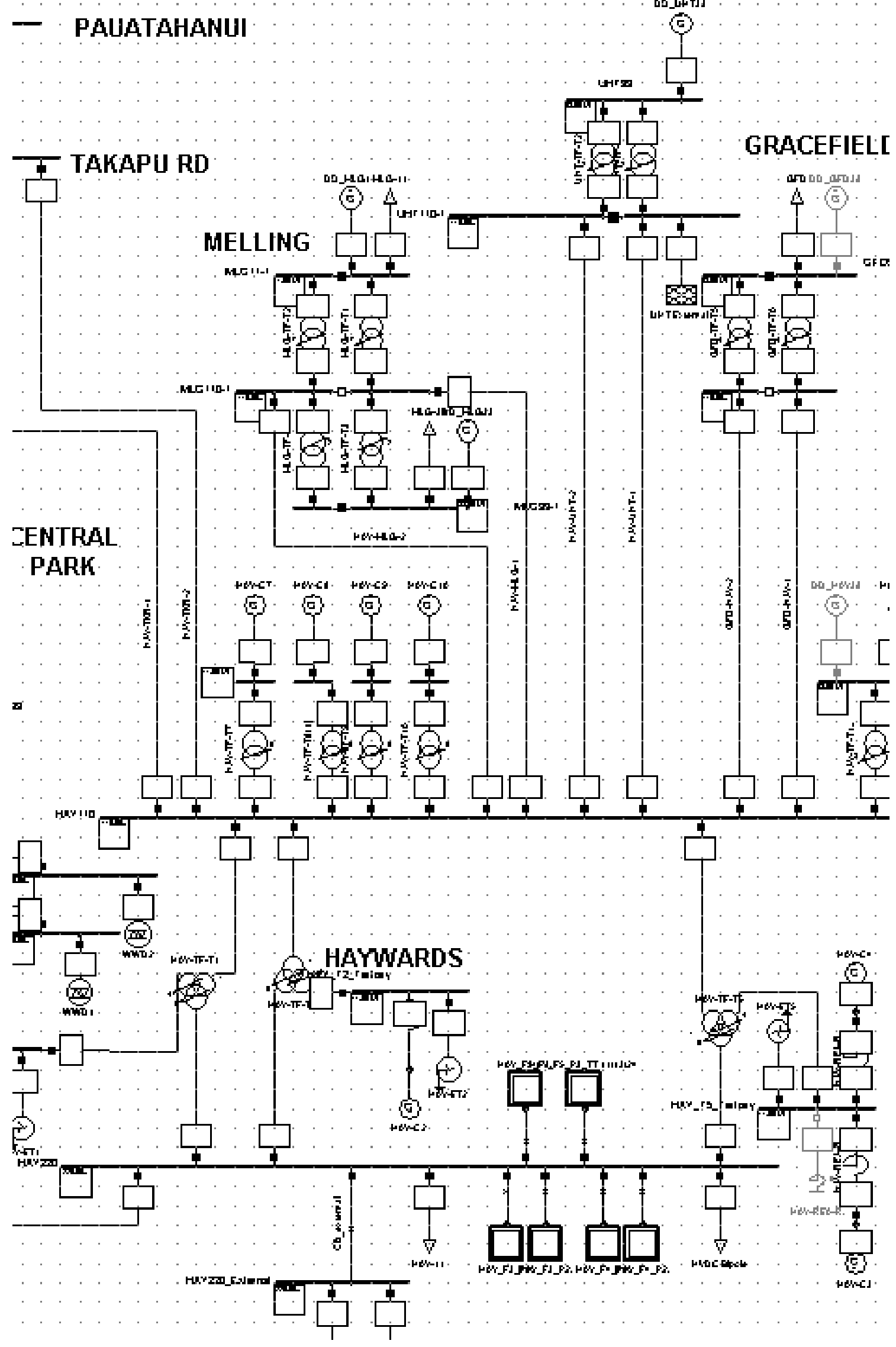


Figure 5-3 shows the model in Digsilent.

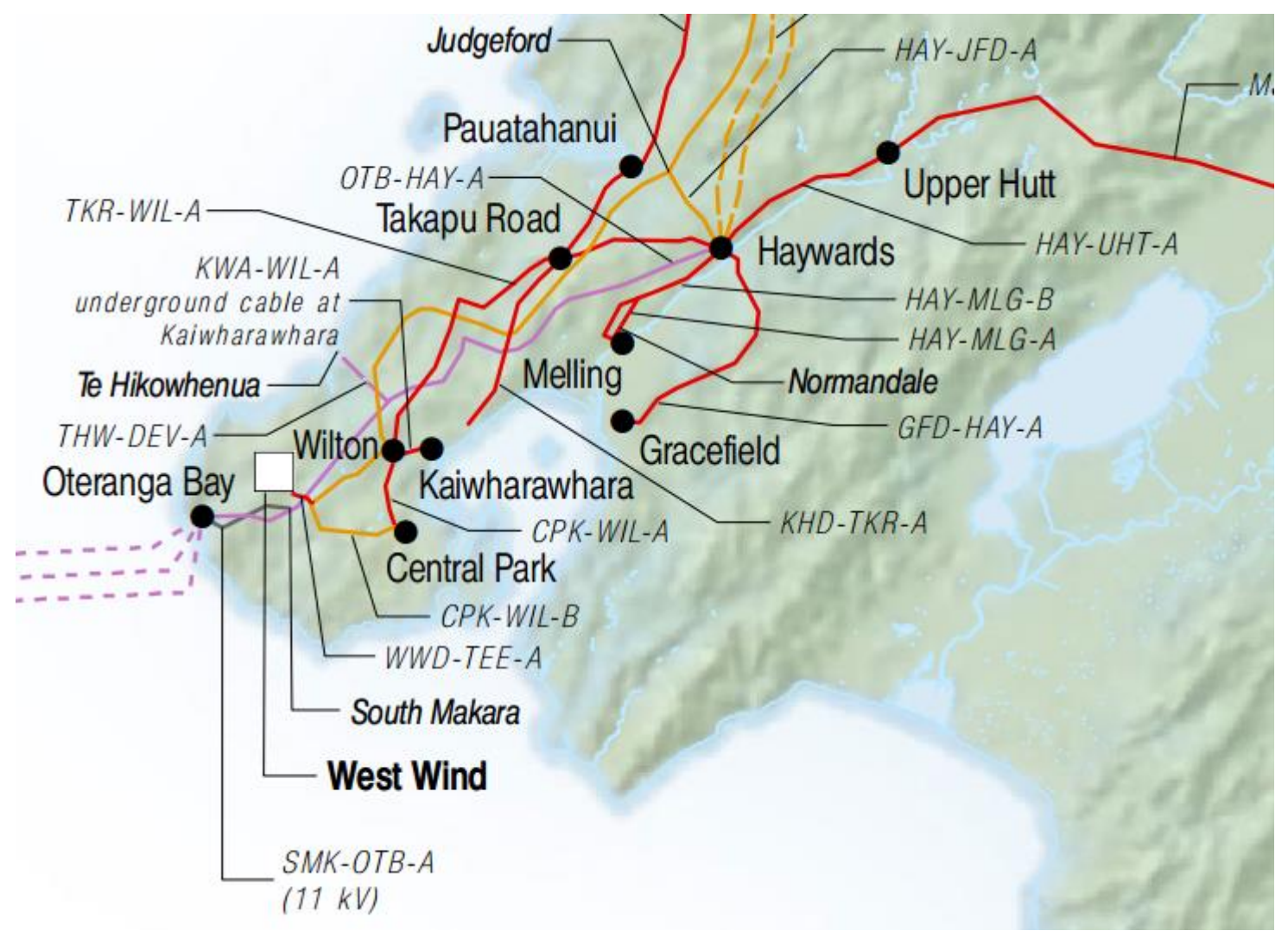

Figure 5-2: Wellington Region power system geographical diagram 


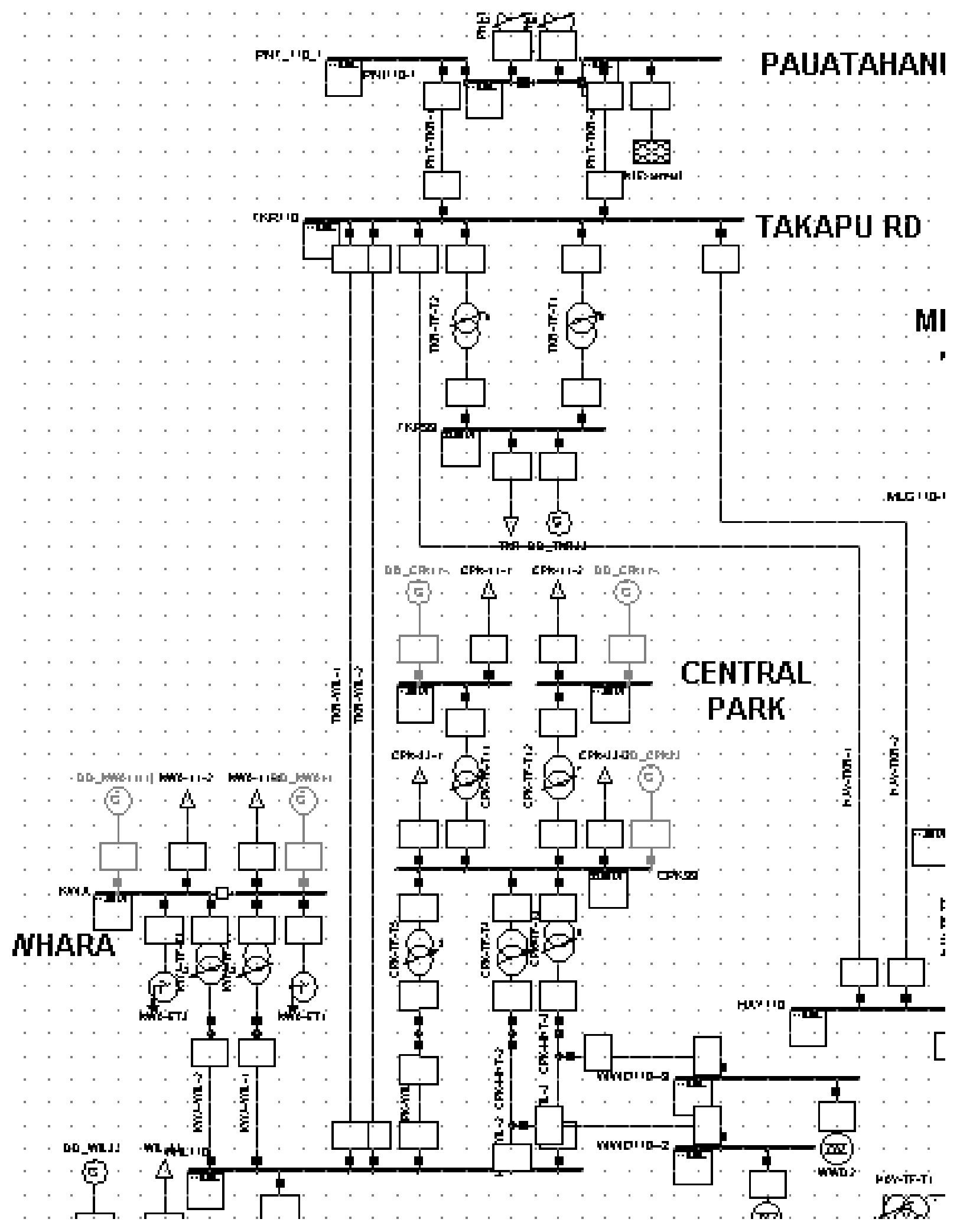


- PAluATAHANUI

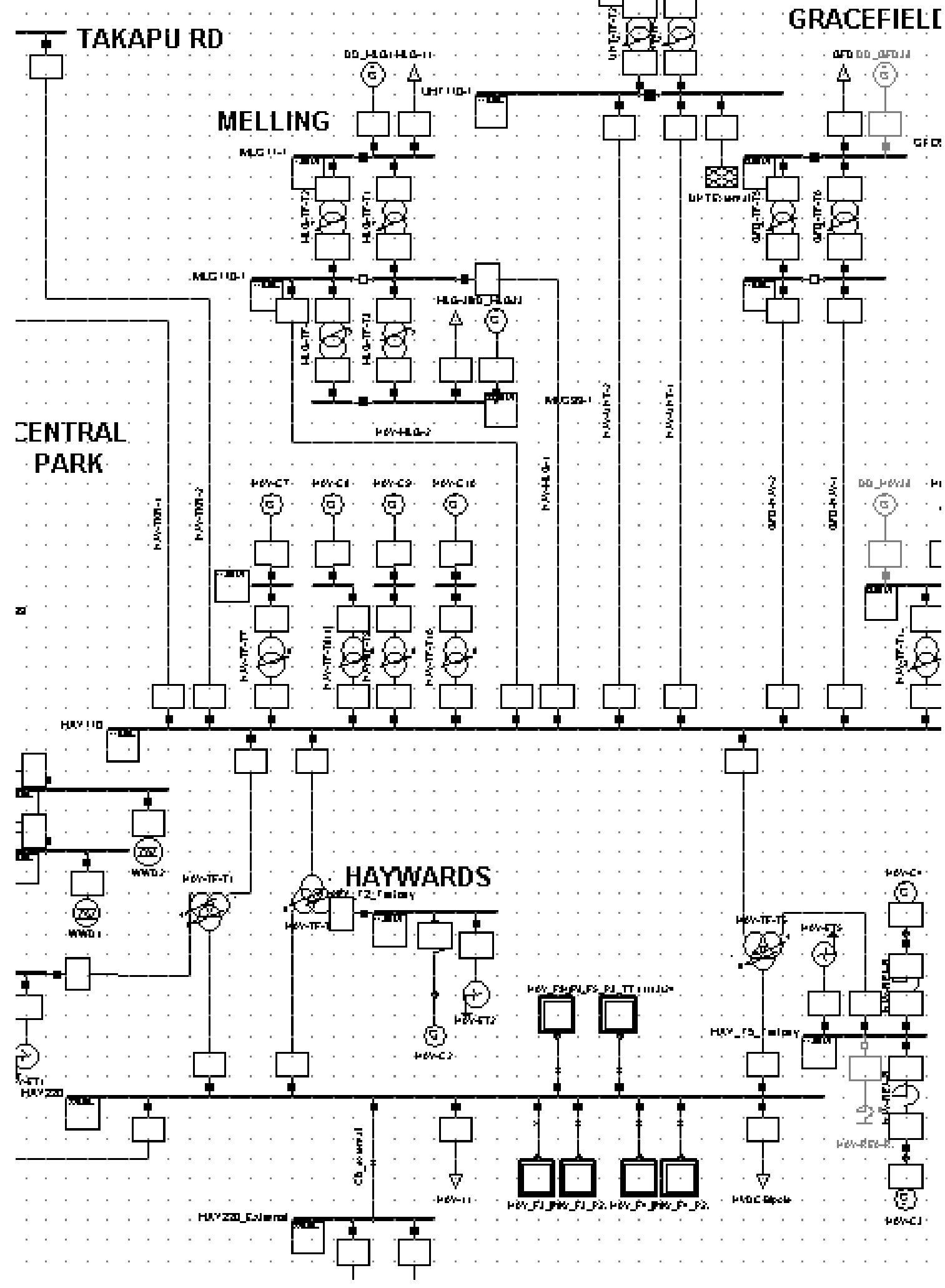

Figure 5-3: Wellington Region Digsilent Model 
The reduction tool produced equivalent network objects attached to the Haywards $220 \mathrm{kV}$ bus, Wilton $220 \mathrm{kV}$ bus, Pauatahanui $110 \mathrm{kV}$ bus, and the Upper Hutt $110 \mathrm{kV}$ bus. These equivalent network objects were replaced by external grid objects in the model.

\subsubsection{System data}

This study included the use of real time data with varying levels of wind power fluctuation from West Wind during eight days in different seasons during years 2013-2014. Power flow data was obtained from Transpower for:

- HVDC (High Voltage Direct Current link transferring power between north and south island) power flow - half hour resolution data

- Power flow into Haywards - half hour resolution data

- Power flow into Wilton - half hour resolution data

- Power flow into Pauatahanui - half hour resolution data

- Power flow into Upper Hutt - half hour resolution data

- All relevant loads in the model - half hour resolution data

- West Wind power flow - 1 minute resolution data

- The resolution of half an hour was chosen for most of the power flow data as this gives an indication of the state of the system at the start of each trading period. Due to the focus on wind generation fluctuation, a higher resolution of data of 1 minute was needed for West Wind power output.

This data was input into the relevant model components as a time characteristic trigger as shown in Figure 5-4. A time characteristic trigger in Digsilent allows the operational values of objects to be varied by adjusting the 'study time' of a case. It is a convenient way of incorporating time based system data into the model. In the example shown in Figure 5-4, setting the study time of the Digsilent case to 12:01am would set the WWD_T1 MW output to $39.1 \mathrm{MW}$, and setting the study time to 12:06am would set the WWD_T1 MW output to 41.26 MW.

As discussed above, data used was of varying resolution, so linear interpolation was used for the half hour resolution data to allow smooth transition of values between half hour data points and avoid any step changes in data with a 1 minute time step simulation. 


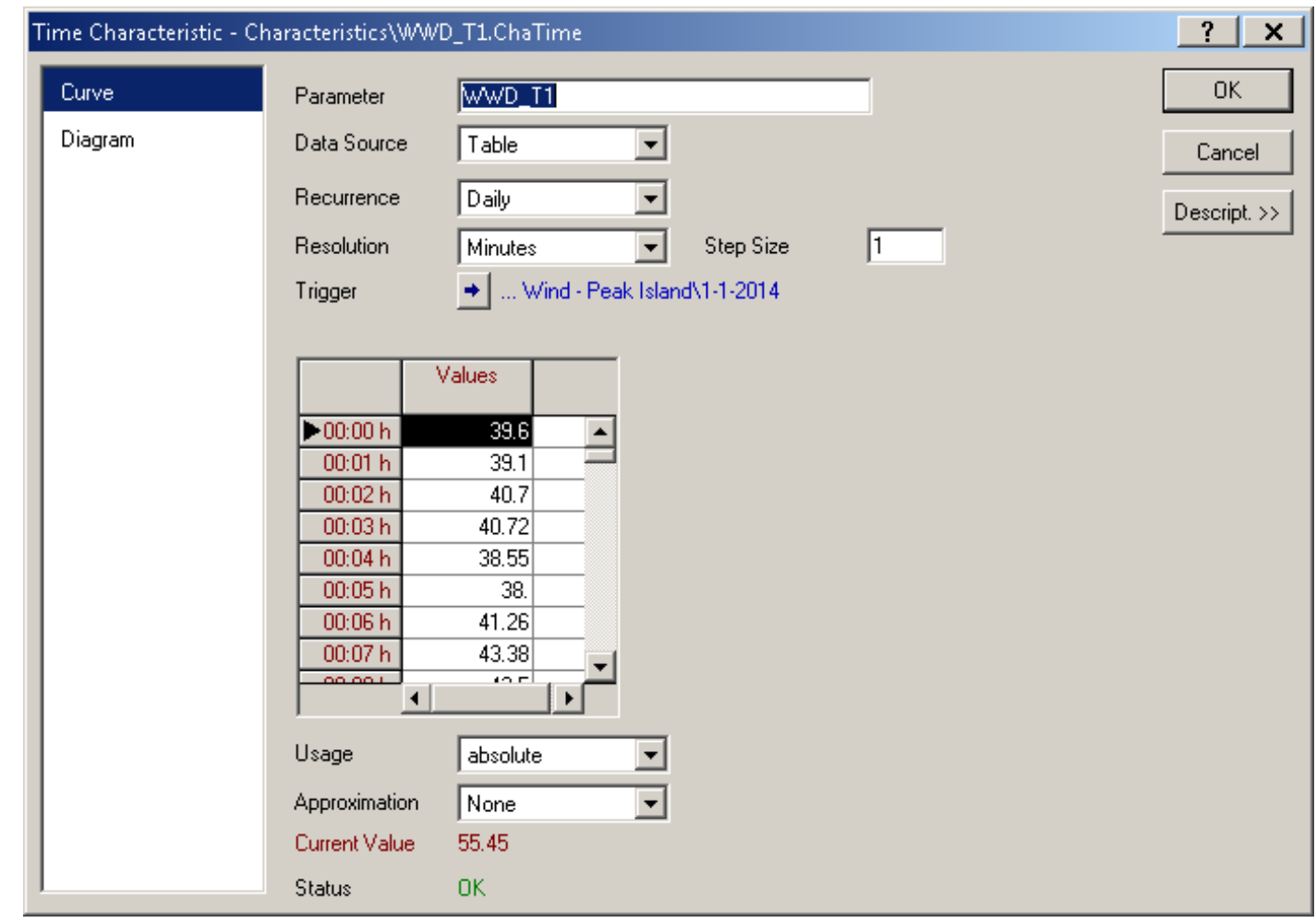

Figure 5-4: West Wind 1 MW time characteristic trigger

\subsubsection{Demand response load balancing}

The demand response load balancing was implemented by setting up slack generation at each load site in the model. Each load was modelled with an associated synchronous generator which would offset the load value by a required amount to balance the load flow generation and load MW. Figure 5-5 shows the example of Central Park. Essentially the total load was considered load + dynamic response generator offset. 


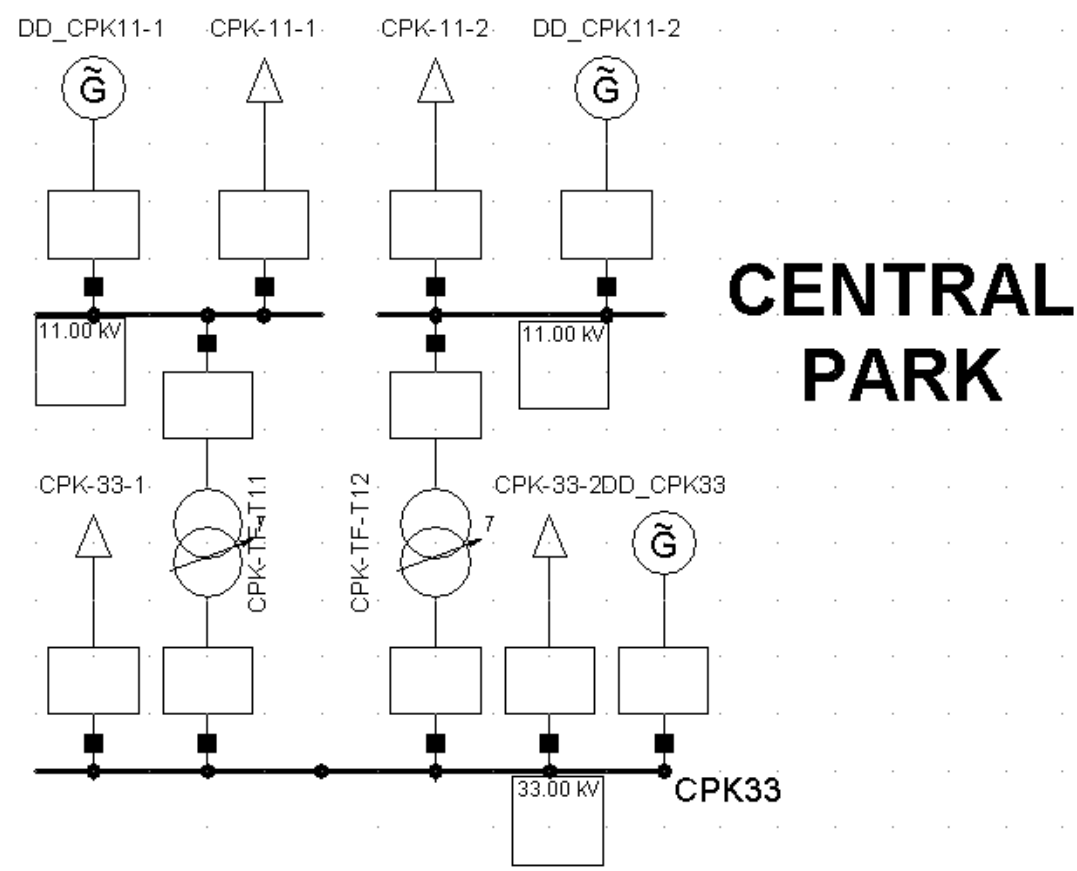

Figure 5-5: Central Park demand response slack generation modelling

The share of load flow balancing from each generator was co-ordinated by the use of a Power-Frequency Controller. All the dynamic response generators and an additional slack generator at Haywards were added to a Power Frequency Controller to determine the share of MW's they would provide. This is shown in Figure 5-6.

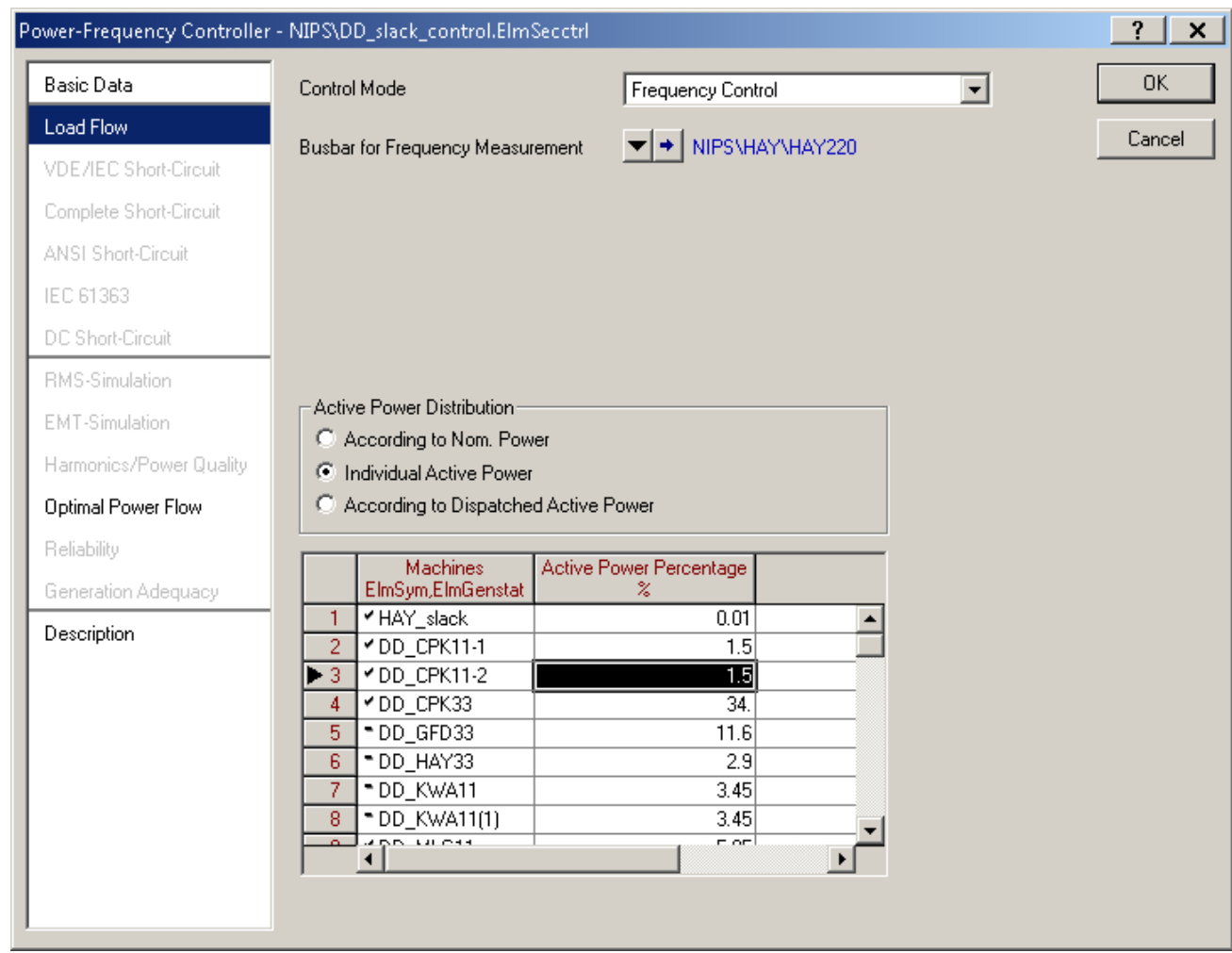

Figure 5-6: Dynamic Response Power Frequency Controller 
Additionally, by selecting in the load flow options to "Consider Active Power Limits", limits of the MW's provided by each of the dynamic response models could be set for each generator and hence, each load. For example, if it was determined that the Gracefield load could reduce load by $3 \mathrm{MW}$, the DD_GFD33 generator should be set with a MW limit of 3 MW.

In order to account for balancing by the power system which the dynamic response will not be able to provide, a slack generator at Haywards was added. This generator was added with an Active Power Percentage in the Power Frequency Controller of $0.01 \%$. This means that it will have minimal input to the balancing of the load flow until all the dynamic response generators had reached their limits, then the Haywards slack will produce whatever MW's are required to balance the system and solve the load flow. This Haywards slack generator will be reflective of what balancing will be required from the rest of the system which the load dynamic response cannot provide.

Another option considered in modelling the load dynamic response was to set up the loads themselves as slack generation. The methodology described above as having the load and an associated slack generator to represent the dynamic response offset was chosen as it easily allowed balancing wind fluctuations while having the time characteristic on the loads and being able to set limits on the dynamic response slack generators.

\subsubsection{Quasi-dynamic simulation}

As mentioned previously, there were no time domain models in the Digsilent case received from Transpower, therefore the study was limited to load flow analysis. The QuasiDynamic Simulation tool allows a series of load flows to be run over discrete time points. Quasi-Dynamic Simulations were run for this study.

Due to the nature of the study not being a full dynamic analysis, any time domain issues such as slow response of load dynamic response have not been considered, it is essentially a MW matching study. Since the system data was input into the models as time triggers, running a quasi-dynamic simulation successfully ran through the system conditions at each time step, giving the available MW's from load dynamic response. Figure 5-7 shows an example of setting options for the quasi-dynamic simulation. 


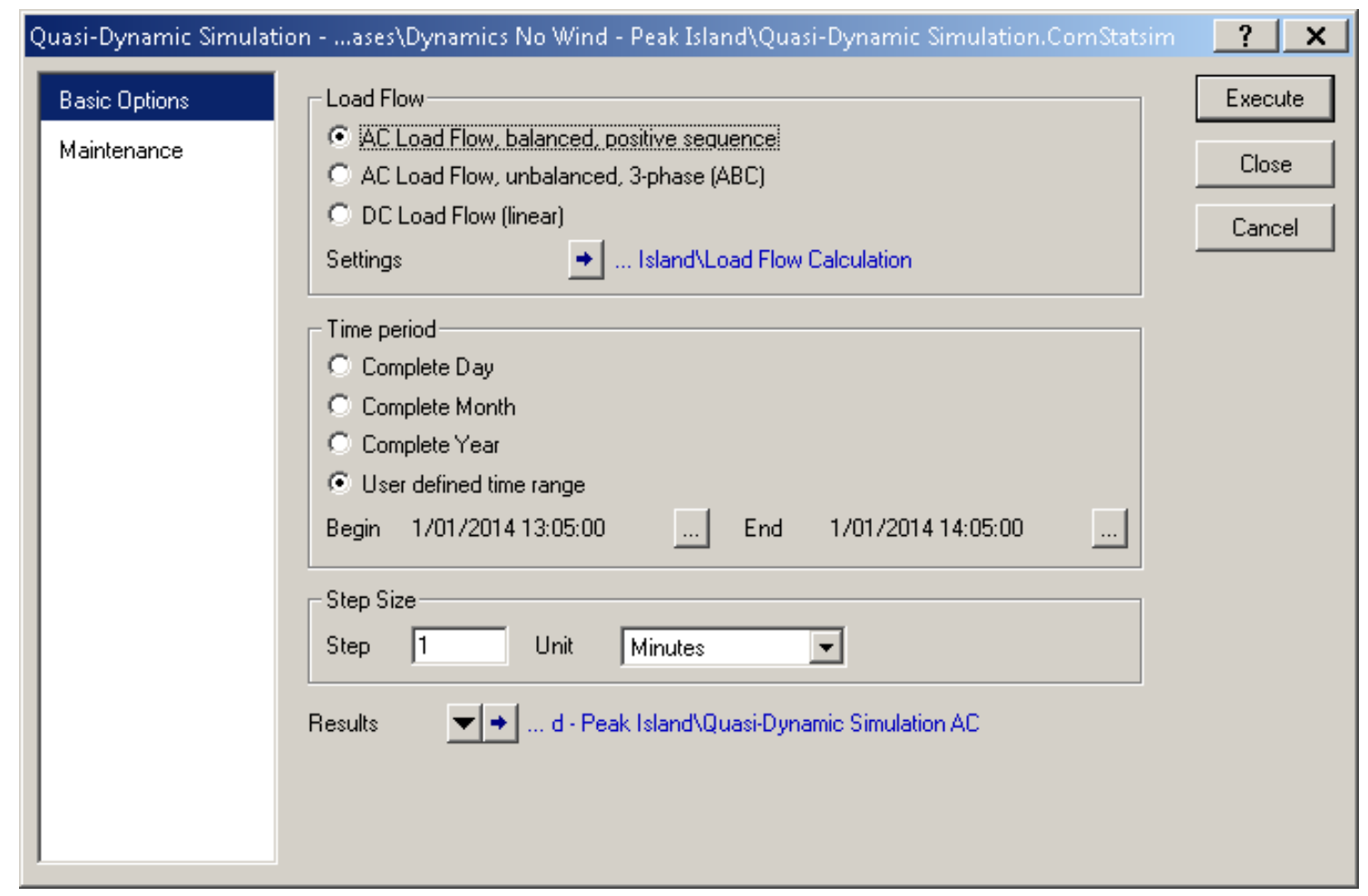

Figure 5-7: Example of setting options for the quasi-dynamic simulation

\subsubsection{Simulations steps}

The overall computation behind this study can be described by the equations below:

The first stage in the calculation is to balance the system data with the wind power averaged over 1 hour periods. This represents the wind generation as an ideal stable power source. The balance of the system data is described in Equation 5-1. Practically this was done by replacing the 1 minute resolution wind data in the Digsilent model with wind power averaged over 1 hour time steps, and running the quasi dynamic simulation with dynamic response generations disabled. The output of the slack generator at Haywards represents the additional balance of the system data required with the 1 hourly averaged wind power input. The averaged wind data described above as averaged on an hourly basis, except during significant ramping events where it was held constant according to the pre-event power output. This is to allow the dynamic response to have maximum input into alleviating the effect on the system from this fluctuation.

In Equation 5-1 below, $P_{\text {Load }}$ represents the combined Wellington region loads in the network model. This includes loads at Haywards, Wilton, Central Park, Kaiwharawhara, Takapu Rd, Pauatahanui, Melling, and Gracefield substations. $P_{\text {Line }}$ represents the combined transmission line flows for circuits into the Wellington region. PHVDC represents the power flow through the HVDC which connects into Haywards. Gslack represents the 
slack generator at Haywards. $\mathrm{WG}_{1 \text { hour }}$ represents the West Wind power output averaged over 1 hourly time periods.

$\sum \boldsymbol{P}_{\text {Load }}+\sum \boldsymbol{P}_{\text {Line }}+\sum \boldsymbol{P}_{H V D C}+\sum \boldsymbol{W} \boldsymbol{G}_{1 \text { hour }}+\sum \boldsymbol{G}_{\text {slack }}=\mathbf{0} \quad$ Equation 5-1

The second stage of the calculation is to input the $\mathrm{G}_{\text {slack }}$ data obtained in Equation 5-1 back into the Digsilent model as a separator generator parallel with the Haywards slack. At this stage the 1 minute resolution West Wind data replaces the 1 hour averaged data used for Equation 5-1. Running the quasi dynamic simulation with this configuration gives the balance required by the system to compensate for fluctuations in the wind power output within the 1 hour time periods and significant ramping events.

In Equation 5-2 below, $\mathrm{WG}_{1 \text { min }}$ represents the actual 1 minute resolution West Wind power output data. $G_{\text {slack }}^{\prime}$ represents the balance required by the system to compensate for fluctuations in the wind power output.

$\sum P_{\text {Load }}+\sum P_{\text {Line }}+\sum P_{H V D C}+\sum W G_{1 \text { min }}+\sum G_{\text {slack }}+\sum G_{\text {slack }}^{\prime}=0 \quad$ Equation 5-2

Running the simulation with the setup described above for Equation 5-2 with varying levels of load dynamic response produces the available power from thermostatic loads to balance wind fluctuations, and the required power from the rest of the system. This is described in Equation 5-3, with RDR representing the power available through load dynamic response and $G_{\text {slack }}^{\prime \prime}$ representing the balance required by the rest of the power system.

$\sum G_{\text {slack }}^{\prime}=\sum G_{\text {slack }}^{\prime \prime}+\sum R D R$

\section{Equation 5-3}

Figure 5-8 shows a simulation output example. The trends in the plot relate to the simulation and model described above as follows:

1 min wind output - 1 min resolution West Wind power output data $\left(W G_{1 \min }\right.$ -

\section{Equation 5-2)}

1 hour modelled power - Balanced system data as described in section above $\left(P_{\text {Load }}+\right.$ $P_{\text {Line }}+P_{H V D C}+G_{\text {slack }}$ - Equation 5-1)

Utilised RDR - Total generation from the dynamic response slack generators simulating load offset ( $R D R$ - Equation 5-3)

Slack generation - Slack generator modelled at Haywards to simulate MW balance required by the rest of the system $\left(G_{\text {slack }}\right)$

Full results and final outputs discussed in section 5.5. 


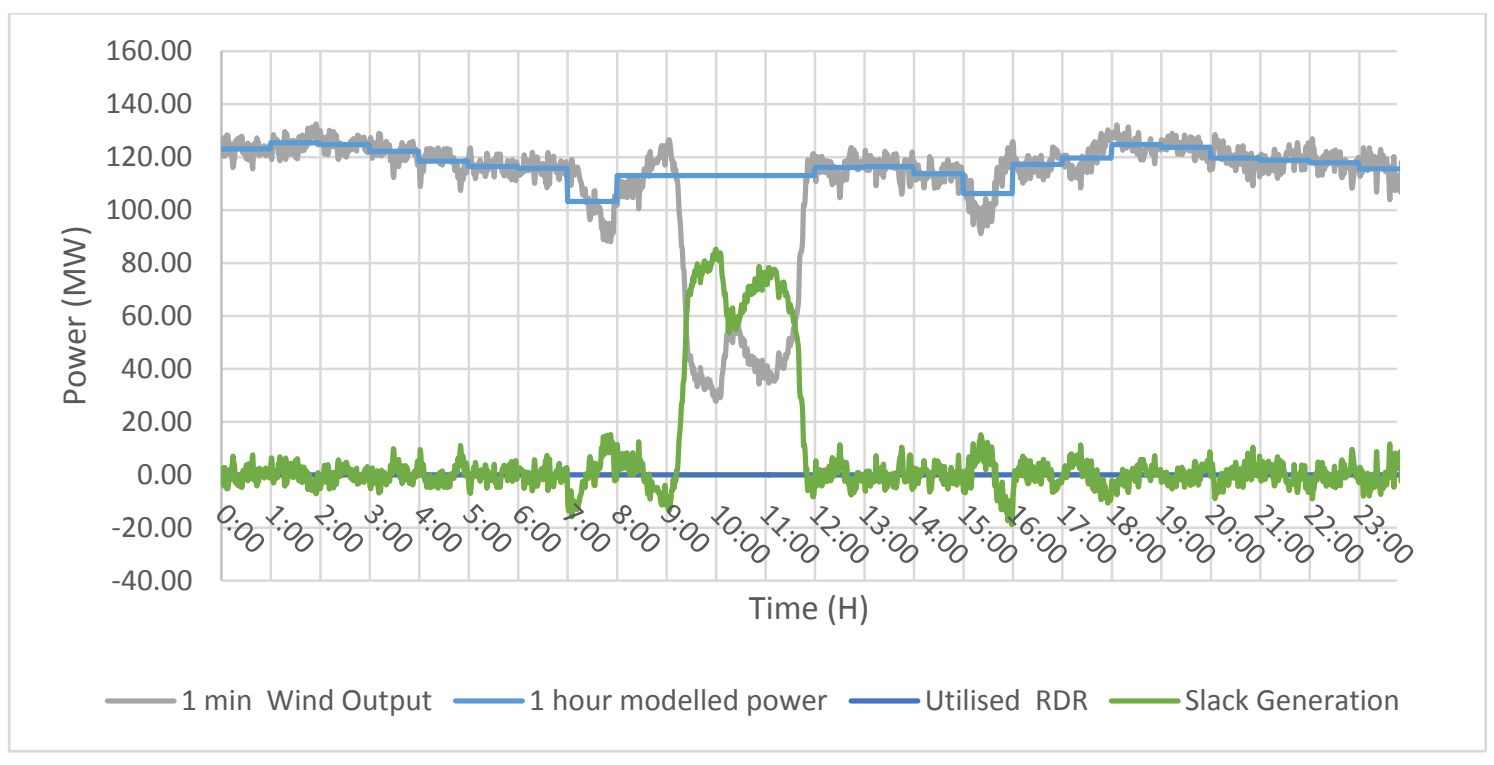

Figure 5-8: Balancing DWR with $100 \%$ of RDR on April 29, 2014

\subsection{Considerations of the study}

Certain aspects of power system simulation were important for this study and other aspects were considered to not be relevant. Discussion on how different aspects of the power system affect this study is below:

Active power flow - this is essentially the core of the study. The study determines active power reduction available from loads to balance out active power fluctuation in wind generation.

Frequency - as this is not a time-domain analysis, but a series of load-flow calculations made in time steps, the frequency does not play a part in this analysis. Frequency would continue to be managed in real time as it is now by generator governor action and the frequency keeper. The dynamic load response will only help the frequency situation as it can provide an element of fast acting load balance and relieve the burden of MW balance from the frequency keeper.

Reactive power flow - no consideration of reactive power flow has been made in this study. The effect of reactive power is minimal to this study as the control of load dynamic response focuses on the active power modulation of thermostatic units.

Voltage - no consideration of voltage issues has been made in this study. During the simulation, the voltage was kept very constant due to the external grids placed at Haywards and Wilton. Both external grids had fixed voltage set points which ensured the voltage remained steady. Different voltage levels may affect the available MW's for voltage dependent loads, however this has not been treated as significant for this study. 
Active power losses - due to the load and generation in this study being Wellington focussed, losses will not be significant. The Digsilent model is a complete model from Transpower and any losses between the supply of power from the system and West Wind to the Wellington load will be modelled. Depending on where the dynamic response loads are supplied from, losses in the network potentially mean that more gain comes from load dynamic response, than balancing with the frequency keeper, since to provide that MW of load the generator must provide $1 \mathrm{MW}$ plus losses which can be significant, especially if the frequency keeper is electrically quite far from the wind farm or load centres.

\subsection{Simulation Results}

\subsubsection{Apr 29, 2014 Event}

As mentioned above, one aim of this study is to see the possibility of firming wind generation by combining wind generation output with responsive load available from the residential sector. Figure 5-9 shows the West Wind wind farm power output on April/29/2014 plotted with 1-minute resolution. Starting at approximately 9 in the morning, wind power out from West Wind Farm reached its peak of that day of $125 \mathrm{MW}$ and started to drop suddenly. In less than 30 minutes, wind generation decreases to $30 \mathrm{MW}$ which constitutes more than $75 \%$ loss of wind power and continued in the 30-60 MW wind output for two hours.

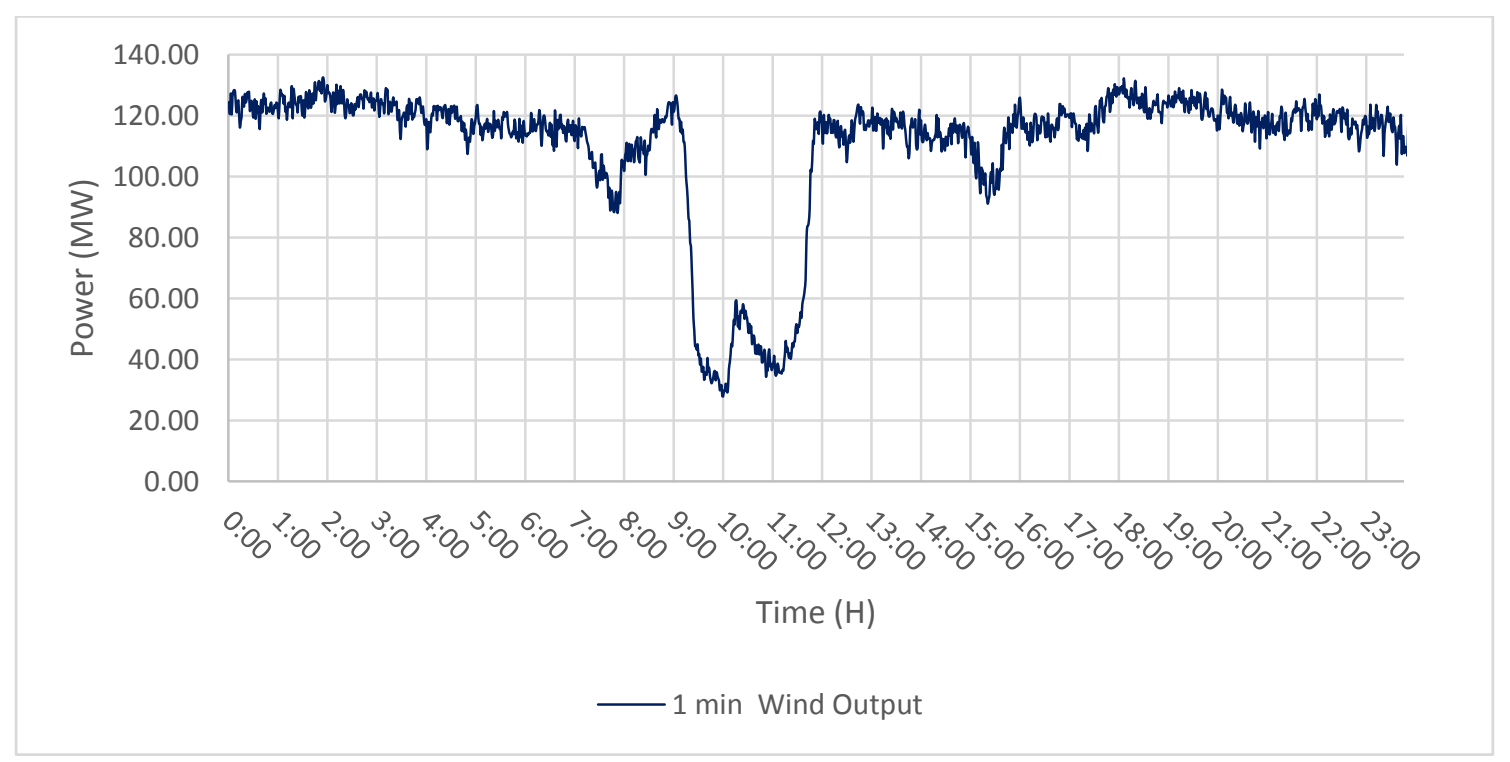

Figure 5-9: Wind output profile on April 29, 2014

This down ramp occurred during the morning peak period which makes it very necessary to have an Figure 5-8, to balance the wind output fluctuation and compensate for the down ramp during these two hours, $80 \mathrm{MW}$ of slack generation was needed. 
The available RDR from controlling responsive loads of $70 \%$ of Wellington region households during these two hours is 40MW. As shown in Figure 5-10, assuming that utilising $100 \%$ of these available responsive load, we can compensate for $50 \%$ of the needed reserve and thus mitigate $50 \%$ of the rate of this large down ramp, and the other $50 \%$ of reserve is provided by the slack generation which is more likely to be from hydro resources.

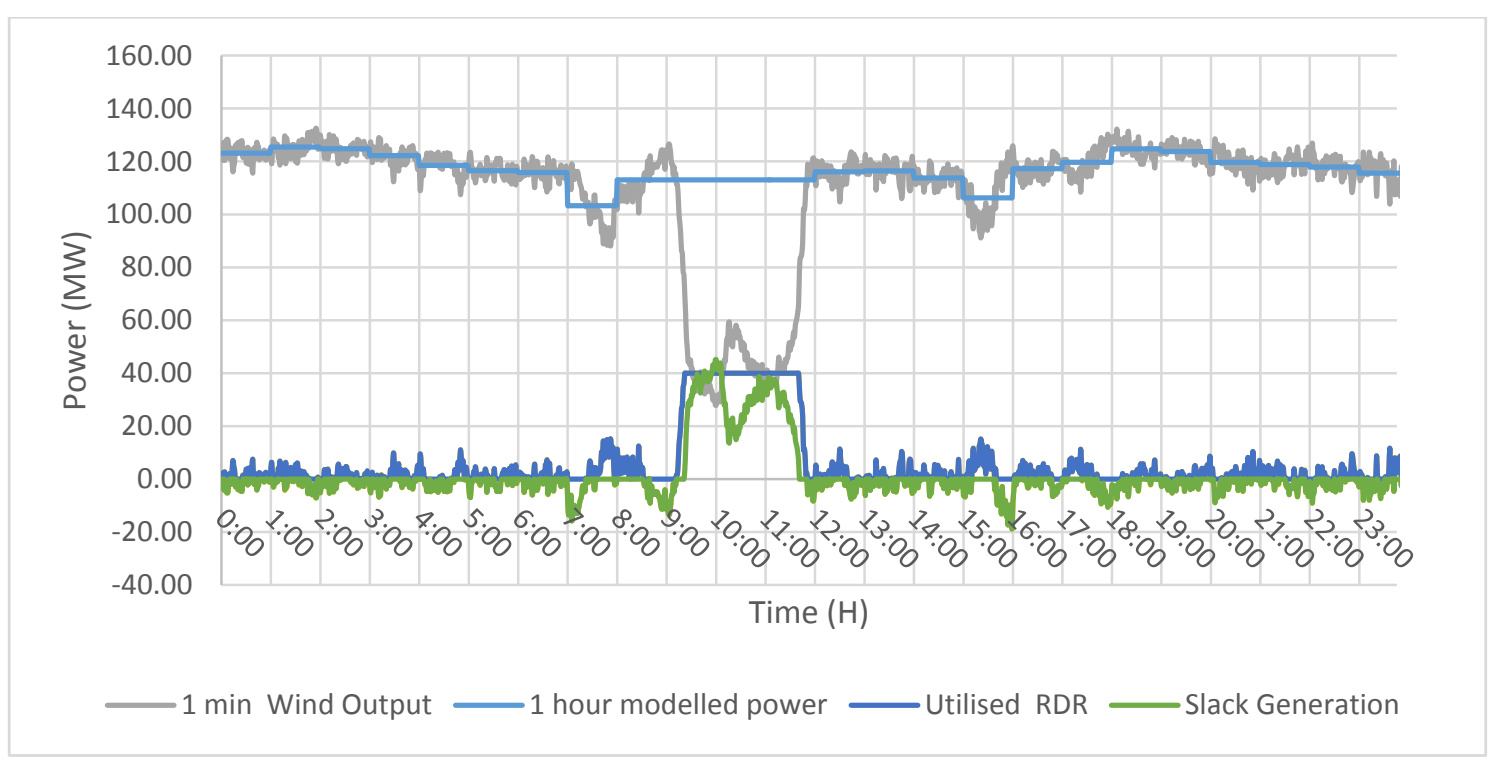

Figure 5-10: Balancing DWR with $100 \%$ of RDR on April 29, 2014

\subsubsection{March 3, 2014 Event}

As mentioned above, one option for firming wind generation is to combine wind generation output with responsive load available from the residential sector. Figure 5-11 shows West Wind power output plotted with 1-minute resolution on 3/3/2014.

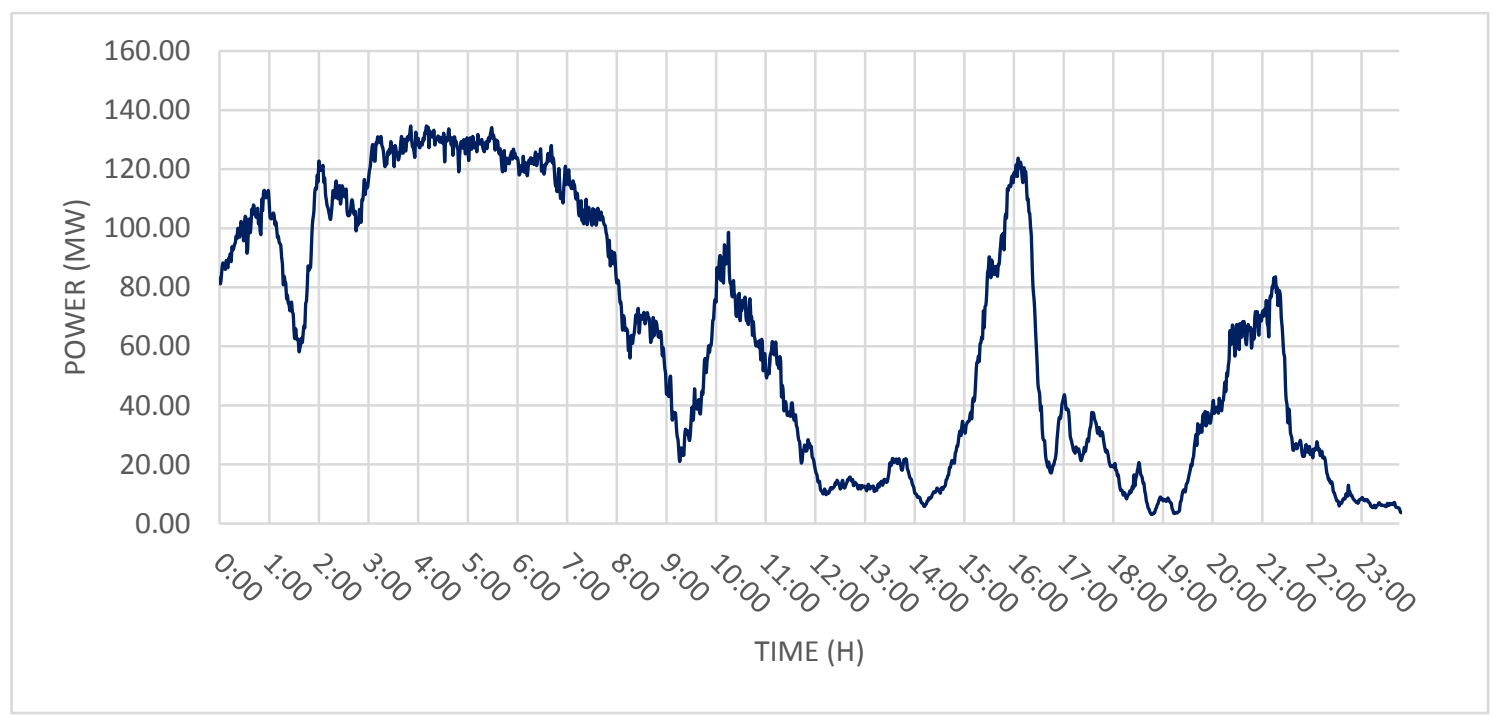

Figure 5-11: Wind power output on March 3, 2014 


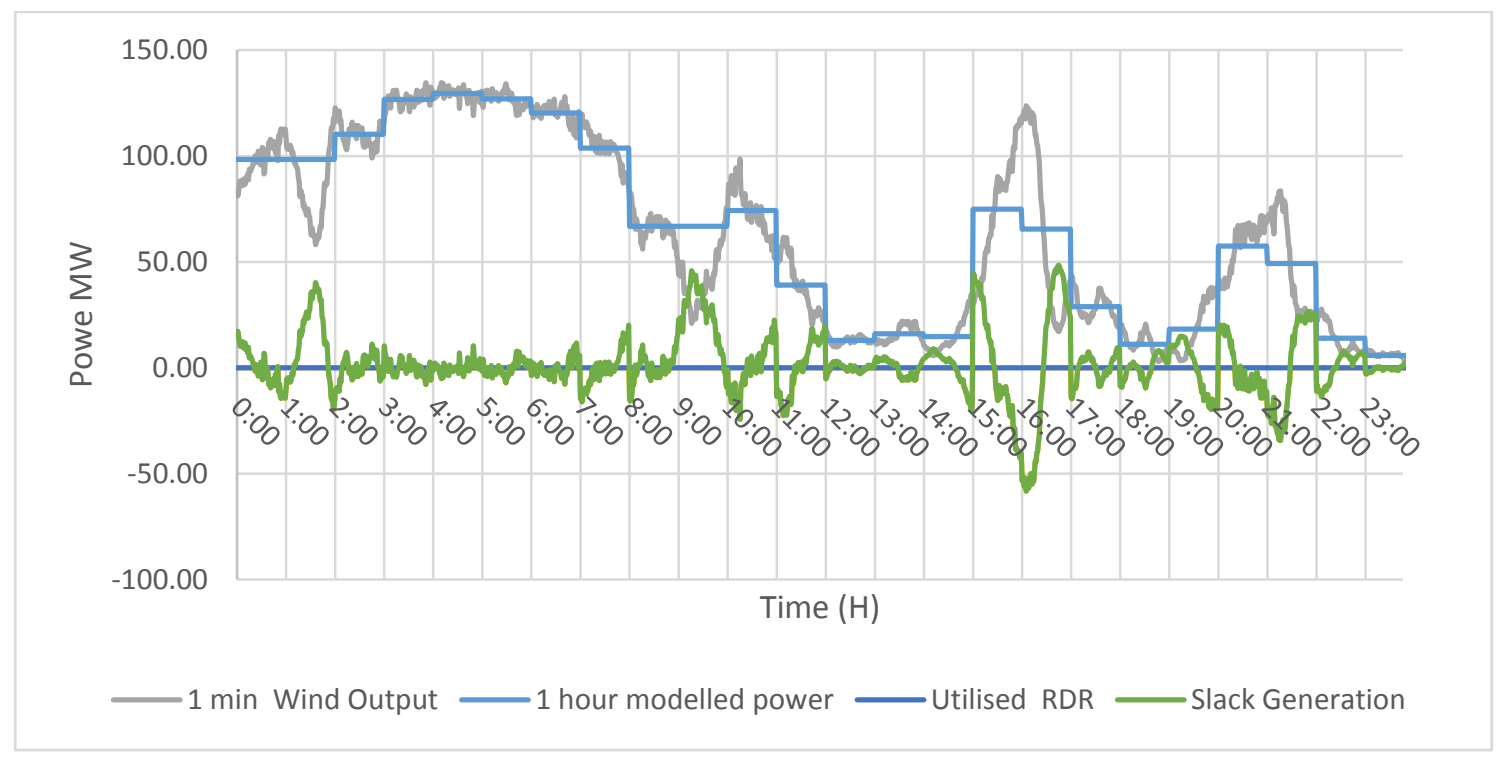

Figure 5-12: Balancing DWR with slack generation Mar 3, 2014

Utilizing 50\% from the available RDR from responsive controlled loads in $70 \%$ of wellington Region households to balance the fluctuation of wind during for 1-2 and 9-10 am time slots. These available responsive loads can be thought of as a virtual generator to contribute to the required reserve to balance these two down ramp periods. Figure 5-13 shows that employing $50 \%$ of the available RDR from controlled loads can contribute to $25 \%$ of the required reserve to mitigate the fluctuation from 1-2 am. However, the RDR is shown to contribute to $50 \%$ of the required reserve towards the ramp down from 9-10 am.

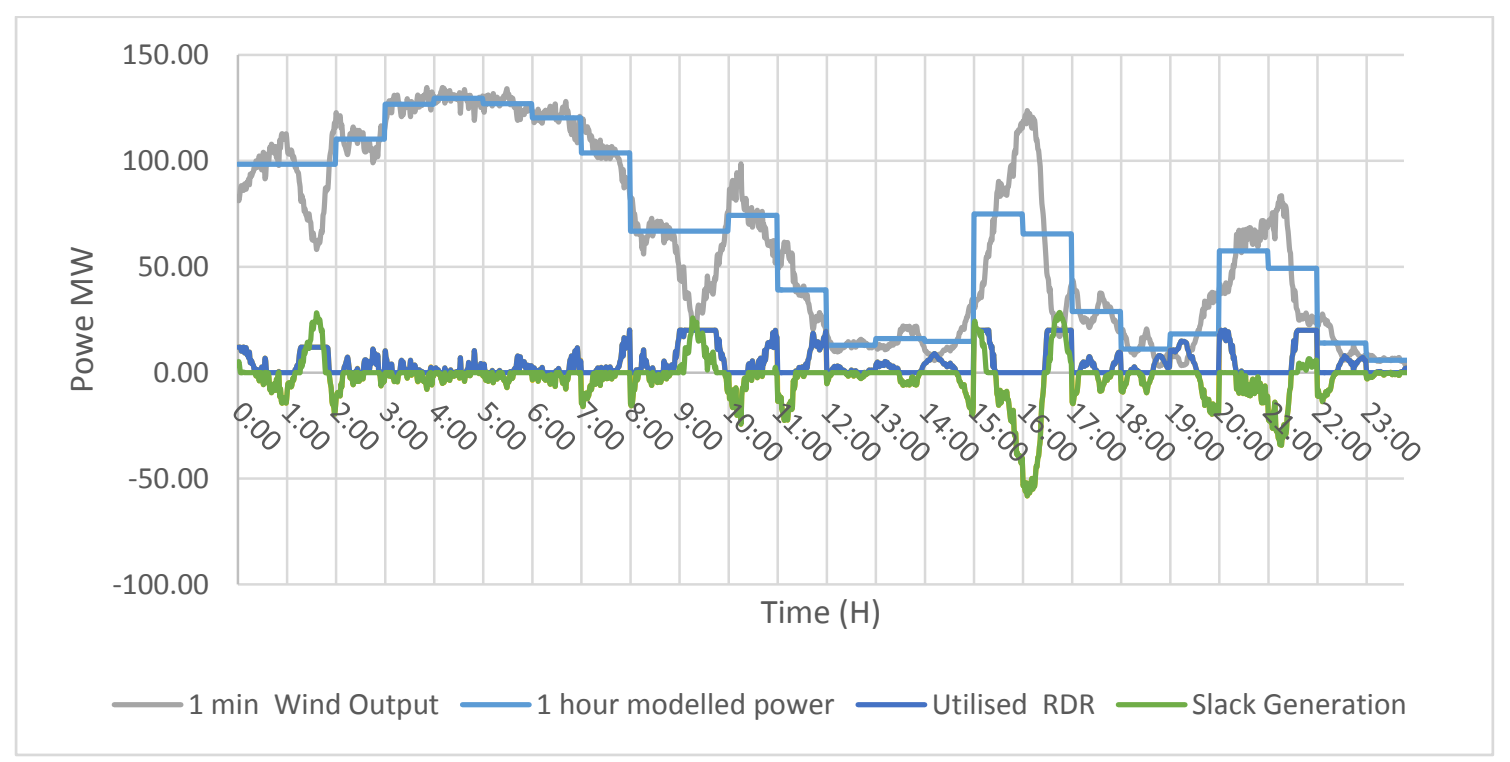

Figure 5-13: Balancing DWR with 50\% of RDR Mar 3, 2014

However, Figure 5-14 shows when utilizing 100\% from RDR available from controlling responsive loads in 70\% of Wellington Region households, the imbalance from 1-2 am can 
be reduced to $50 \%$ and from $9-10$ am, the imbalance can be reduced to around $90 \%$. This can be due to the fact that the residential loads available from 1-2 am from water heaters are more likely to not be operating at this time and therefore their contribution will not be counted. Thus, it is expected that the contribution of the RDR will depend on the time of day fluctuations occur.

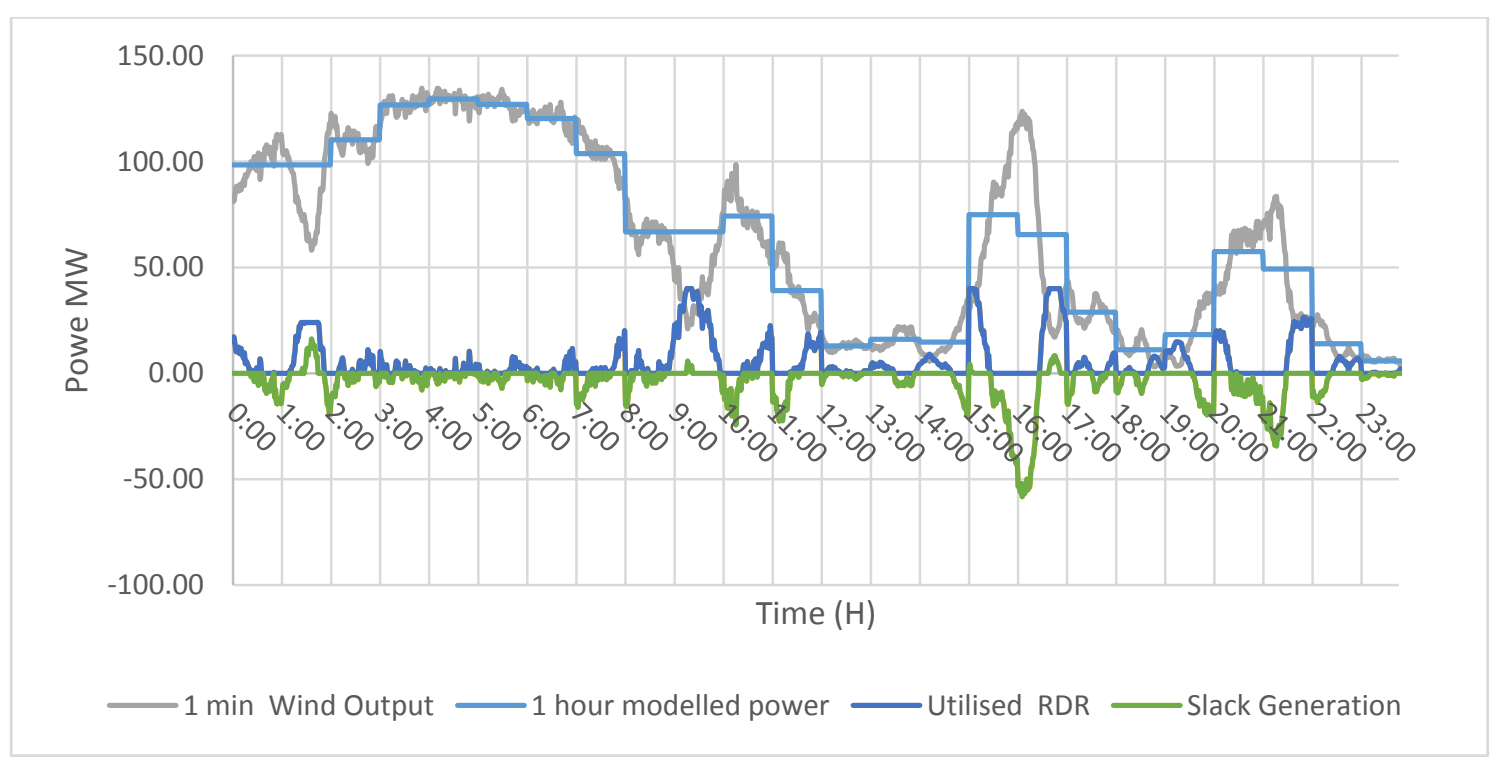

Figure 5-14: Balancing DWR with 100\% of RDR Mar 3, 2014

Hence it is concluded that contributing load to DLC demand response programs yields better results to the balancing the down ramps of wind. RDR can be used to compensate for imbalance caused by wind fluctuation. There are many high short term fluctuations in wind generation in this event. This shows that RDR can correspond to the small fluctuations.

\subsubsection{Jan 1, 2014 Event}

Figure 5-15 presents the West Wind wind farm power output plotted with 1-minute resolution on the first day of the New Year. There are two large ramps. The first down ramp started at 13:15 after the wind output reached its peak with a generation output of $132 \mathrm{MW}$. It gradually dropped and generated only half of its capacity at $2 \mathrm{pm}$. Then, wind output starts to increase gradually reaching a second peak of $125 \mathrm{MW}$ at 15:17 Pm. Then, it decreases again within one hour and a half leading to a second down ramp with a loss of half of its generation capacity at around 5pm. This means that there were two big down ramps within four hours happening at a peak time when Wellingtonians were celebrating the New Year. 


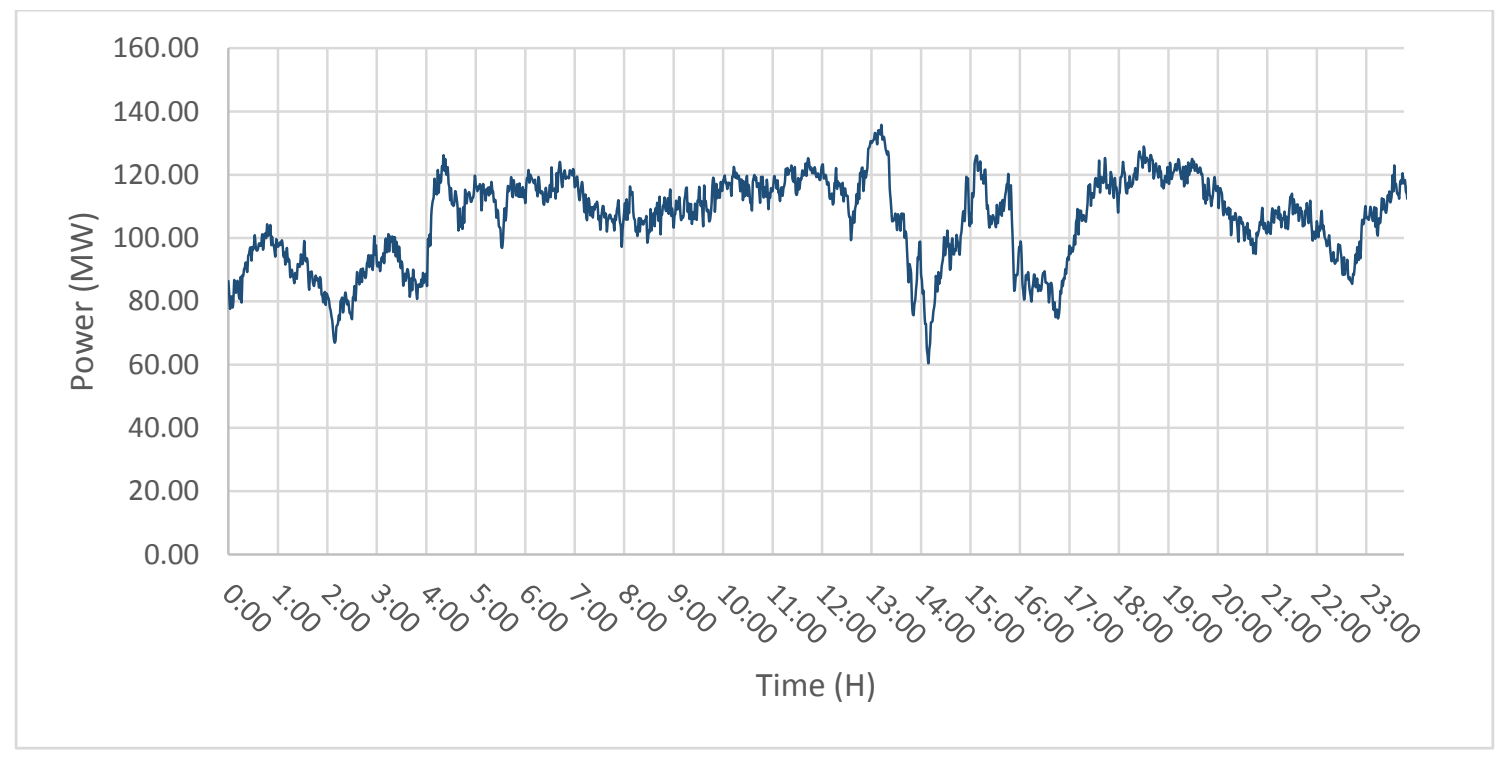

Figure 5-15: Wind profile on January 1, 2014

To compensate for the loss of power generation during each down ramp, $47 \mathrm{MW}$ of slack generation without utilizing RDR was needed to balance the fluctuation in the first ramp and $32 \mathrm{MW}$ to compensate for the loss of generation in the second down ramp as shown in Figure 5-16.

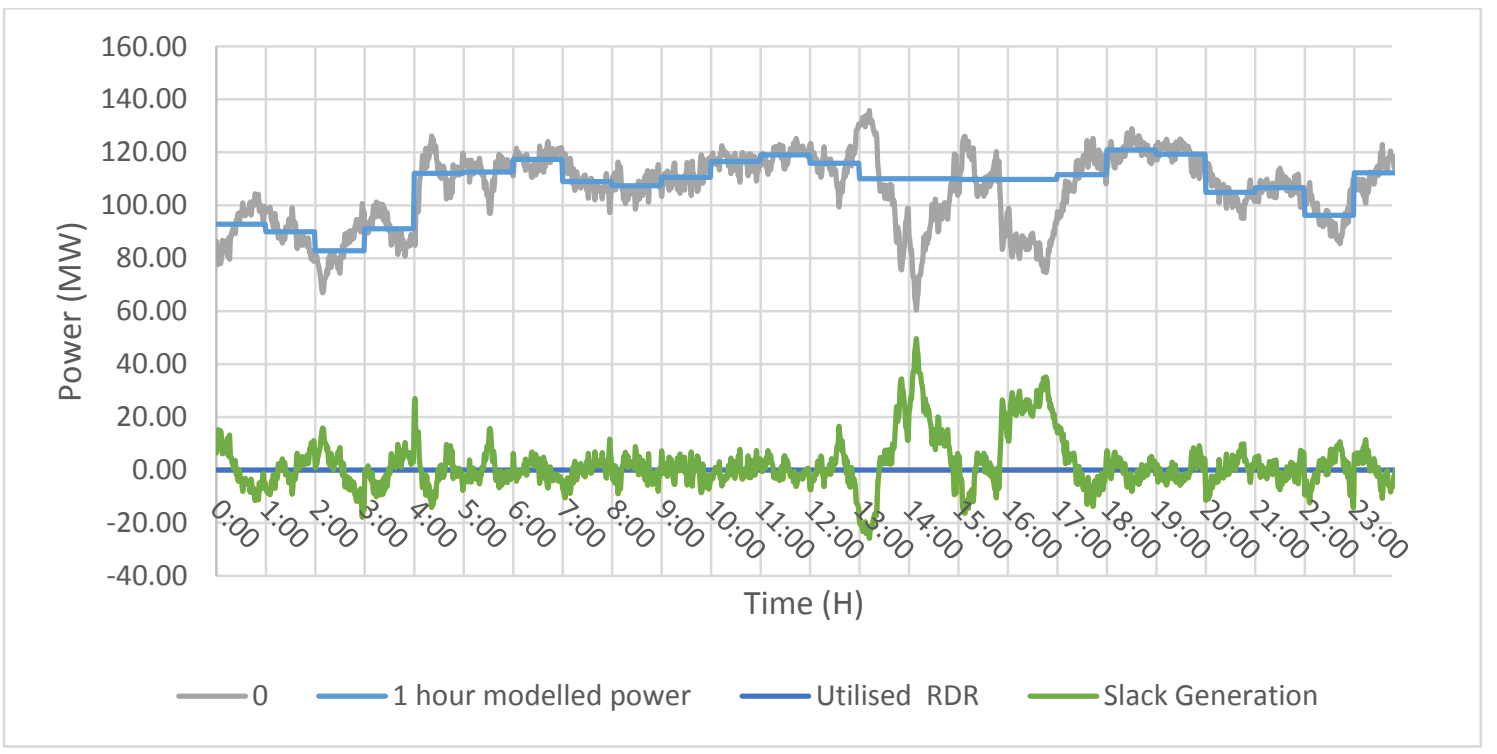

Figure 5-16: Balancing DWR with Slack generation on Jan 1, 2014

When conducting a simulation which integrates $100 \%$ of available responsive loads which provided $37 \mathrm{MW}$ and $34 \mathrm{MW}$ respectively, wind fluctuation is completely balanced during these two down ramps. This is represented in Figure 5-17. 


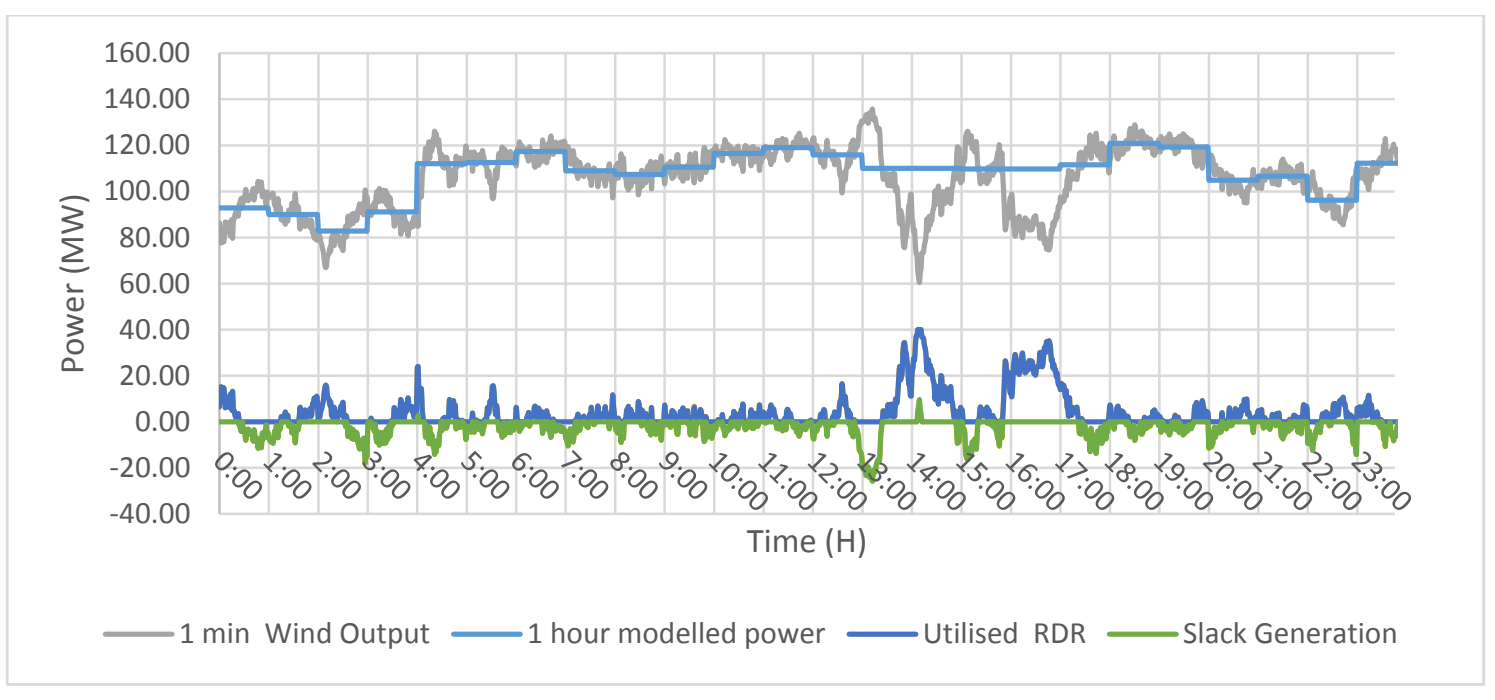

Figure 5-17: Balancing DWR with 100\% of RDR on Jan 1, 2014

\subsubsection{Oct 25, 2013 Event}

The wind profile in this day as shown in Figure 5-18 shows the most frequent large down ramps in these seven days. There are two large ramps. The first large down ramp started at 9 in the morning when the wind generation reached its peak of $105 \mathrm{MW}$ and it took three hours to reach its minimum generation at rate $38 \mathrm{MW}$.

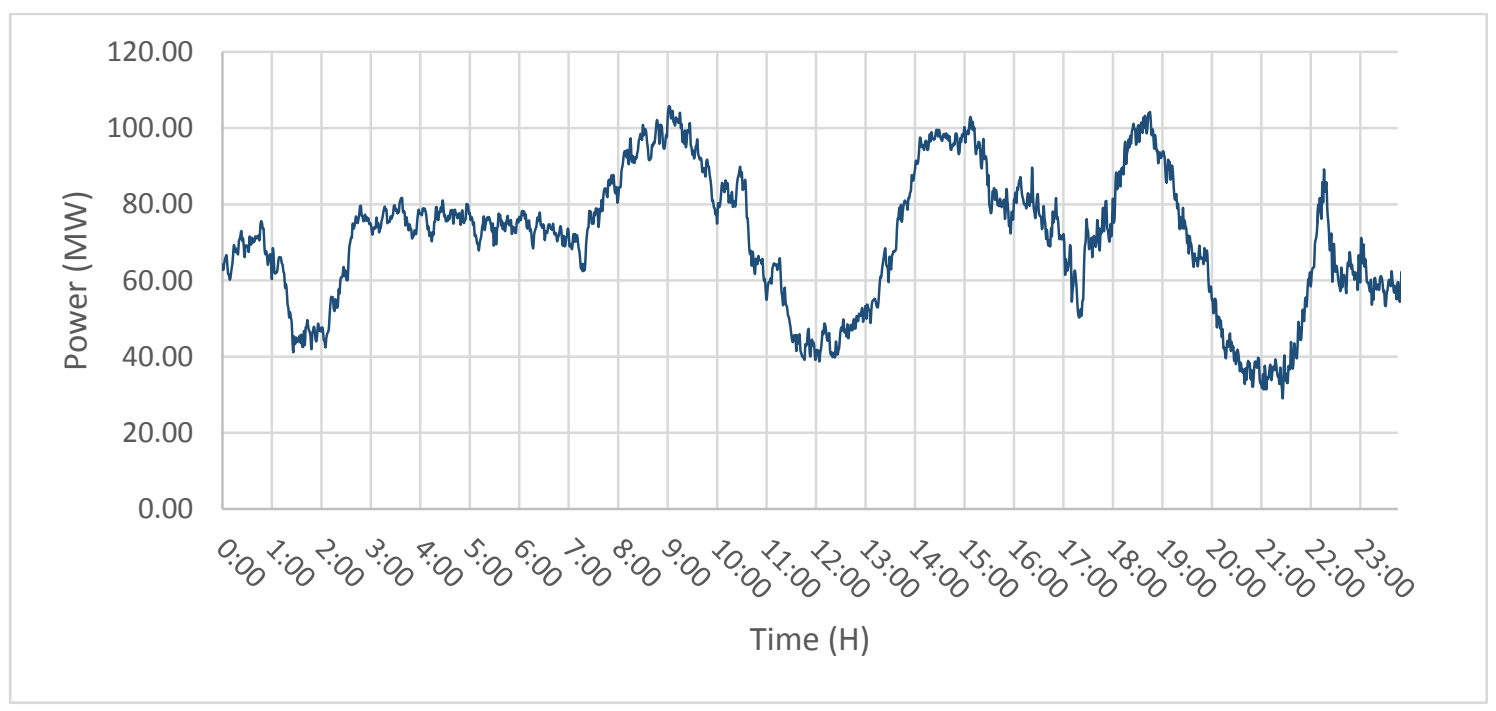

Figure 5-18: West Wind power output on Oct 25, 2013

The second large ramp started to occur at 18:46 when the wind generation peak was $103 \mathrm{MW}$ and it gradually decreased till it generated $30 \mathrm{MW}$ only at 21 and it continues in this decrease for half an hour. To balance the fluctuation during these two large down ramps, the slack generation provided a maximum of $36 \mathrm{MW}$ at $12 \mathrm{pm}$ and $45 \mathrm{M}$ at 21:30 as shown in Figure 5-19. 


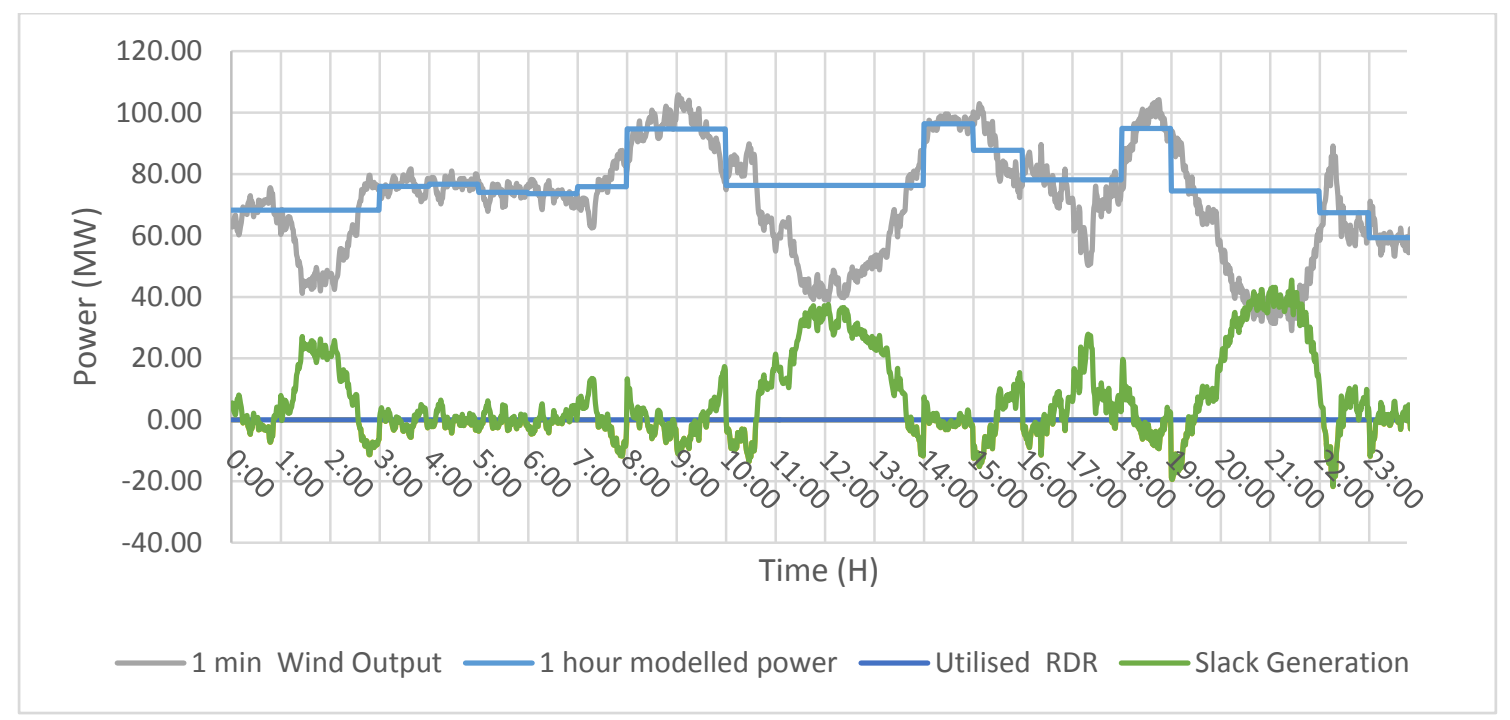

Figure 5-19: Balancing DWR with Slack generation on Oct 25, 2013

Utilizing $100 \%$ of available RDR has the potential to provide this amount of necessary reserves in the amount of $37 \mathrm{MW}$ and $40 \mathrm{MW}$ respectively during these two down ramps. Also, as can be seen from the figure, the RDR is able to balance the medium and small fluctuations of wind power throughout the day by providing the necessary reserve to firm the wind power as show in Figure 5-20.

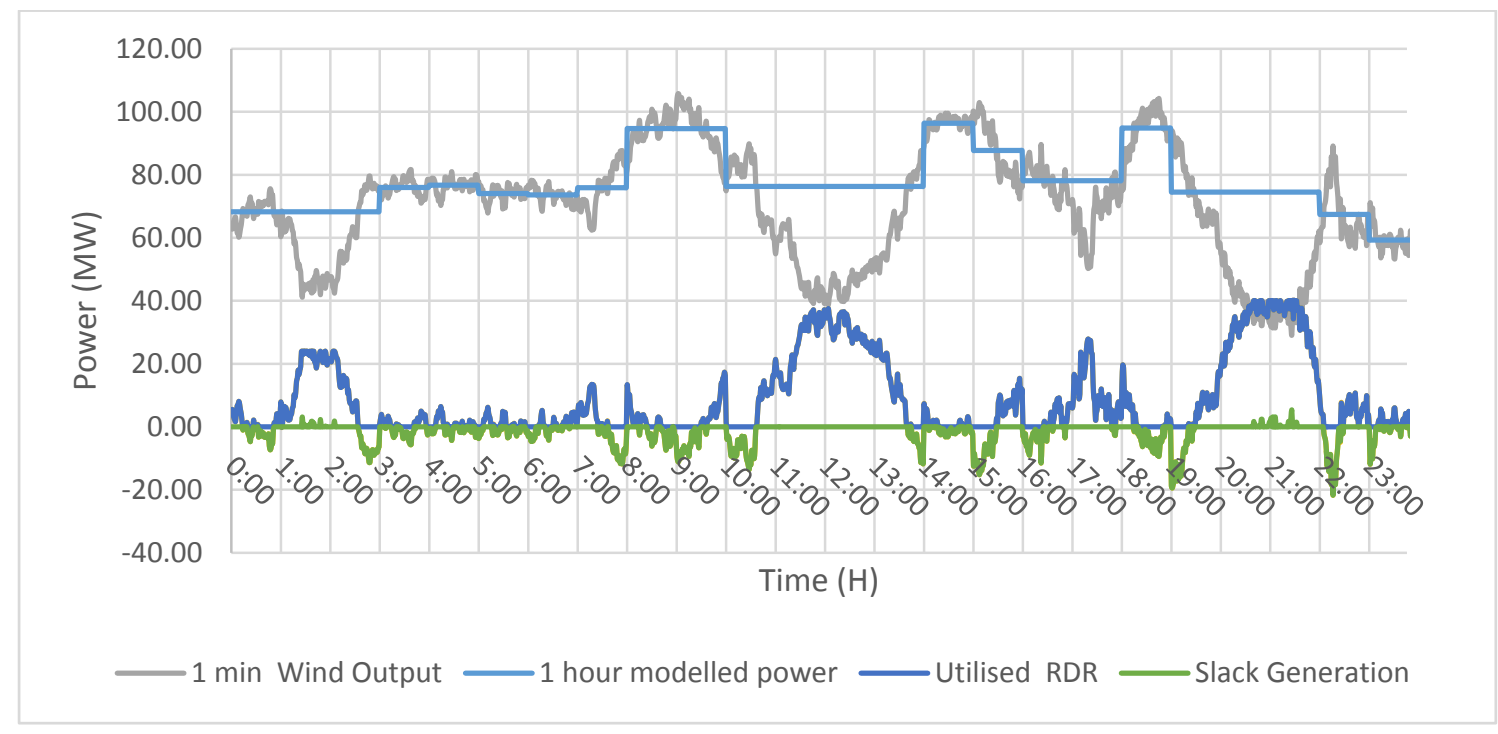

Figure 5-20: Balancing DWR with $100 \%$ of RDR

\subsubsection{Sep 13, 2013 Event}

In this winter day shown in Figure 5-21, there are three large down ramps occurring in the early morning, noon, and late evening. In this example, the difference between daily maximum power and daily minimum power is over than $100 \mathrm{MW}$. Starting at about $88 \mathrm{MW}$ at 12:00 am it took about 5 hours for the wind power to decrease to around $20 \mathrm{MW}$. The 
wind power increased to about $70 \mathrm{MW}$ within two hours. Then, in less than half an hour, the wind generation decreases to less than $23 \mathrm{MW}$. Then, it starts to decrease at 9 am till 10:20am when the generation amount was $11 \mathrm{MW}$ only. Starting at about $110 \mathrm{MW}$ at 18:44 am it took about 5 hours for the wind power to decrease to around $23 \mathrm{MW}$.

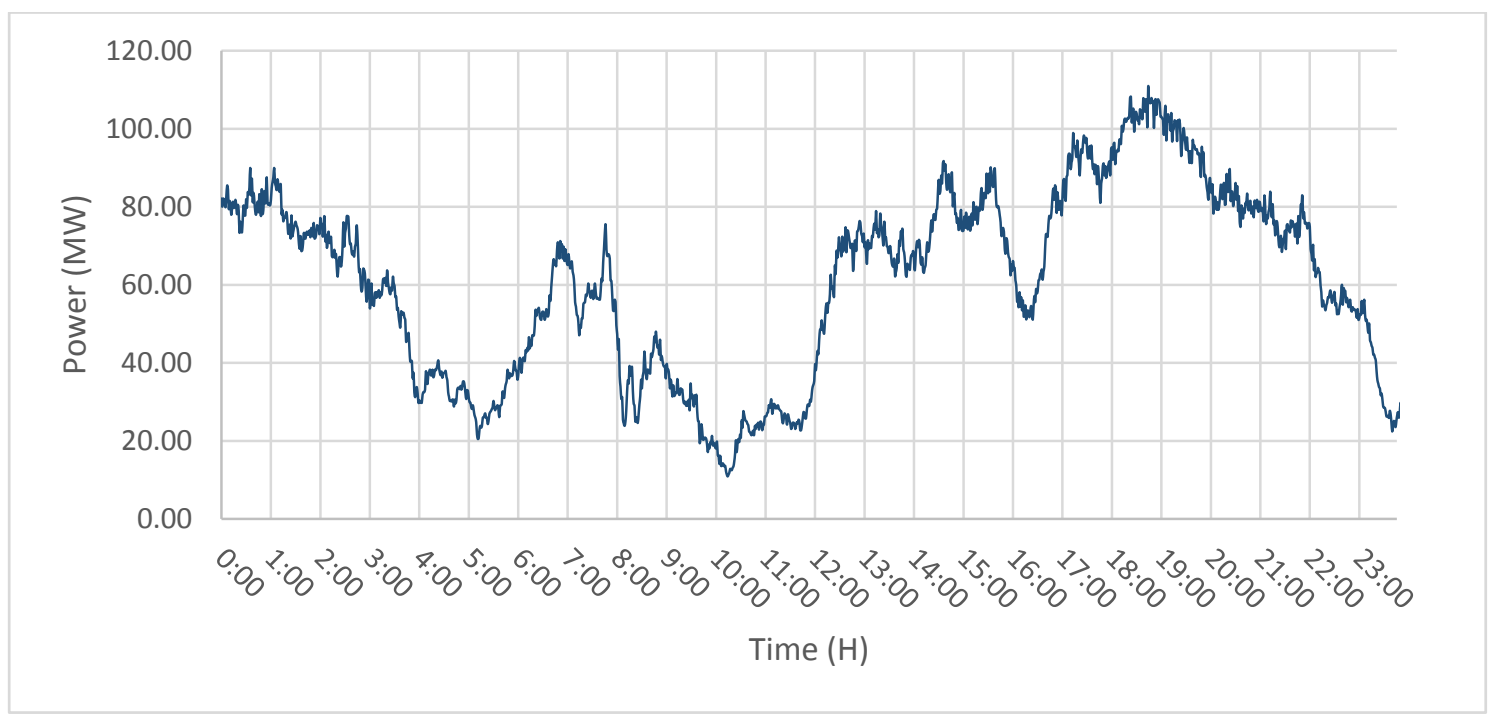

Figure 5-21: West Wind power output on Sep 13, 2013

In all of these down ramps, the decrease percentage is more than $60 \%$. As shown in the Figure 5-21, there are smaller up and down movements with durations ranging from minutes to hours interspersed in between that create local peaks and valleys. For the electric system to operate reliably, generation must match load all the time. To balance the fluctuation from 3-6 am, the slack generation contributed $30 \mathrm{MW}$ as shown in Figure 5-22. At $12 \mathrm{pm}$, it provided $22 \mathrm{MW}$ and at 4:20, it provided $24 \mathrm{MW}$ to firm the wind generation during those times.

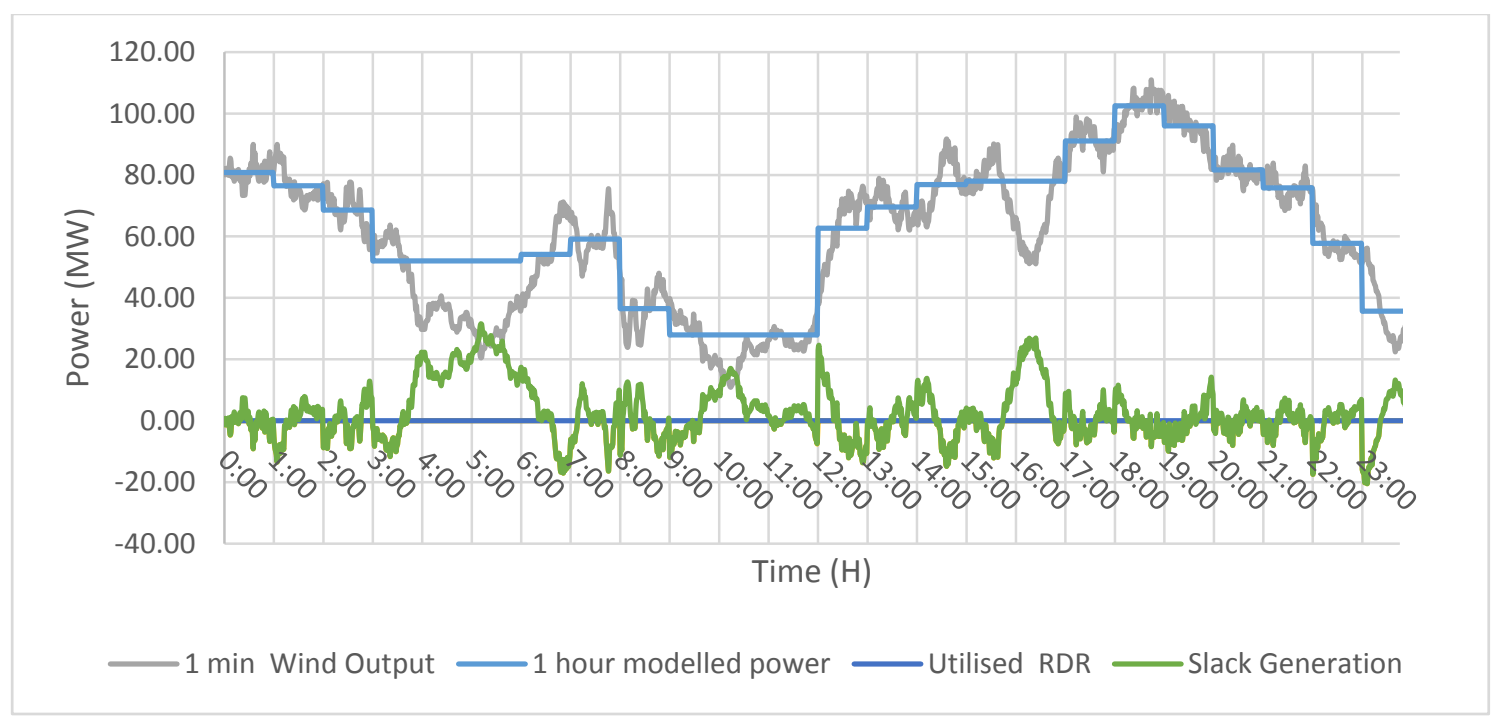

Figure 5-22: Balancing DWR with slack generation on Sep 13, 2013 
As shown in Figure 5-23, simulating the integrating of available RDR with wind power during these down ramps shows that utilizing $80 \%$ from available loads can balance these fluctuations and compensate to the required reserve. It can provide a maximum of $27 \mathrm{MW}$ from 16:00 -17:00.

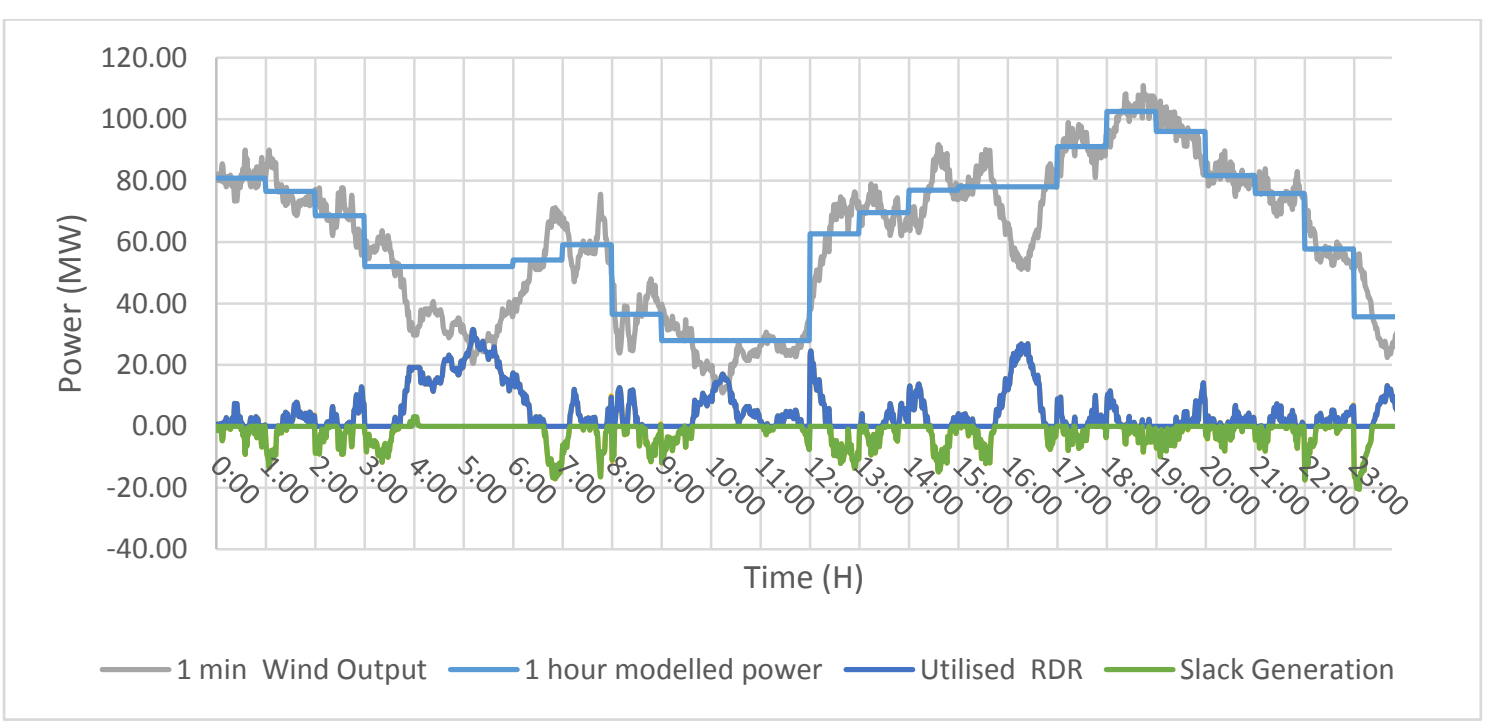

Figure 5-23: Balancing DWR with 80\% of RDR on Sep 13, 2013

\subsubsection{Jul 2, 2013 Event}

Figure 5-24 provides a profile of the West Wind wind farm power output plotted with 1minute resolution on winter day in July 2, 2013. Starting at about 124 MW at 17:20 am it took about one hour for the wind power to decrease to around $60 \mathrm{MW}$. The wind power increased to about $116 \mathrm{MW}$ in less than one hour. There are smaller up and down movements with minutes durations from minutes to hours interspersed in between that create local peaks and valleys.

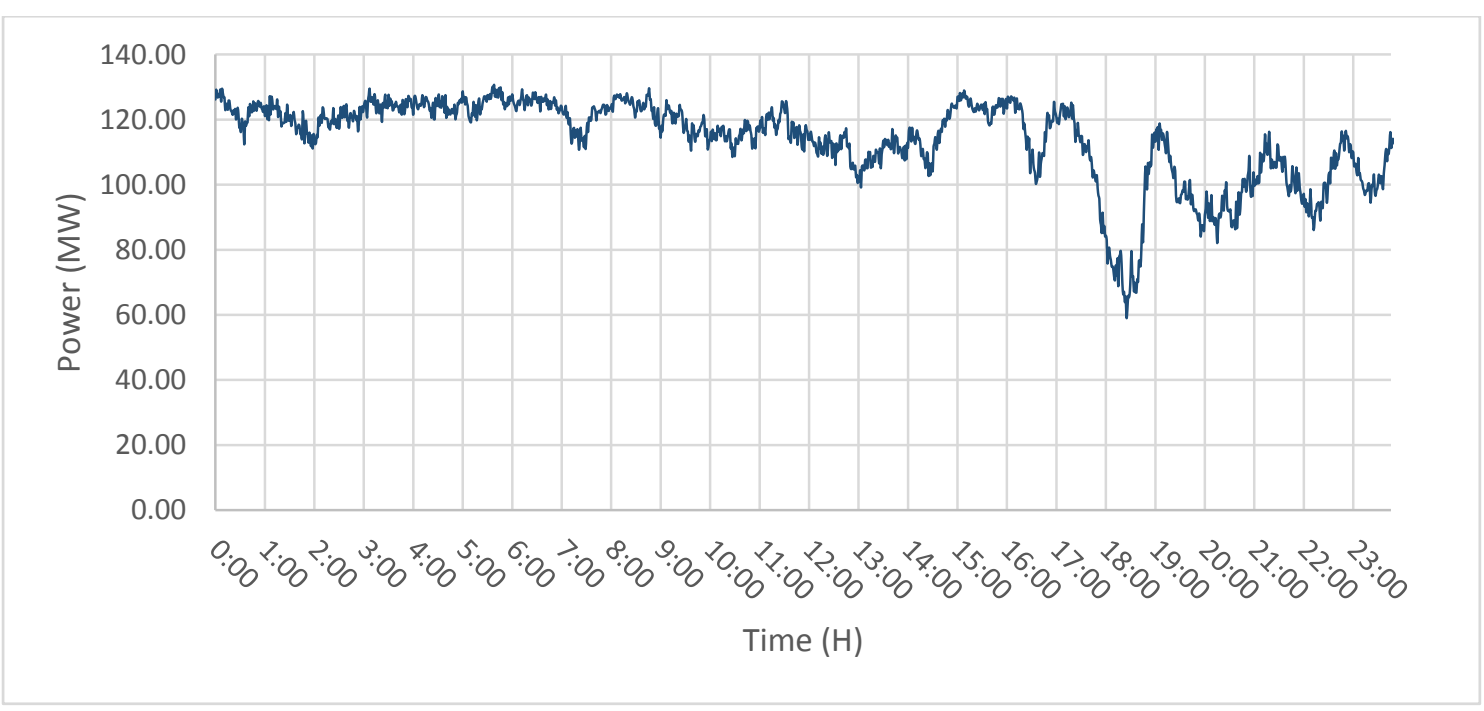

Figure 5-24: West Wind power output on Jul 2, 2013 
There is more than 50\% decrease in wind generation represented in this down ramp. As shown in Figure 5-24, this decrease in wind generation required an additional $52 \mathrm{MW}$ to balance the fluctuation and maintain reliability in the power system. The slack generation compensated for the fluctuation of wind when utilizing $0 \%$ of the available RDR as shown in Figure 5-25.

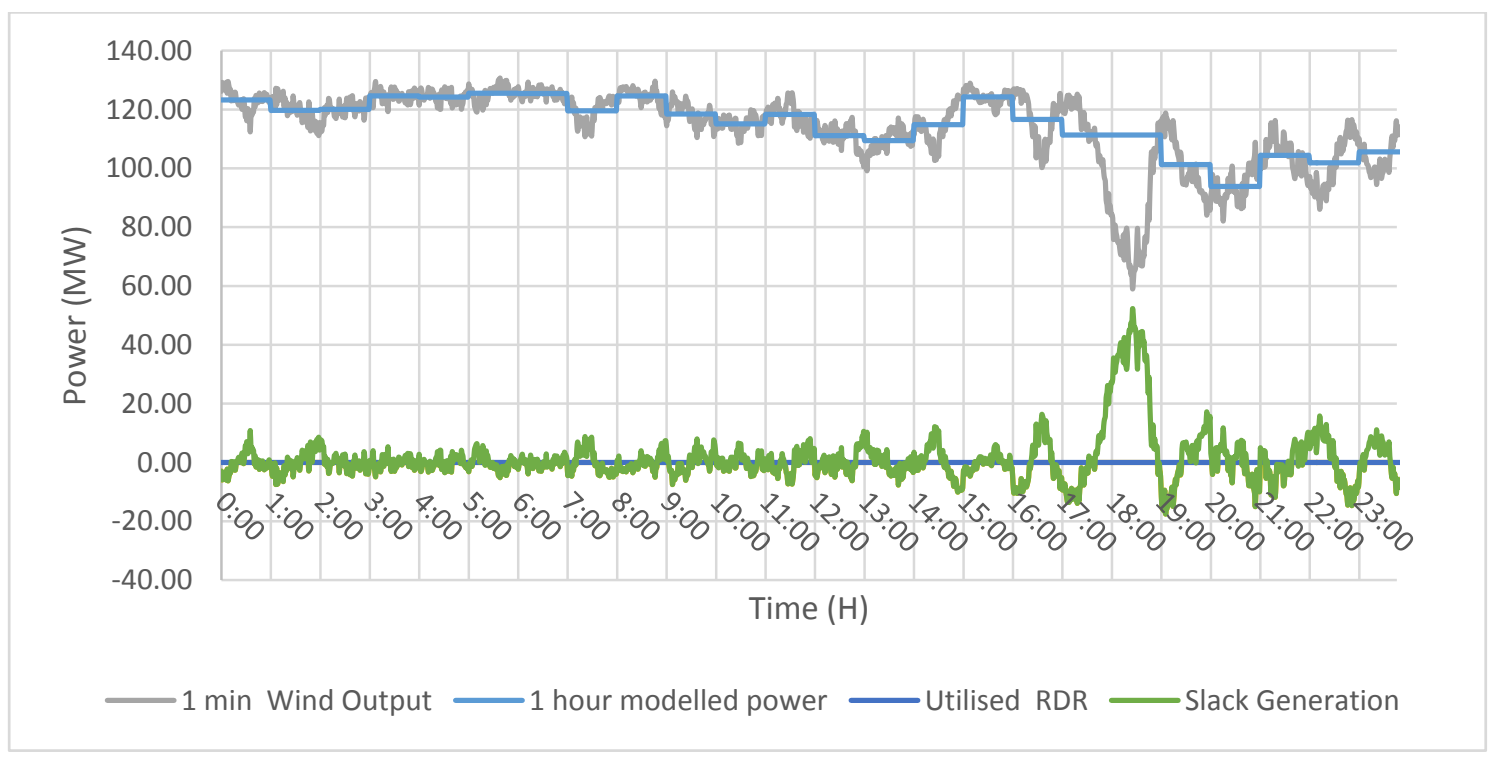

Figure 5-25: Balancing DWR with Slack generation on Jul 2, 2013

When integrating $50 \%$ of available RDR to contribute to the reserve needed for balancing the fluctuation in this down ramp, we could get 20MW approximately and $30 \mathrm{MW}$ from the slack generation. It was able to compensate for all the small fluctuations throughout the days as shown in Figure 5-26.

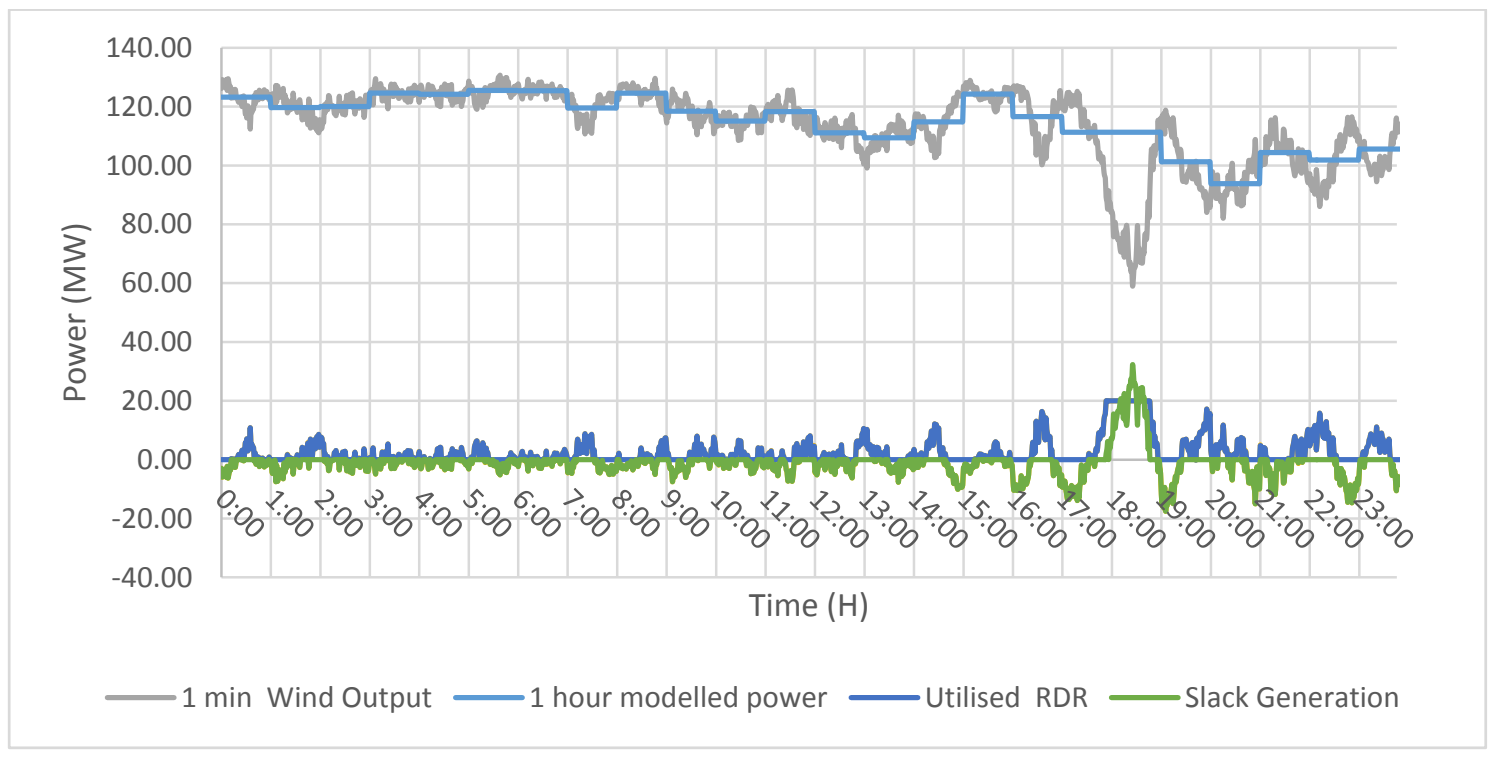

Figure 5-26: Balancing DWR with 50\% of RDR on Jul 2, 2013 
Utilizing $100 \%$ of the available RDR which can provide a maximum of $40 \mathrm{MW}$ and 10 MW from the slack generation to compensate for the largest down ramp from 17-19 pm which reached its peak at 17:30 and coincided with the evening load peak. The RDR was able to balance the fluctuations of small ramps easily by providing small amount of reserve as shown in Figure 5-27.

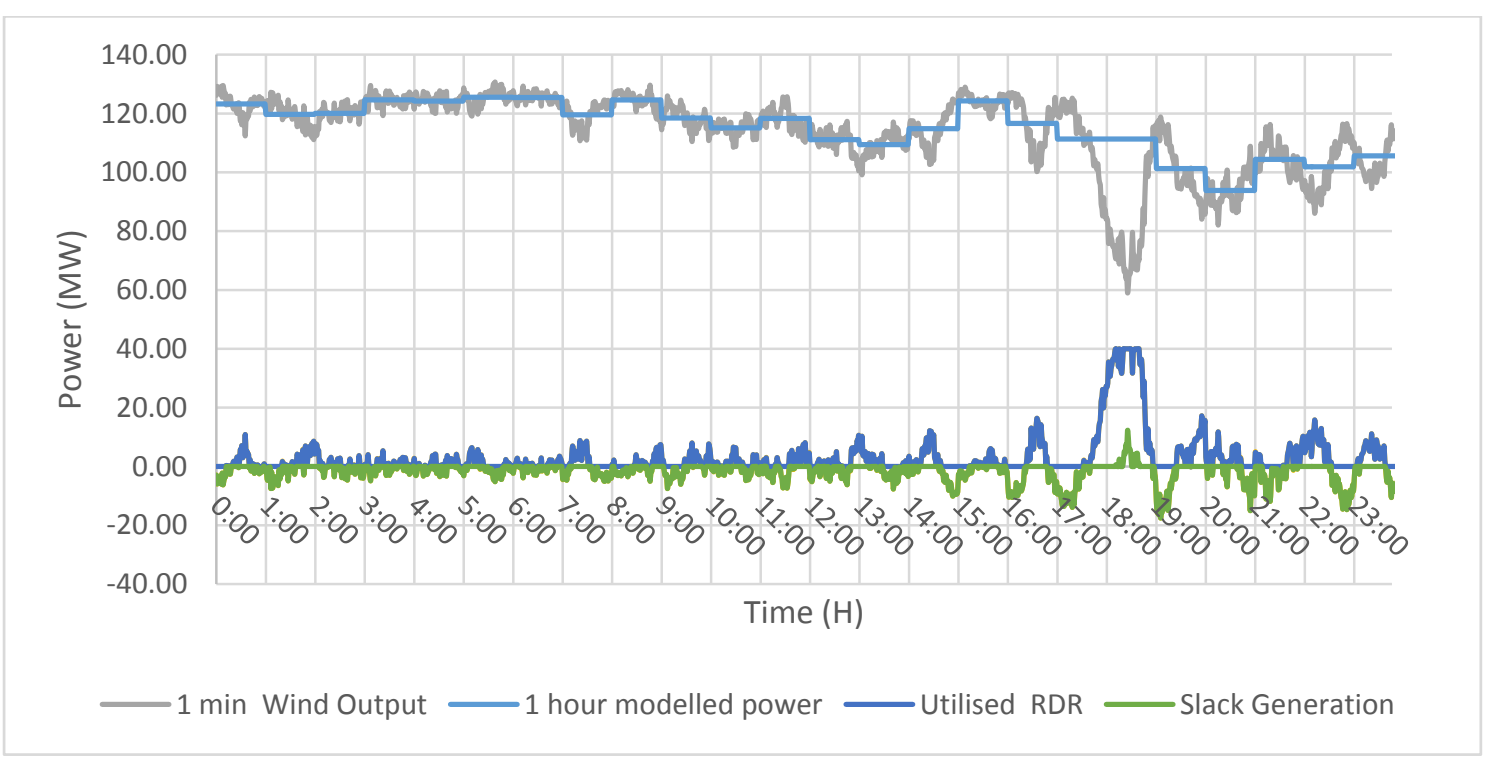

Figure 5-27: Balancing DWR with $100 \%$ of RDR on Jul 2, 2013

\subsubsection{June 27, 2013 (Winter Time)}

Figure 5-28 shows the West Wind farm power output on 27/6/2014 plotted with 1-minute resolution. There are many short small fluctuations.

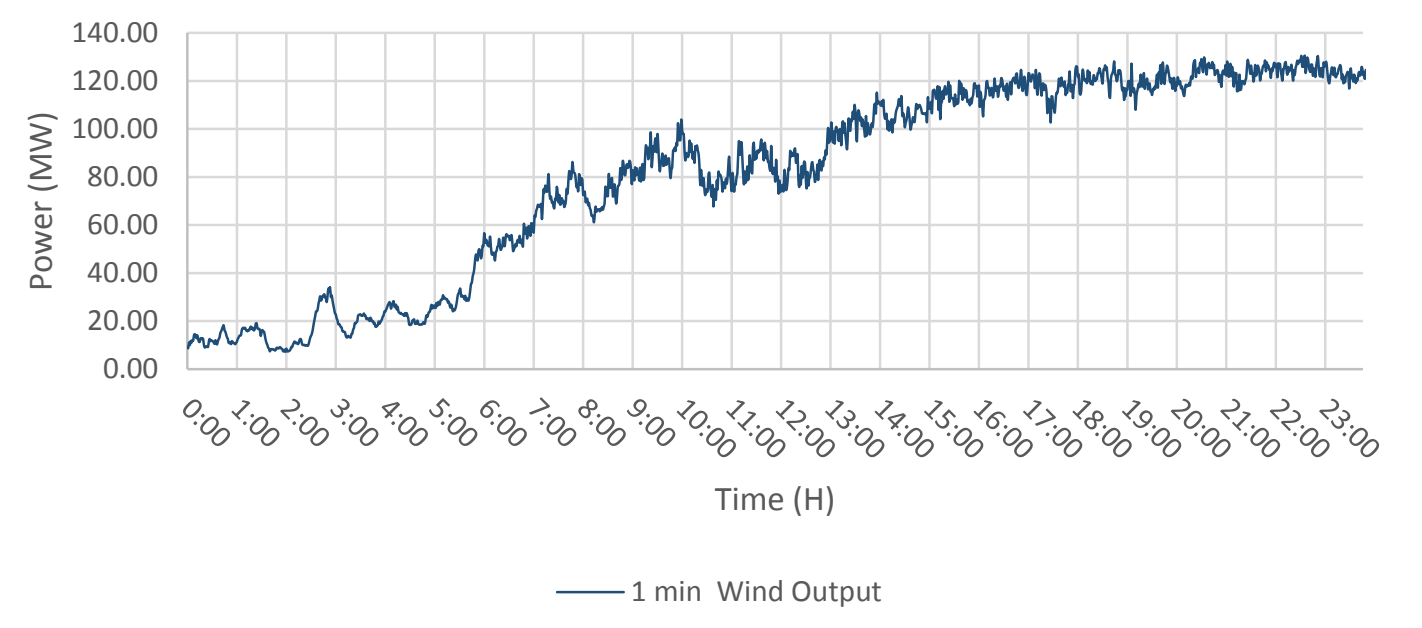

Figure 5-28: WWF wind output on June 27, 2013 
Although there are many frequent short fluctuation throughout the 24 hours, there is no sever down ramp occurring during this day. The maximum slack generation needed to firm the variable wind power was $17 \mathrm{MW}$ at 7 am in the morning as shown in Figure 5-29.

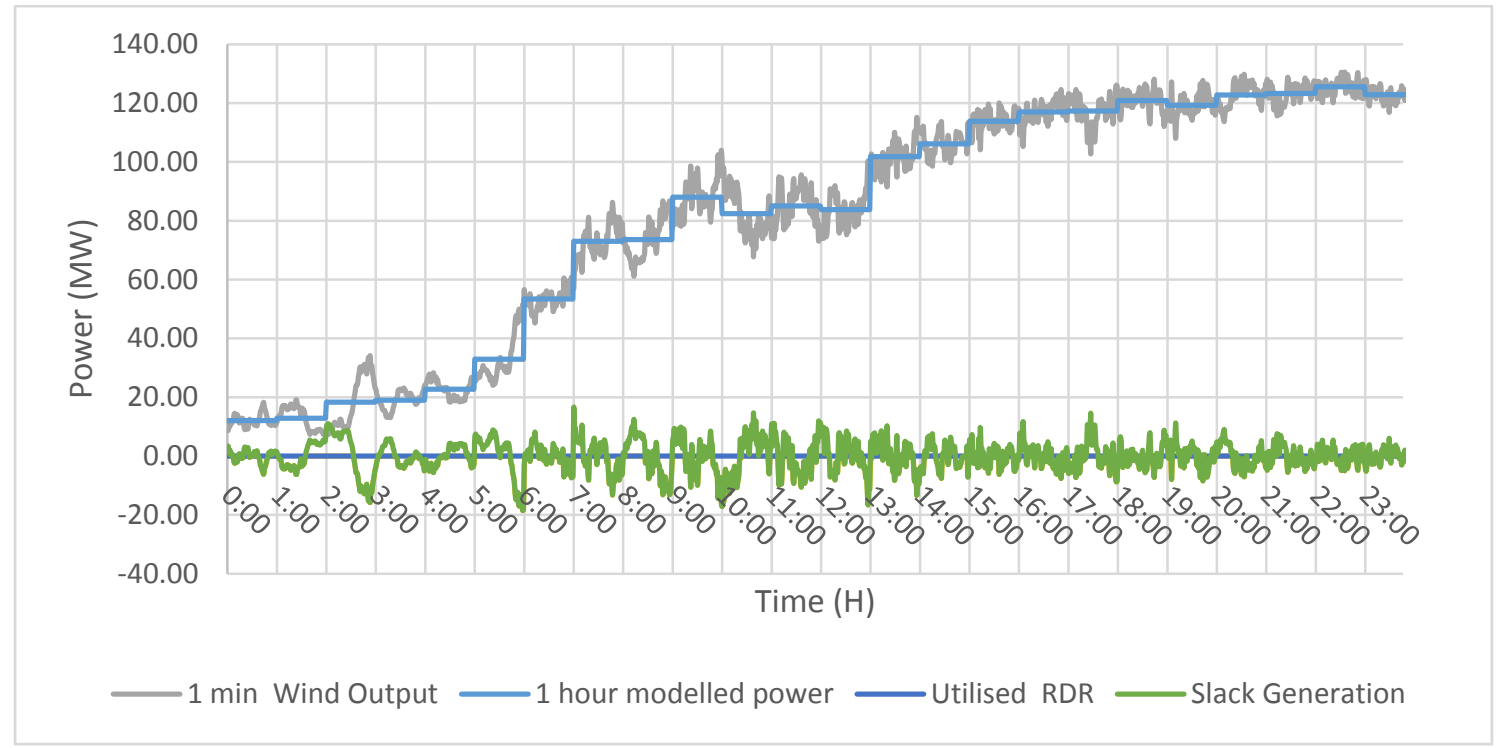

Figure 5-29: Balancing DWR with Slack generation June 27, 2013

When utilizing $30 \%$ of RDR, it easily compensated for these small down ramps and provided $100 \%$ of the reserve needed to balance the fluctuation throughout the day. This shows that RDR will be needed in variable amounts depending on the fluctuation rate of wind generation day by day as shown in

Figure 5-30.

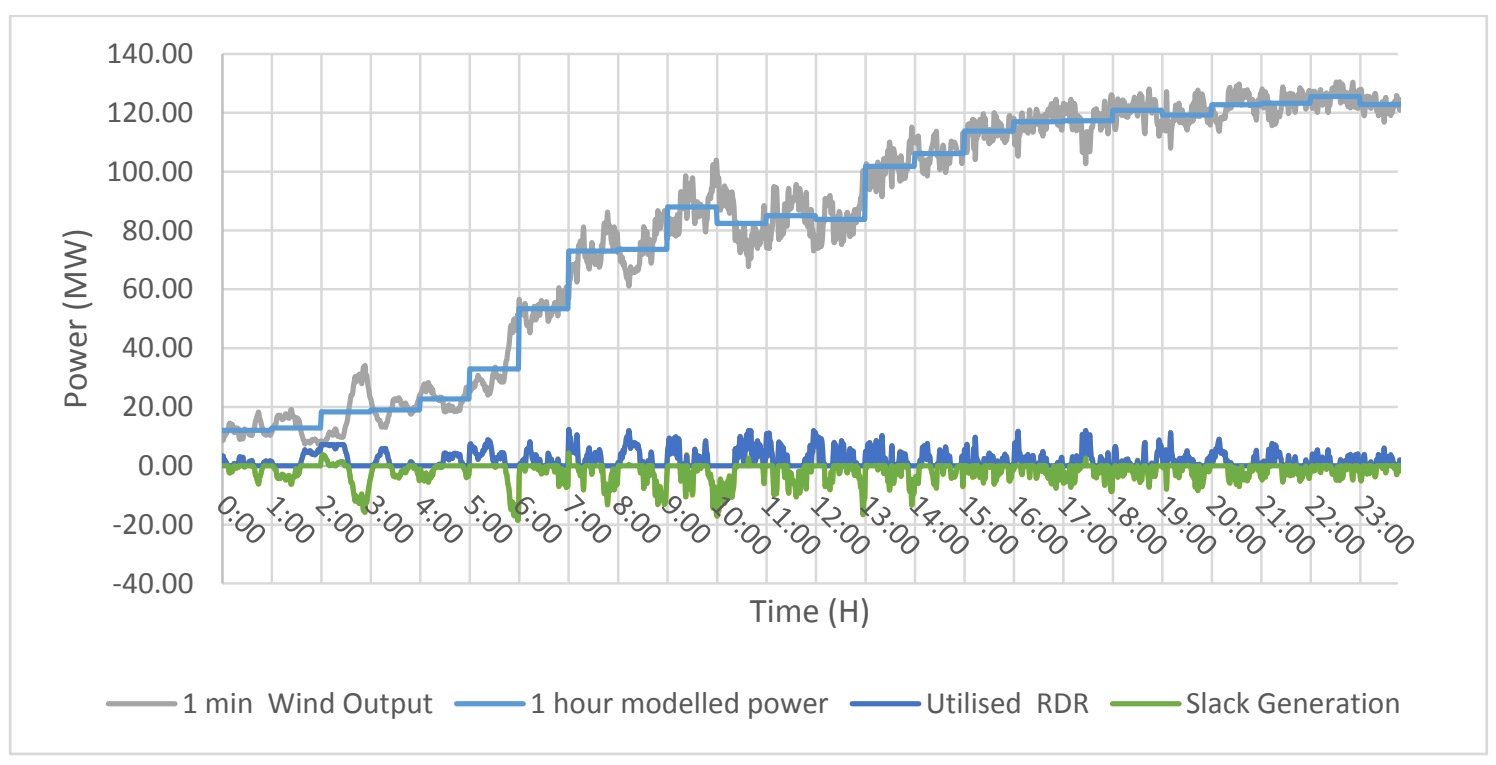

Figure 5-30: Balancing DWR by 30\% of RDR June 27 


\subsection{Summary}

A key aspect of system security is its ability to closely balance demand and supply over different time horizons. This case study has demonstrated that demand side resources can contribute to balance wind fluctuation and mitigate its variability and thus improve system adequacy and contribute to the increased flexibility needs of the system with high levels of wind penetration needed in the future. RDR generation helps to cancel out any fluctuations in wind power. Further research is required into the overall costs and reliability of such programs. Ideally, to gain proper insight into the nature of the response, trial data would be required. Once RDR is utilized to provide grid reserve less conventional generation, especially from hydro resources, will be needed. 


\section{CHAPTER 6 CONCLUSION}

\subsection{Summary}

As New Zealand is expected to generate more than $20 \%$ of its electricity from wind power by 2025 , the variable and unpredictable characteristics of wind creates certain integration problems, which require increased levels of instantaneous reserve to balance wind fluctuation [9]. This research has quantified the available capacity for residential demand response for the provision of instantaneous reserve to counter and mitigate wind variability. The first major part of this work focused on modelling responsive loads of domestic refrigerators, freezers and water heaters. These household appliances were selected due to their thermal storage capability which makes their loads suitable for short interruptions without sacrificing the service provided. By controlling the loads of these appliances, the amount of reserve which usually is provided by conventional generation can be provided by short interruptions of the loads without causing inconvenience for consumers. The analysis of load capabilities predicted significant availability from these household appliance. The maximum interruption time has been set to 15 minutes for all loads. A large resource is available throughout the day with range of 152- $500 \mathrm{MW}$ available for interruption.

This research shows that residential demand response could play a significant role in contributing to meet the systems reserve requirements in the years 2014, 2020 and 2030. From the small case study, it can be concluded that in a system with high wind energy production, demand response, can be useful to partially level out variations in wind production. Analysing the impact of demand response in systems with even higher wind production rates is left for future research. The modelling conducted in this research provides an insight into typical amounts of reserve which could be made available through a direct load control program, but further research is required in order to understand the precise nature of the response. At the end of the control period demand will increase as the loads are reconnected and the energy is paid back. This is particularly the case for refrigeration and water heaters loads which will reclaim the shifted energy over a relatively short period of time after reconnection. The precise nature of this response requires more detailed attention, and severe demand spikes will need to be managed with time delays. Similar schemes already exist in the US where air conditioning loads are reduced. The 
potential for refrigeration loads to provide frequency regulation is also being explored, with trials currently under way in the UK.

By extending this control methodology into the whole New Zealand power system a kind of market can be provided for responsive demand which can work like the reserve market in which the participants can declare the amount that they are willing to provide as a responsive load.

\subsection{Future research directions}

This study did not take into account the economics of participation, the effort required to enable the end-uses effectively to participate in demand response programs. This study calls for Transpower to provide an opportunity for residential demand side aggregators to participate in the market in future years. The potential revenue that can be generated from market participation will determine the cost effectiveness of operating residential demand response programs. Further analysis is required into the benefit that residential demand response would offer to the system in terms of improved efficiencies and reliability and to contribute to the increased flexibility needs of the system with high levels of wind penetration. Further research is also required into the overall costs and reliability of such

programs. This will require conducting a pilot study using real data to accurately assess the economic value of residential demand response program when balancing the fluctuation of wind power.

Data to confirm and refute the predictions of load capabilities must be gathered and analysed. Most of these loads will be operating continuously or almost continuously throughout the year and will overlap with wind down ramps occur. Recent developments of ICT, such as NEST Technologies, are more likely to facilitate the participation of these loads to respond instantaneously to the operator requests. The additional cost of enabling technologies for the direct load control of residential loads could be relatively modest. Further, research is also required into the overall costs and reliability of such programs.

In this study, the input for the model was consisted of average probabilistic distributions of use for refrigerators, freezers, and water heaters, but household meters can be programmed in a way that provide accurate information regarding the loads of these appliances Such potential residential demand response program will require support from a number of stakeholders, industry players, traditional industry, governmental and nongovernmental agencies and consumers. 


\section{REFERENCES}

[1] J. Ma, "Evaluating and planning flexibility in a sustainable power system with large wind penetration," The University of Manchester, Manchester, 2012.

[2] New Zealand Wind Energy Association, "Electricity supply and wind generation," Wellington, 2011.

[3] Ministry of Economic Development, “New Zealand energy strategy 2011-2021," Wellington, 2011.

[4] R. Brown, "Wind power in the New Zealand power system," in Wind Power in Power System, Chichester: John Wiley \& Sons, Ltd, 2012, pp. 667-688.

[5] Y. Wan, "Analysis of wind power ramping behavior in ERCOT," 2011.

[6] MIT Energy Initiative, "Managing large-scale penetration of intermittent renewables," 2011.

[7] D. Corbus, M. Schuerger, L. Roose, J. Strickler, T. Surles, D. Manz and D. Burlingame, "Oahu wind integration and transmission study: Summary report," 2010.

[8] H. Holttinen, "Design and operation of power systems with large amounts of wind power," International Energy Agency, Paris, 2009.

[9] G. Strbac, D. Pudjianto, A. Shakoor, M. Castro, G. Waipara and G. Telfar, "New Zealand wind integration study," Meridian Energy Limited, 2008.

K. Driesen and J. De Vos, "Impact of wind power reserve requirement," in 12th IAEE European Energy Conference, Venice, Italy, 2012.

K. De Vos, J. Morbee and R. Belmans, "Impact of wind power on sizing and allocation of reserve requirements.," IET Renewable Power Generation, vol. 7, no. 1, pp. 1-9, 2013.

B. Kirby, "Spinning reserve from responsive loads," Oak Ridge National Laboratory, 2003.

P. Denholm, E. Ela , B. Kirby and M. Milligan, "The Role of Energy Storge with Renewable Electricity Generation," NREL, 2010.

S. Gyamfi, "Demand response assessment and modelling of peak electricity eemand in the residential sector: Information and Communication Requirement," PhD Thesis, University of Canterbury, New Zealand., 2010. 
[15] B. Kirby, "Demand Response For Power System Reliability: FAQ," Oak Ridge National Laboratory, Tenessee, 2006.

Federal Energy Reulatory Commission, "Reports on demand response \& advanced metering," 2008.

[17] A. Faruqui and S. Sergici, "Household response to dynamic pricing of electricity:survey of 15 experiments.," Journal of Regulatory Economics, 2010.

P. Khajavi, H. Abniki and B. Arani, "The role of incentive based Demand Response programs in smart grid," Environment and Electrical Engineering," in Environment and Electrical Engineering (EEEIC), 2011 10th International Conference, Rome, 2011.

P. Khajavi, H. Monsef and H. Abniki, "Load profile reformation through demand response programs using Smart Grid," in 2010 Proceedings of the International Symposium, 20-22 September-2010.

S. Koch, "Demand response methods for ancillary services and renewable energy integration in electric power systems, ETH Zurich: Power Systems Laboratory, 2012.

M. Milligan and B. Kirby, "Utilizing Load Response for Wind and Solar Integration and Power System Reliability," May 2010.

[22] X. Zhao, J. Ostergaard and M. Togeby, "Demand as Frequency Controlled Reserve," Power Systems, IEEE Transactions, 2011.

[28] Transpower, "Chapter 14: Wellington Region," 2013. Electricity Authority, "Pricing Methodology," 2010.

R. Strahan, A. Miller and Q. Tahau, "Systems to implement demand response in New Zealand," in EEA Conference \& Exhibition, 18 - 20 June, 2014, Auckland, 2014. 
B. Chakrabarti, D. Bullen, C. Edwards and C. Callaghan, "'Demand Response in the New Zealand Electricity Market," in Transmission and Distribution Conference and Exposition, 2012.

Commerce Comission, "Amending the outputs for Transpower's demand response programme in the Upper North Island: Decisions and reasons paper," 2013.

Electricity Authority, "Introduction to instantaneous reserve - a presentation to the Wholesale Advisory group,," 2013.

\section{Electricity Authority, "Electricity Industry Participation Code 2010 - Part 1} Preliminary Provisions," 2013.

EnerNOC, "FAQ - New Zealand Interruptible Load," 2013.

EnerNOC, “FAQ - Genesis Programme,” 2013.

The Lines company, "Pricing Methodology," 2014.

Vector Ltd, "Vector SunGenie - Better. Smarter. Solar Power," 2013.

K. Bojanczyk, "Redefining Home Energy Management Systems," Green Tech Media, 2013.

R. Ford, J. Stephenson, N. Brown and W. Stiehler, "Energy Transitions: Home Energy Management Systems," Dunedin, 2014.

L. Soder, "Experience From Wind Integration in Some High Penetration Areas," IEEE Transaction on Energy Conversation,, vol. 22, no. 1, pp. 4-12, 2007.

ENTSO-E, “P1 - Policy 1: Load-Frequency Control and Performance,” , 2009.

$\mathrm{H}$. Holttinen, The impact of large scale wind power production on the Nordic electricity system, VTT Publications, 2004.

R. Doherty, "'All-Island Grid Study Workstream 2A - High level assessment of suitable generation portfolios for the All-Island system in 2020'," 2008.

Dena, "Planning of the grid integration of wind energy in Germany onshore and offshore up to the year 2020," Deutsche EnergieAgentur Dena, , 2005. 
[48] T. Molinsk, "Manitoba Hydro wind power reserve requirements," Integration of Wide-Scale Renewable Resources Into the Power Delivery System," in CIGRE/IEEE PES Joint Symposium, Calgary, 2009.

[49]

D. Nedic, G. Strbac, P. Shakoo, G. Black, M. Wasto and P. Shakoor, "Security assessment of futures electricity scenarios,," Tyndall Centre Technical Report 30, 2005.

[50] R. Piwko, P. Manager, X. Bai, K. Clark, G. Jordan, N. Miller and J. Zimberlin, "The Effects Of Integrating Wind Power On Transmission System Planning, Reliability, And Operations," 2005.

[51] Enernex Corporation, "Final Report - 2006 Minnesota Wind Integration Study Volume I," 2006.

[52] J. DeCesaro and K. Porter, "Wind energy and power system operations: A review of wind integration studies to date," 2009.

[53] C. Loutan and D. Hawkins, "Integration of Renewable Resources:Transmission and Operating Issues and Recommendations for Integrating Renewable Resources on the California ISO-Controlled Grid,," California Independent System Operator, 2007.

Enernex Corporation, "Eastern Wind Integration and Transmission Study," Prepared for the National Renewable Energy Laboratory," 2010.

C. Goldman, M. Reid and R. Levy, "Coordination of energy efficiency and demand response," Lawrence Berkeley National Laboratory Report: LBNL-, Berekly, CA, 2010.

[56] R. Stamminger, "Synergy potential of smart domestic appliances in renewable energy systems'. Smart-A Project," University of Bonn, Germany.

P. Finn, C. Fitzpatrick and M. Leahy, "Increased penetration of wind generated electricity using real time pricing \& demand side management," in IEEE International Symposium, 2009.

C. Alvarez, A. Gabaldon and A. Molina, "Assessment and simulation of the responsive demand potential in end-user facilities: application to a university customer," Power Systems, IEEE Transactions, vol. 19, no. 2, pp. 1223-1231, 2004.

\section{R. Burke and M. Henderson, "Incorporating demand response in operating} reserve in New England," Power Engineering Society General Meeting, 2005. IEEE, vol. 2, p. pp. $1570-1574,2005$. 
[60] B. Kirby, J. Kueck, T. Laughner and K. Morris, "Spinning reserve from hotel load response," The Electricity Journal, vol. 21, no. 10, pp. 59-66, 2008.

H. E. Joseph, J. Nelson-Hoffman, E. Parker, C. Bernier, P. Young, D. Sheehan, J. D. Kueck and B. J. Kirby, "“Demand response spinning reserve demonstratio, phase 2 findings from the summer of 2008," Ernest Orlando Lawrence Berkeley National Laboratory, 2009.

A. Yousefi, E. Shayesteh, F. Daneshvar and M. Moghaddam, "“An approach for improving spinning reserve capacity by means of optimal utilization of $d r$ program," in Power and Energy Conference, 2008. PECon, 2008.

Intelligent Energy Europe, "Smart Domestic Appliances in Sustainable Energy Systems (Smart-A)," IEE program, 2009.

L. Paull, H. Li and L. Chang, "A novel domestic electric water heater model for a multi-objective demand side management program," Electric Power Systems Research, p. 1446-1451, 2010.

P. Steffes, "Grid-interactive Renewable Water Heating Analysis of the Economic and Environnemental Value," Steffes Corporation white paper, 2010.

\section{Klobasa, "Analysis of demand response and wind integration in Germany's} electricity market," IET Renewable Power Generation, vol. 4, no. 1, p. 55-63, 2010.

I. Stadler, "Power grid balancing of energy systems with high renewable energy," Utilities Policy, vol. 16, pp. 90-98, 2008.

P. Finn, C. Fitzpatrick, M. Leahy and L. Relihan, "Promotion of wind generated electricity using price responsive demand side management: price predictionanalysis for imperfect energy storage," in IEEE International Symposium onSustainable Systems and Technology (ISSST), Arlington, VA, USA, 17-12 May, 2010.

V. Hamidi, F. Li and F. Robinson, "Responsive demand in networks with high penetration of wind power," in IEEE/PES Transmission and Distribution Conference and Exposition, Chicago, IL, USA, 21-24 Aporil 2008.

J. Short, "Dynamic Demand - can intelligent cold appliances help balance the electricity," 2006.

D. Callaway, "Tapping the Energy Storage Potential in Electric Loads to Deliver Load Following and Regulation, with Application to Wind Energy," Energy Conversion and Management, vol. 50, p. 1389-1400, 2009. 
[72] M. Aunedi, P.-A. Kountouriotis, J. Calderon, D. Angeli and G. Strbac, "Economic and Environmental Benefits of Dynamic Demand in Providing Frequency Regulation," Smart Grid, IEEE Transactions, vol. 4, no. 4, pp. pp.2036-2048, Dec. 2013.

R. Stamminger, "Synergy Potential of Smart Domestic Appliances in Renewable Energy Systems'. Smart-A Project," University of Bonn, 2008.

N. Isaacs, M. Camilleri, L. French , A. Pollard, K. Saville-Smith, R. Fraser, P. Rossouw and J. Jowett, "Energy Use in New Zealand Households, Final Report on the Household," BRANZ, 2010.

[75] I. Page and L. French, "E528 Regional heat pump energy loads," report to Transpower," BRANZ, 2009.

New Zealand Statistics, "2013 Census Quick Stats about housing," 2014. [Online]. Available: http://www.stats.govt.nz/Census/2013-census/profile-and-summaryreports/quickstats-about-housing/types-occupied-dwellings.aspx. [Accessed 154 2014].

E NZ Home Energy Web, "How Much energy is Used in New Zealand Homes," [Online]. Available:

http://www.physics.otago.ac.nz/eman/hew/ehome/euappliances.html. [Accessed 1611 2013].

Ministry of Economic Development, “New Zealand Energy Data File,” 2011.

[79] V. Hamidi, F. Li and F. Robinson, "Demand response in the UK's domestic sector," Electric Power Systems Research, vol. 79, no. 12, pp. 1722-1726, 2009.

W. Mert and W. Tritthart, "Get smart! Consumer acceptance and restrictions of Smart Domestic Appliances in Sustainable Energy Systems," IFZ - Inter-university Research Centre for Technology, Work and Culture, Graz, Austria, 2008.

Wind Energy Association, "Wind Energy Association," [Online]. Available: http://www.windenergy.org.nz/generation. [Accessed 910 2014].

Meredian Energy, "Mill Creek wind project," [Online]. Available: http://www.meridianenergy.co.nz/about-us/generating-energy/our-generationprojects/mill-creek-wind-project/. [Accessed 1810 2014].

New Zealand Statistics, "National demographic projections," [Online]. Available: http://www.stats.govt.nz/browse_for_stats/population/estimates_and_projectio ns/demographic-trends-2012/national\%20demographic\%20projections.aspx. [Accessed 2910 2014]. 
[84] .J. H. Eto and K. Coughlin, "Analysis of Wind Power and Load Data at Multiple Time Scales," 2010. 